\title{
Metal-Free Trifluoromethylthiolation of Arylazo Sulfones
}

Ankun Li, ${ }^{\text {a, }}$ Y Yuxuan Li, a,c, $\$$ Junjie Liu, a,c Jingqi Chen, ${ }^{a}$ Kui Lu, ${ }^{c}$ Di Qiu, ${ }^{a}$ Maurizio Fagnoni, ${ }^{\mathrm{b}}$ Stefano Protti*,b and Xia Zhao*,a

${ }^{a}$ Tianjin Key Laboratory of Structure and Performance for Functional Molecules, MOE Key Laboratory of Inorganic-Organic Hybrid Functional Materials Chemistry, College of Chemistry, Tianjin Normal University, Tianjin 300387, P. R. China.

${ }^{b}$ PhotoGreen Lab, Department of Chemistry, University of Pavia, V. Le Taramelli 12, Pavia, Italy.

${ }^{c}$ College of Biotechnology, Tianjin University of Science \& Technology, Tianjin 300457, China.

$\S$ These authors contributed equally to this work.

\section{CONTENTS}

1) Mechanistic insight into the visible-light driven

trifluoromethylthiolation process

S2

2) Copy of the ${ }^{1} \mathrm{H},{ }^{13} \mathrm{C}$ and ${ }^{19} \mathrm{~F}$ NMR spectra of the prepared compounds 
1. Mechanistic insight into the visible-light driven trifluoromethylthiolation process.

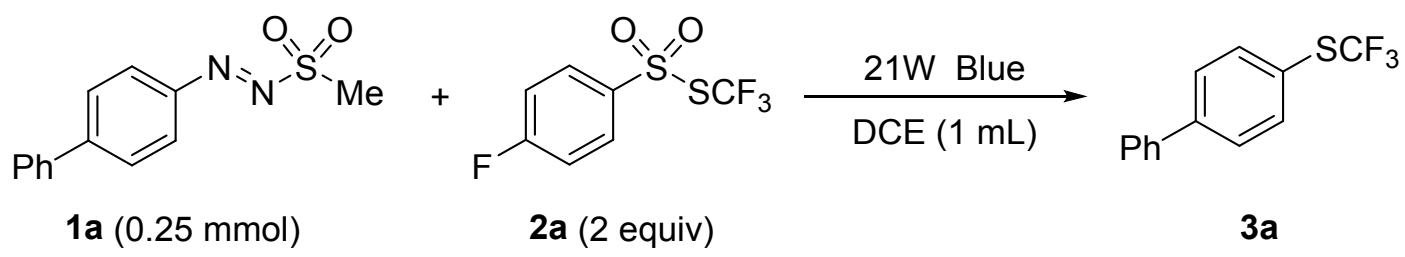

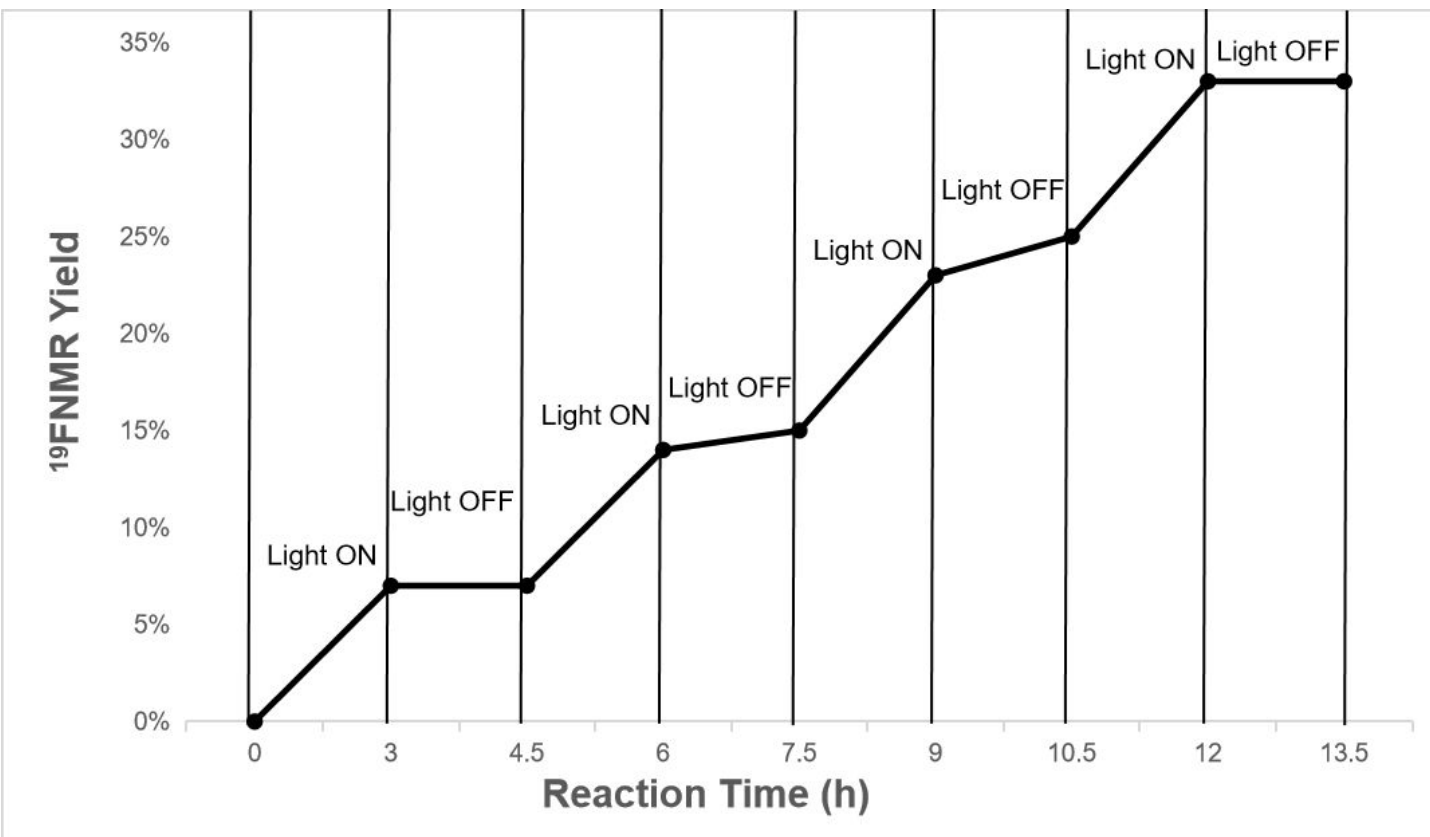

Figure S1. On-Off experiments carried out on the visible-light driven formation of arylthiotrifluoromethyl derivative $\mathbf{3 a}$ from aryl azosulfone $\mathbf{1 a}$. 


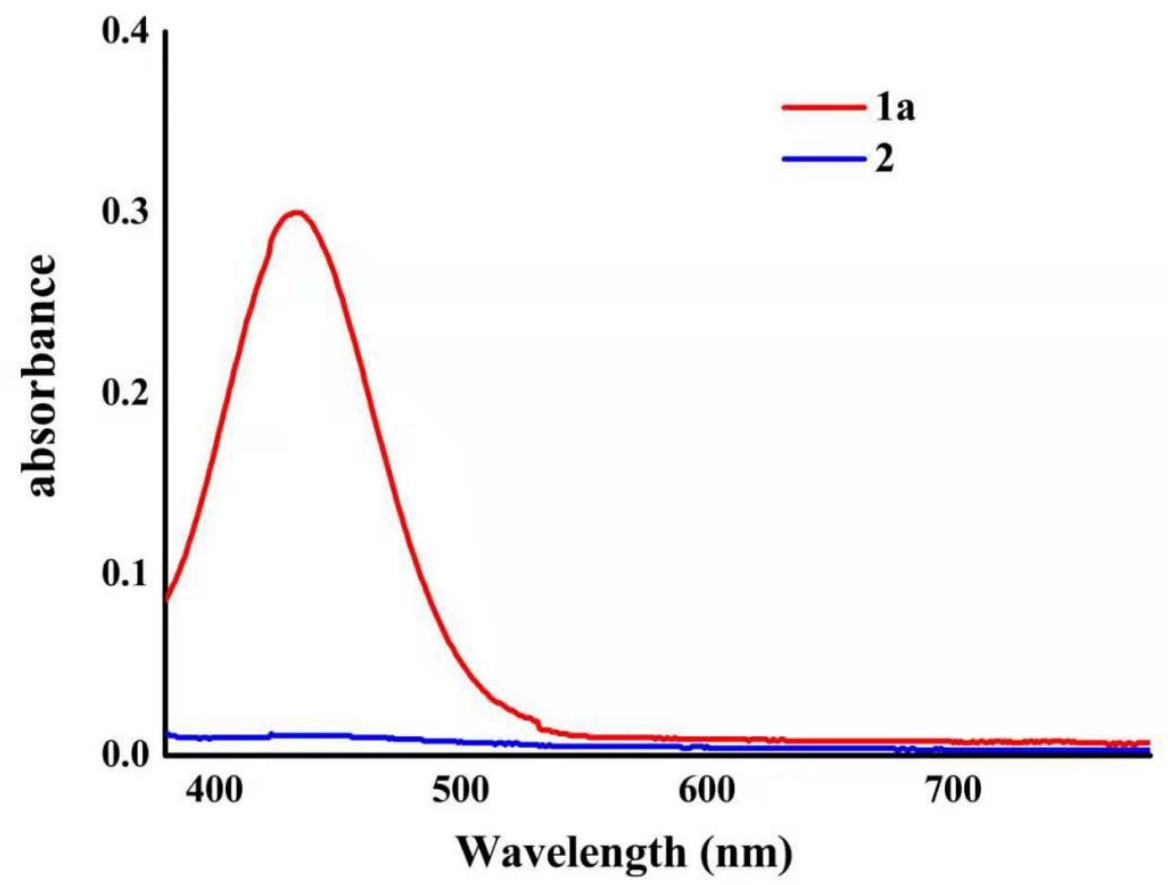

Figure S2. UV/Vis absorption spectra of DCE solutions of ethyl 4((methylsulfonyl)diazenyl)benzoate $\left(\mathbf{1 a}, 4 \times 10^{-4} \mathrm{M}\right.$, Red Line) and $S$-(trifluoromethyl) 4-fluorobenzenesulfonothioate (2a, $8 \times 10^{-4} \mathrm{M}$, Blue Line). 
2. Copy of the ${ }^{1} \mathrm{H},{ }^{13} \mathrm{C}$ and ${ }^{19} \mathrm{~F}$ NMR spectra of the prepared compounds

${ }^{1} \mathrm{H}$ NMR spectra of 1-([1,1'-Biphenyl]-4-yl)-2-(methylsulfonyl)diazene (1a) in $\mathrm{CDCl}_{3}$
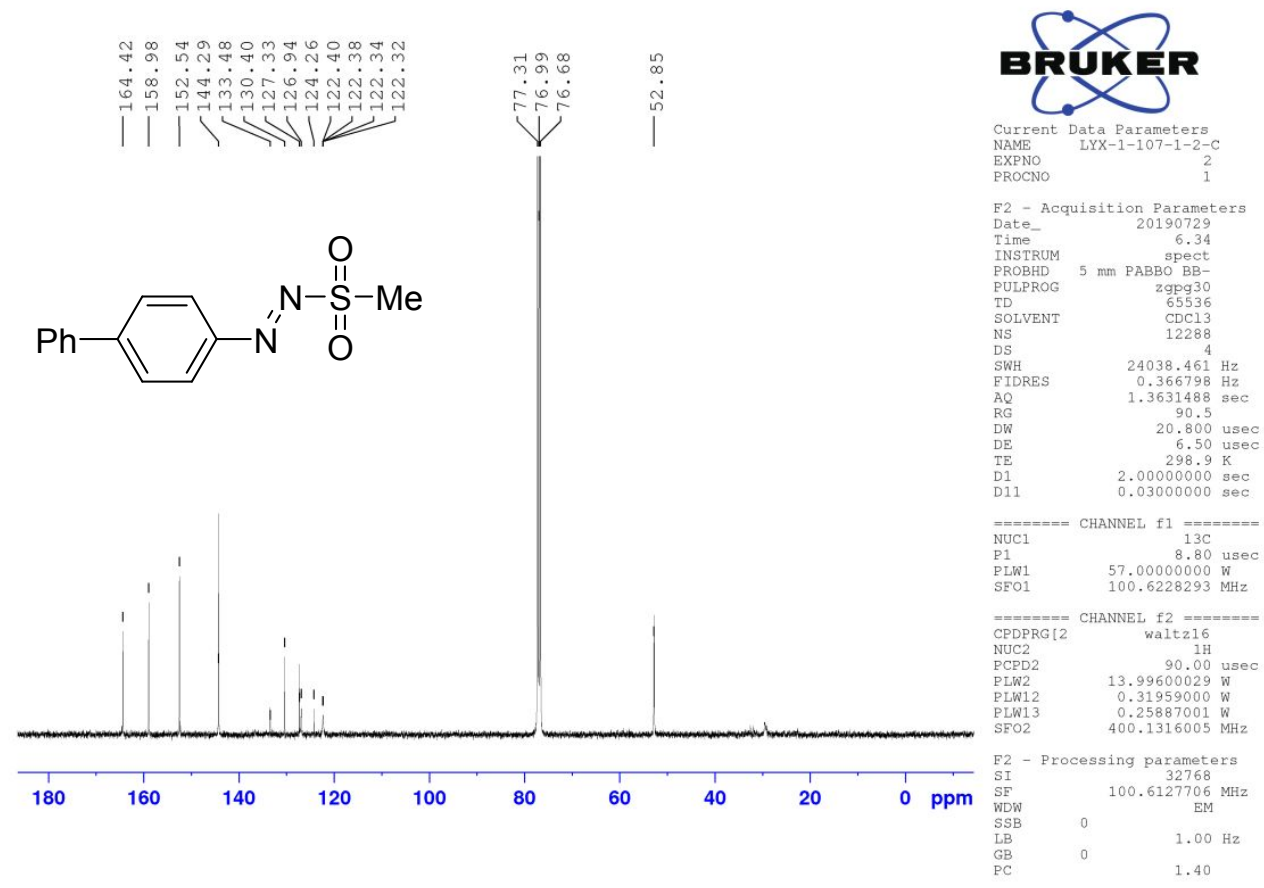

${ }^{1} \mathrm{H}, \quad$ and $\quad{ }^{13} \mathrm{C} \quad \mathrm{NMR} \quad$ spectra of $1-\left(\left[1,1^{\prime}\right.\right.$-biphenyl]-4-yl)-2-((4nitrophenyl)sulfonyl)diazene (1a') in $\quad \mathrm{CDCl}_{3}$

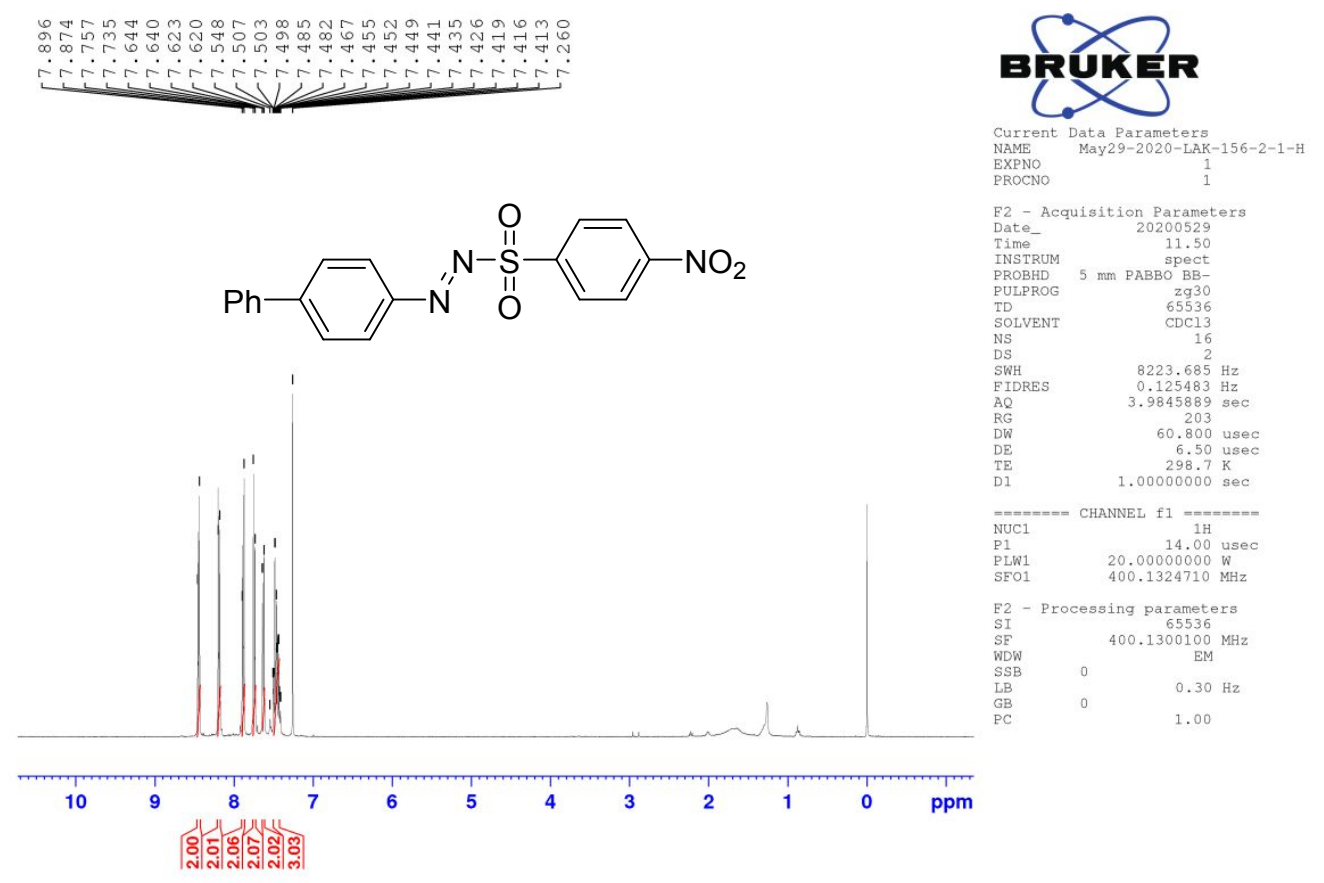




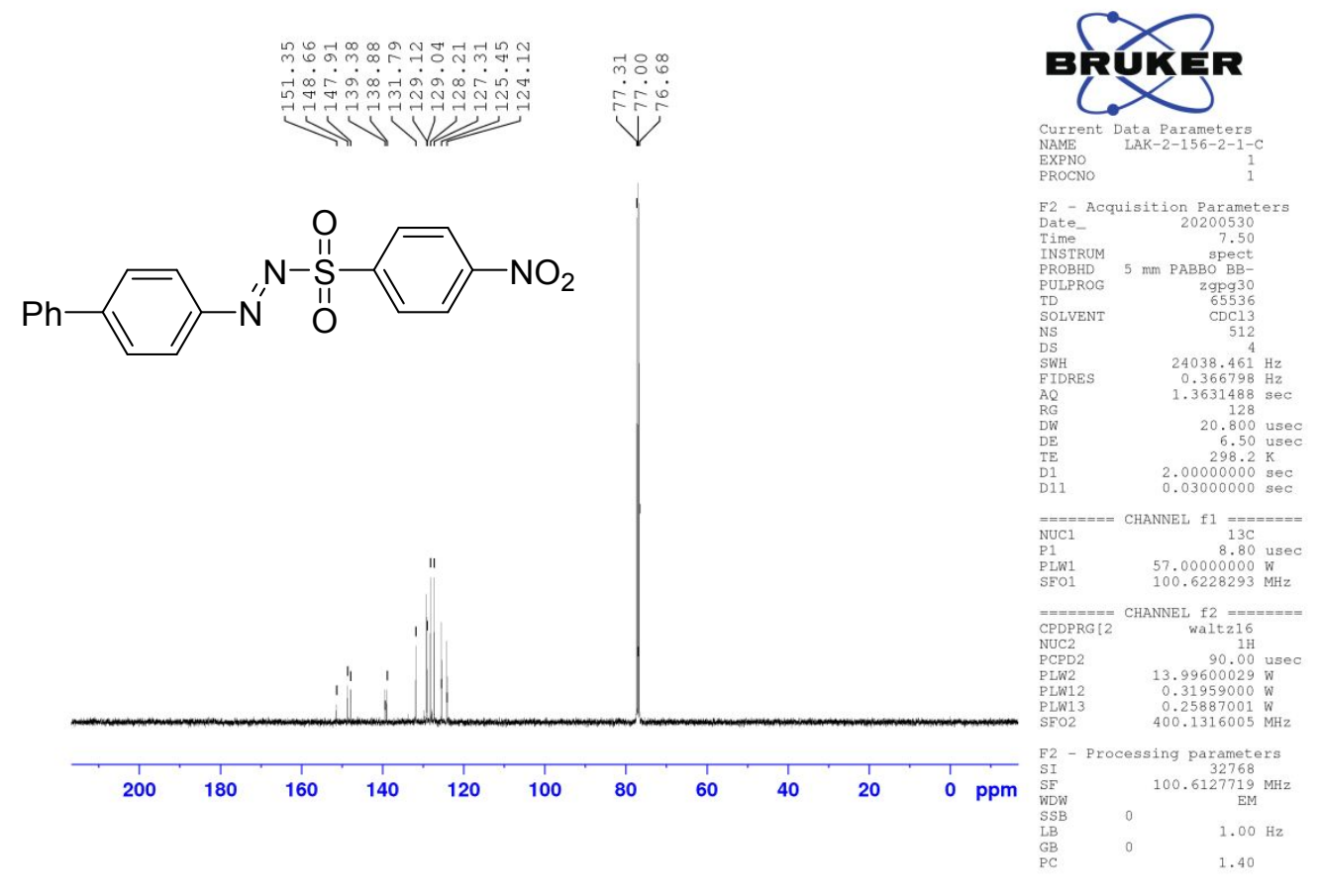

${ }^{1} \mathrm{H}$, and ${ }^{13} \mathrm{C}$ NMR spectra of 4-(4-((methylsulfonyl)diazenyl)phenyl)morpholine (1b) in $\mathrm{CDCl}_{3}$

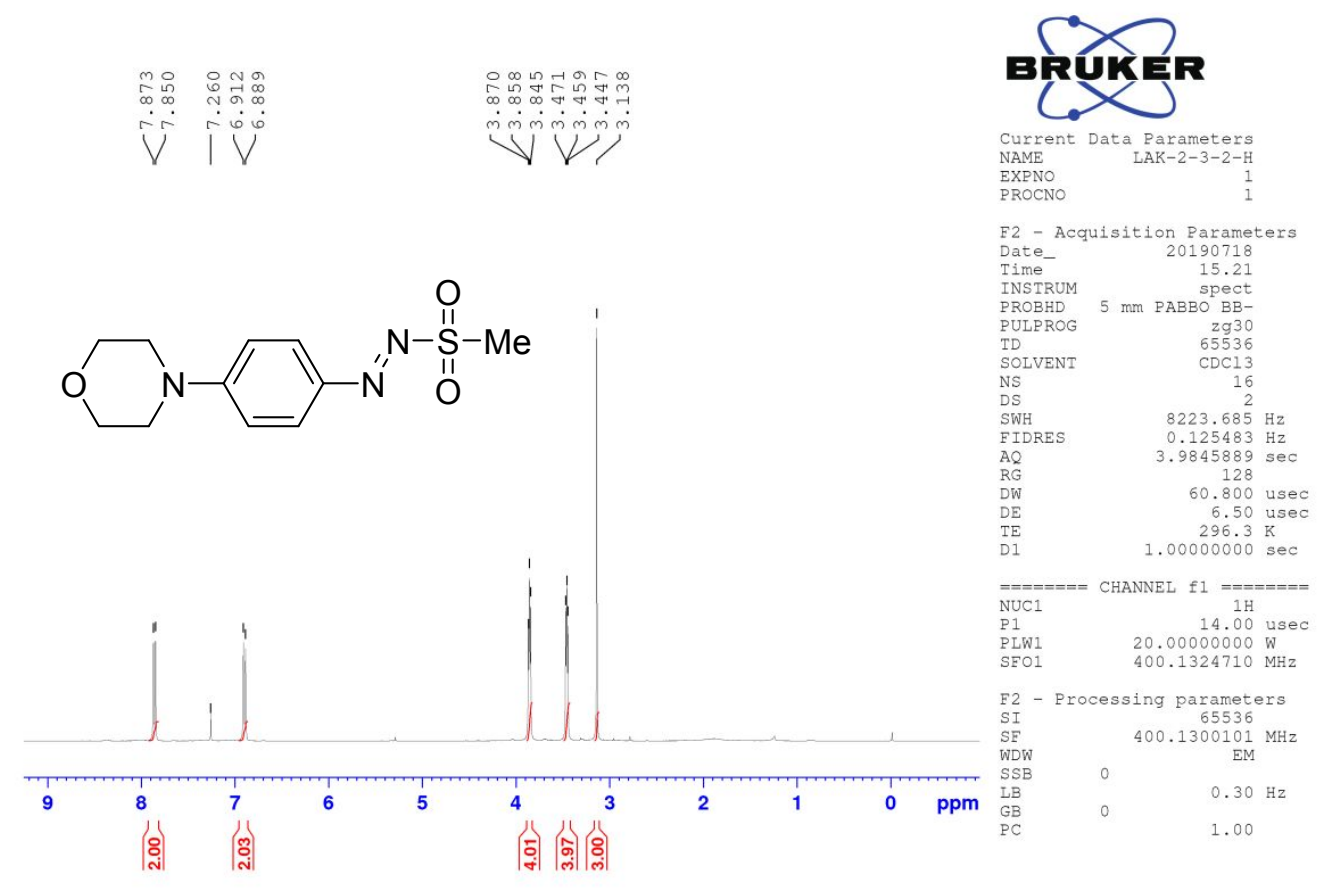




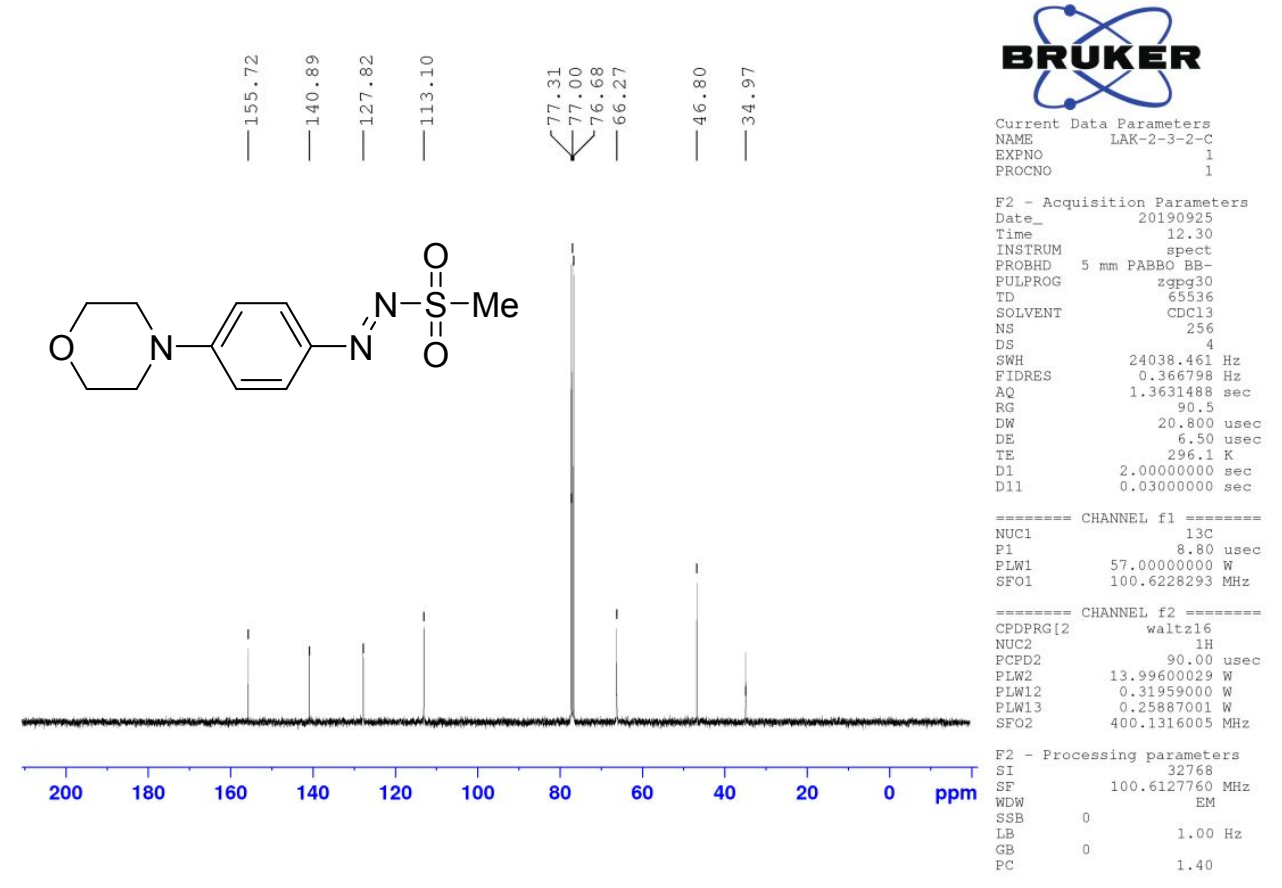

${ }^{1} \mathrm{H}$, and ${ }^{13} \mathrm{C}$ NMR spectra of 1-(methylsulfonyl)-2-(4-phenoxyphenyl)diazene (1c) in $\mathrm{CDCl}_{3}$

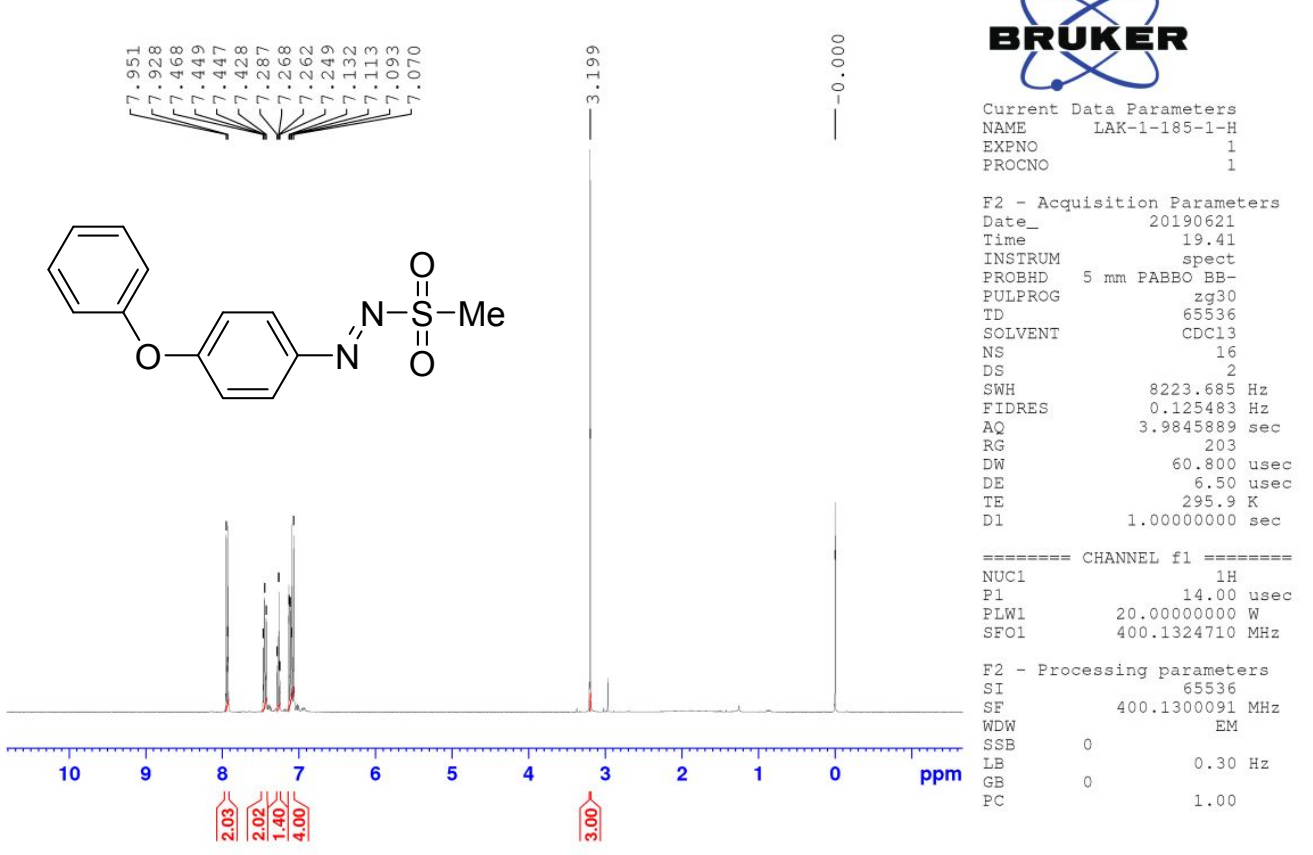




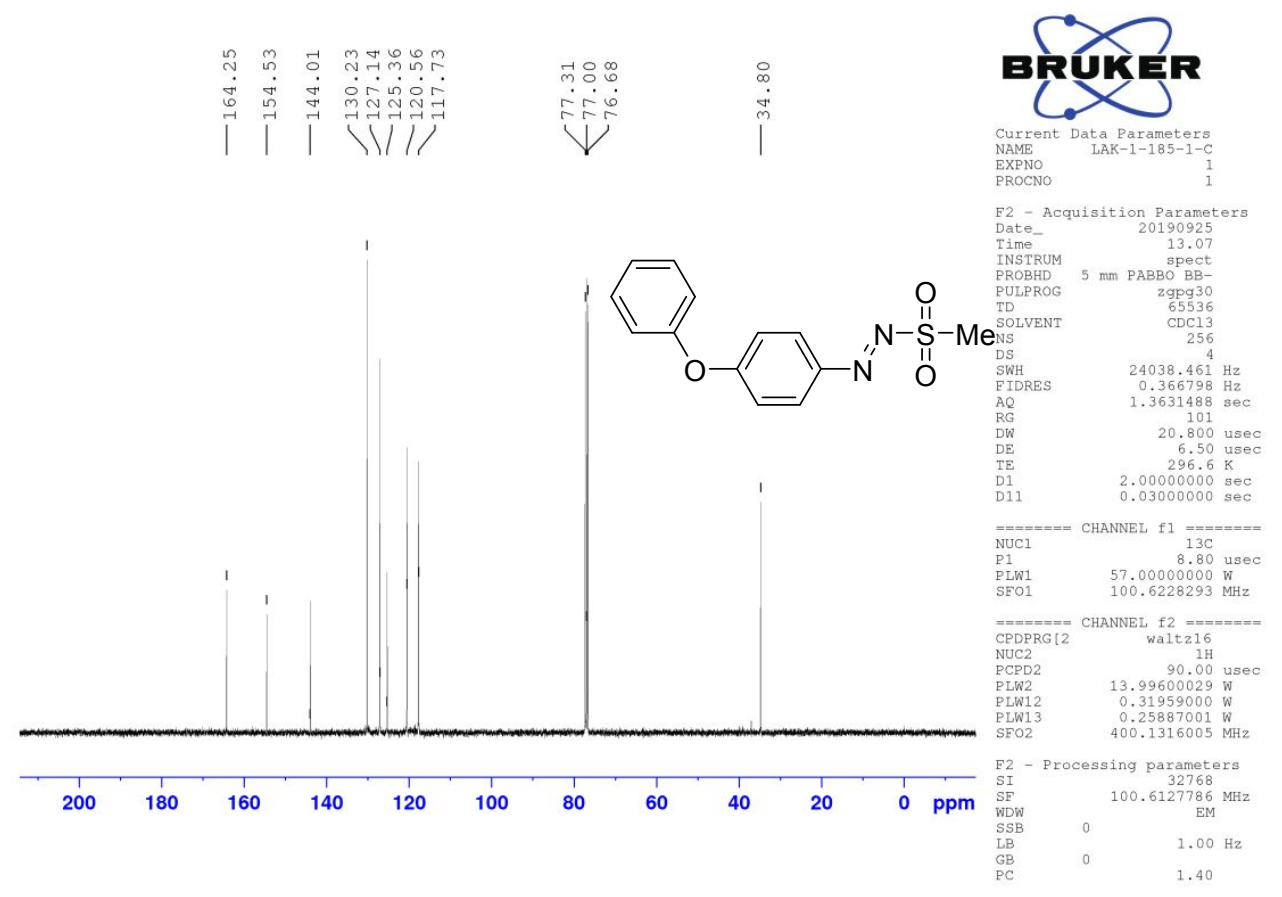

${ }^{1} \mathrm{H}$, and ${ }^{13} \mathrm{C}$ NMR spectra of (4-(benzyloxy)phenyl)-2-(methylsulfonyl)diazene (1d) in $\mathrm{CDCl}_{3}$

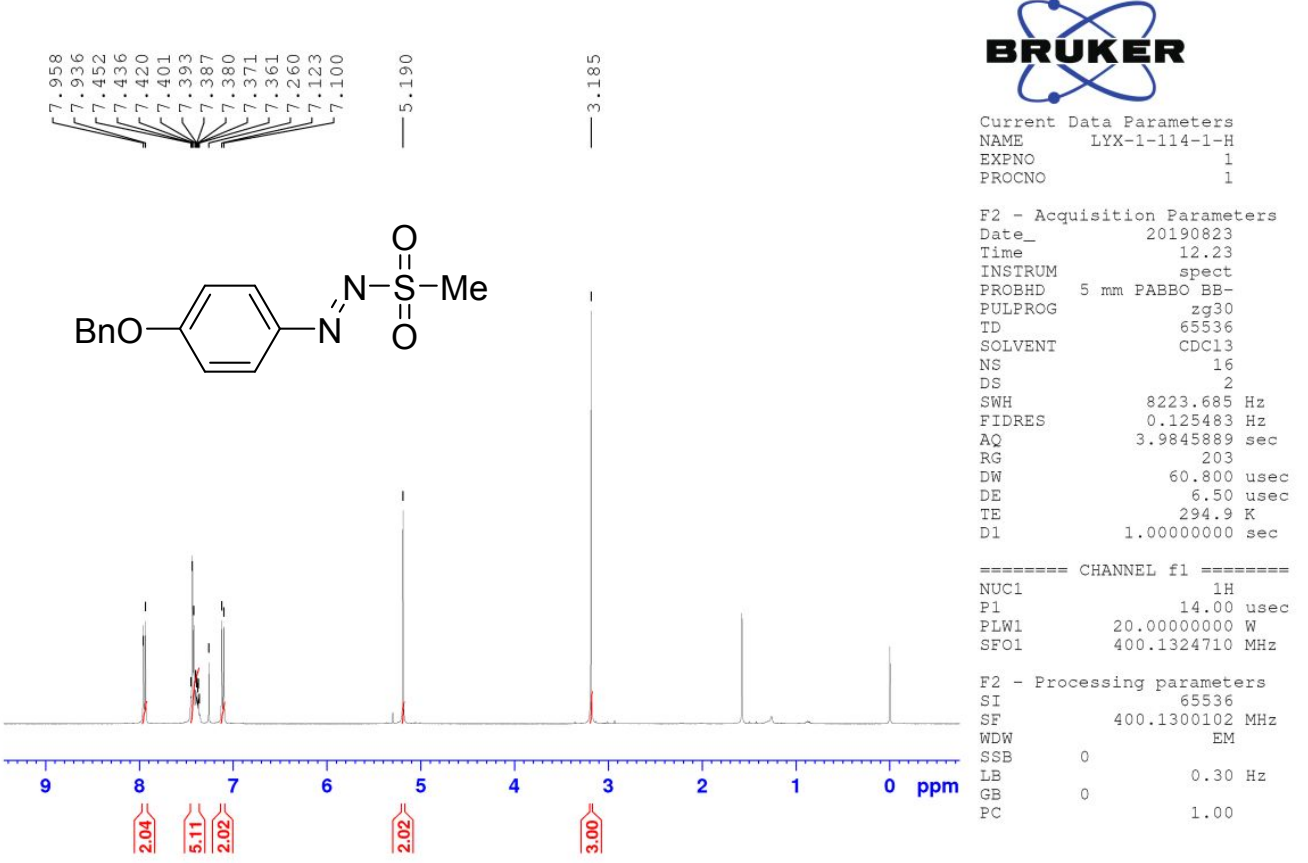




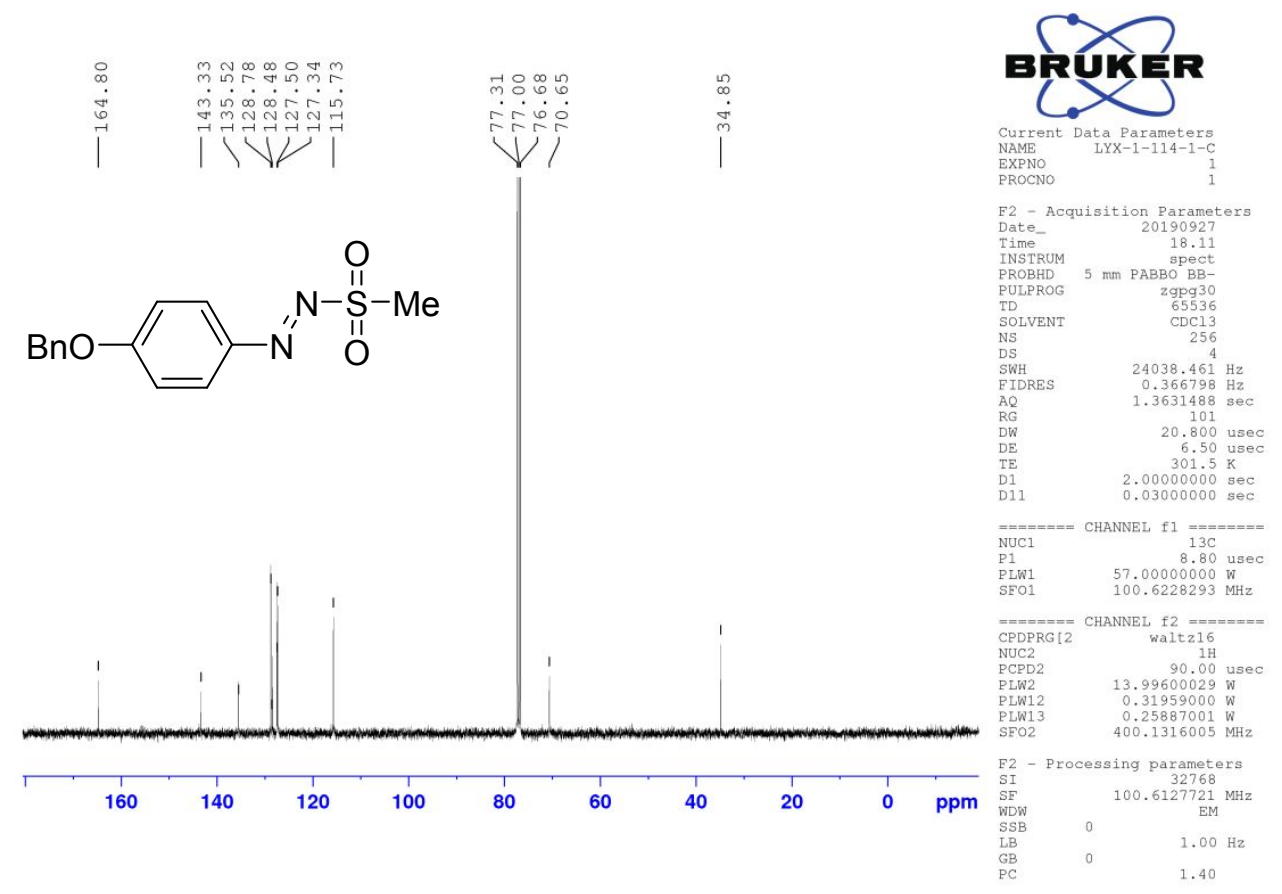

${ }^{1} \mathrm{H}$, and ${ }^{13} \mathrm{C}$ NMR spectra of 1-(methylsulfonyl)-2-(4-(methylthio)phenyl)diazene (1e) in $\mathrm{CDCl}_{3}$

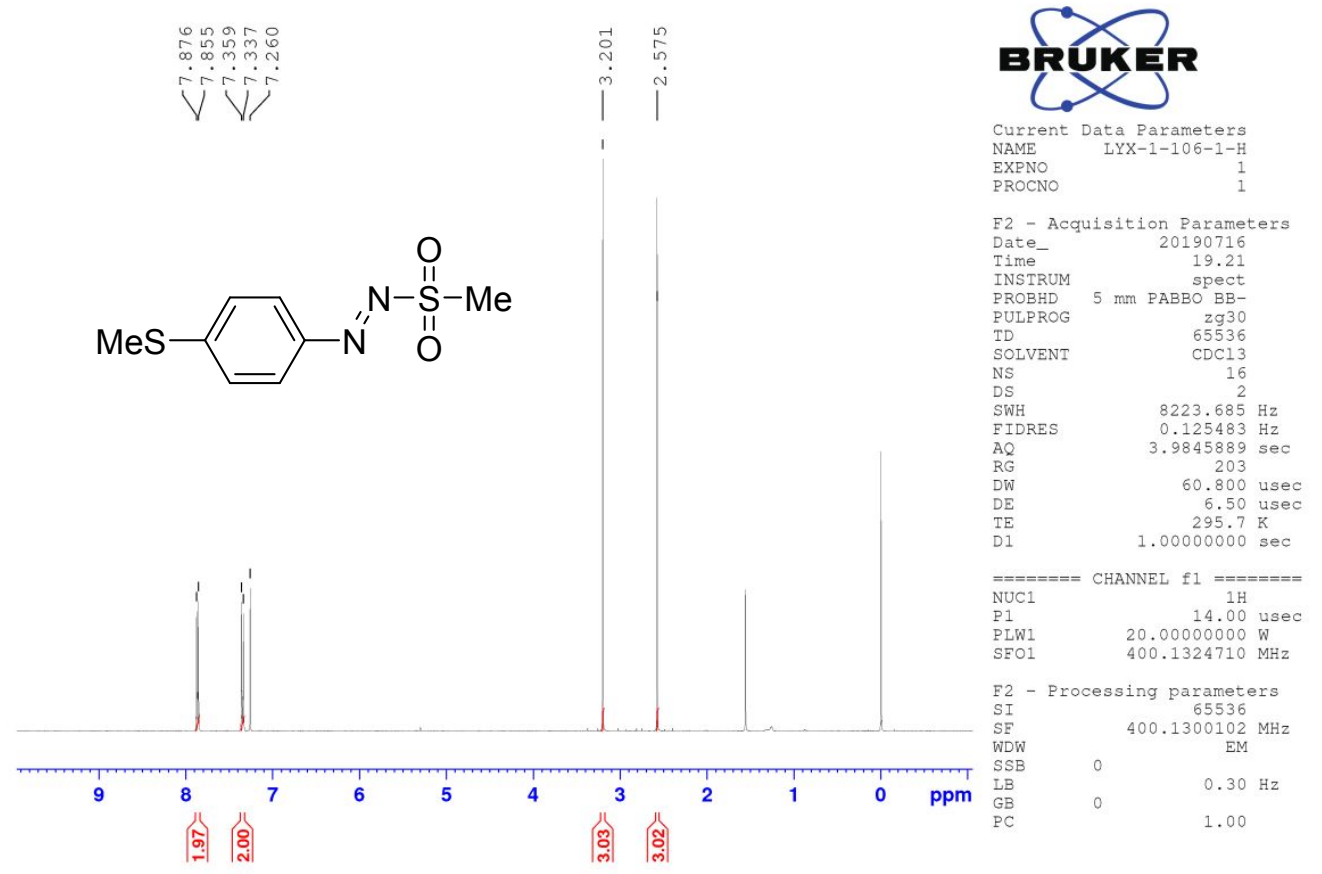




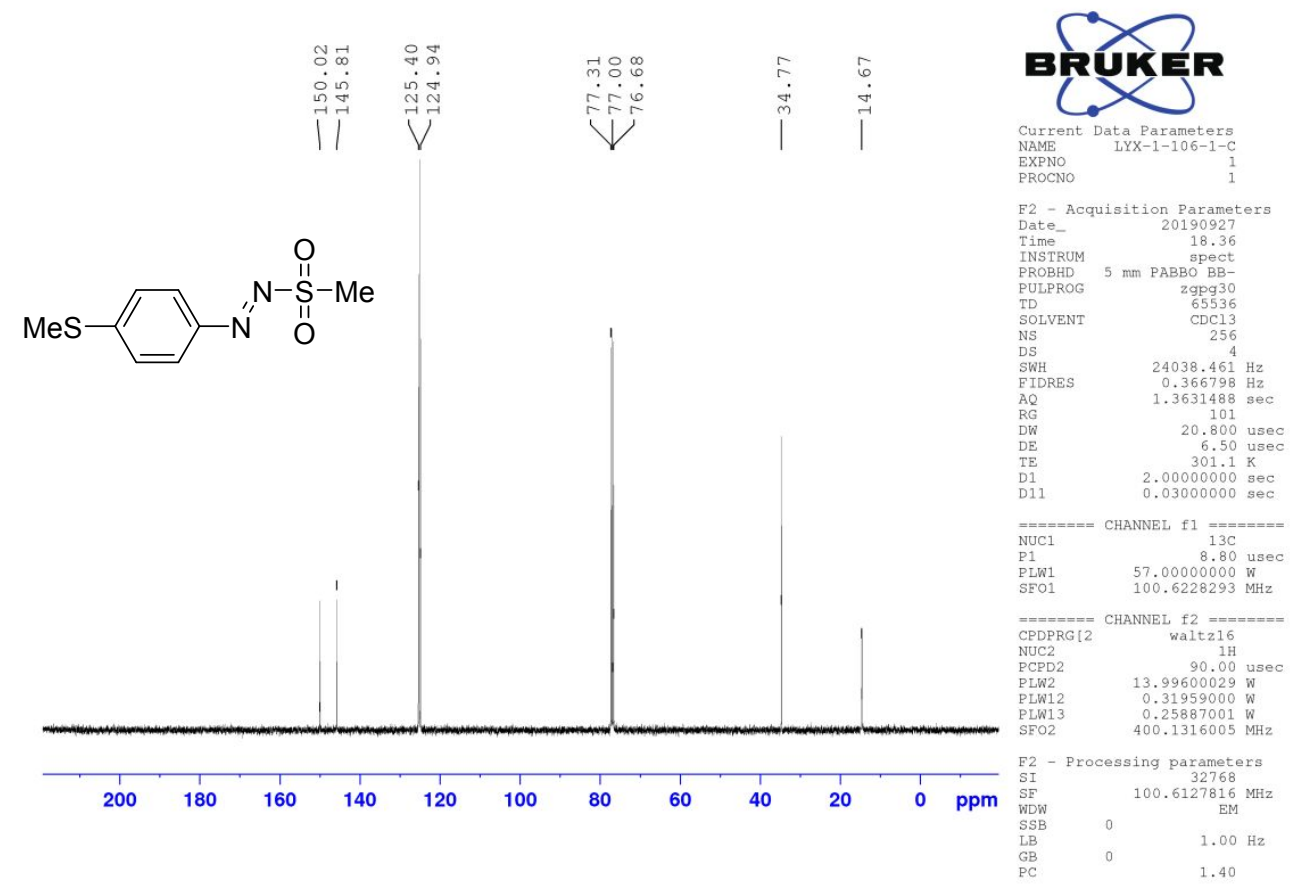

${ }^{1} \mathrm{H}$ NMR spectra of 1-(4-(tert-Butyl)phenyl)-2-(methylsulfonyl)diazene (1f) in $\mathrm{CDCl}_{3}$

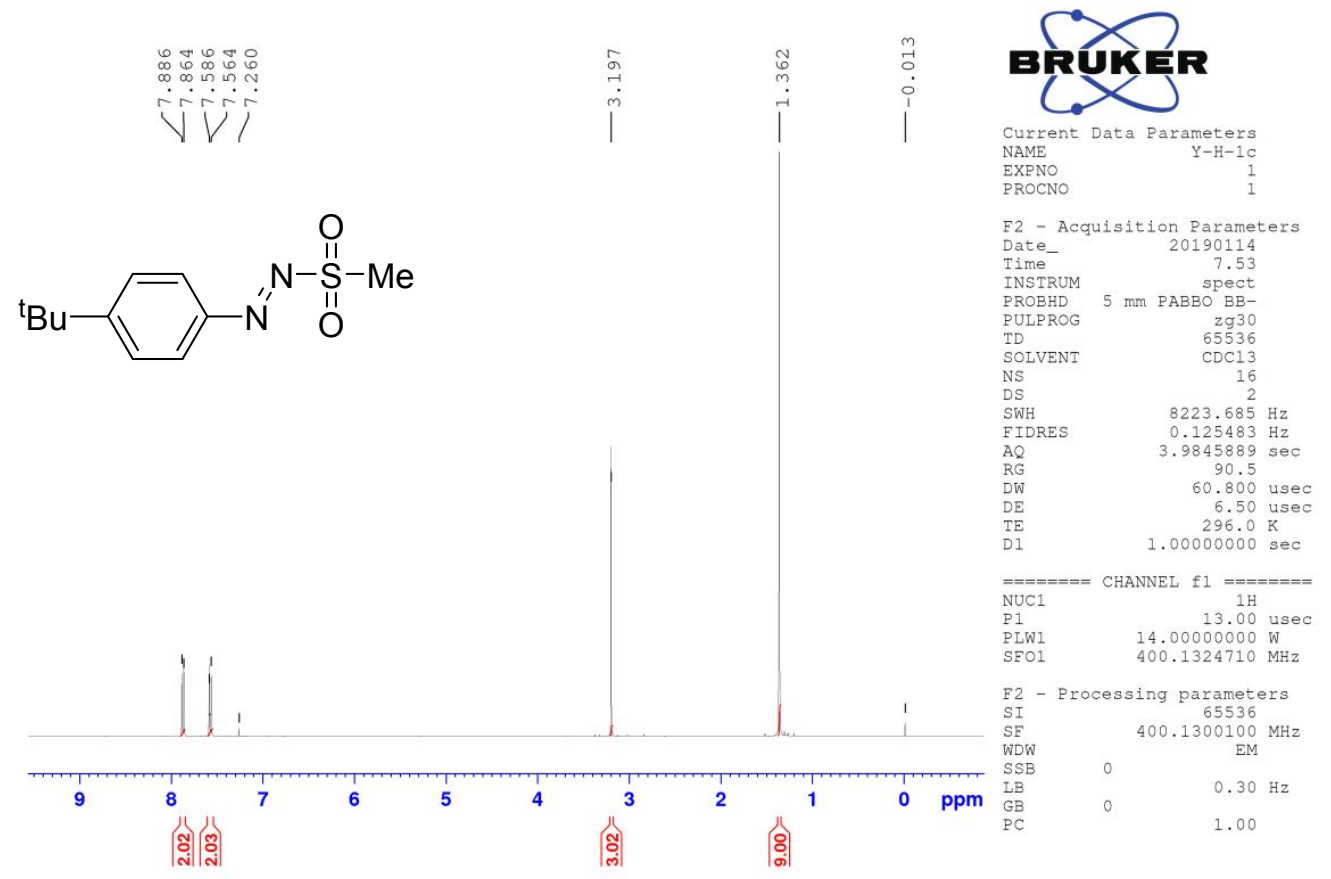


${ }^{1} \mathrm{H}$ NMR spectra of Ethyl 3-(4-((E)-(methylsulfonyl)diazenyl)phenyl)acrylate (1g) in $\mathrm{CDCl}_{3}$

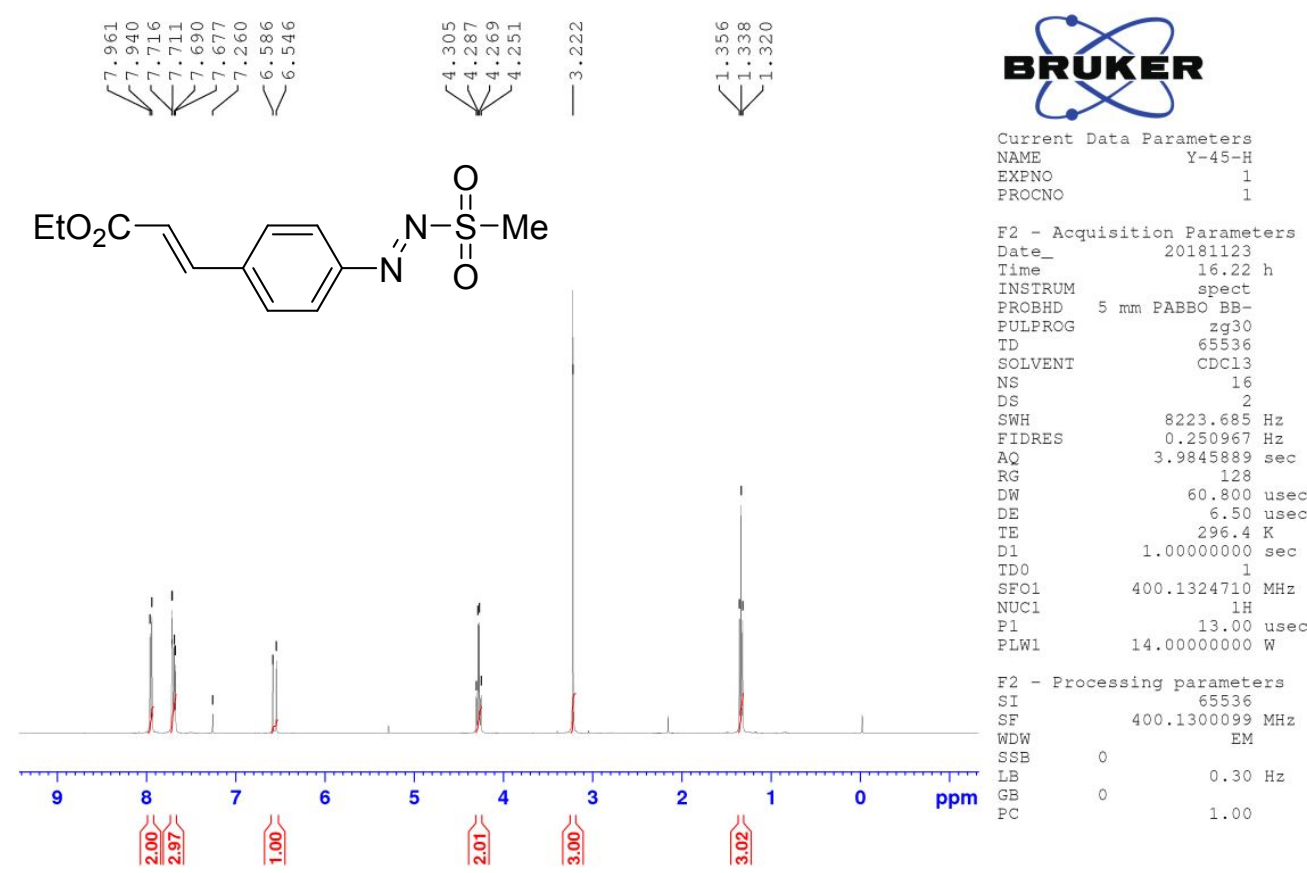

${ }^{1} \mathrm{H} \quad \mathrm{NMR} \quad$ spectra $\quad$ of $\quad$ 1-(Methylsulfonyl)-2-(4((triisopropylsilyl)ethynyl)phenyl)diazene (1h) in $\mathrm{CDCl}_{3}$

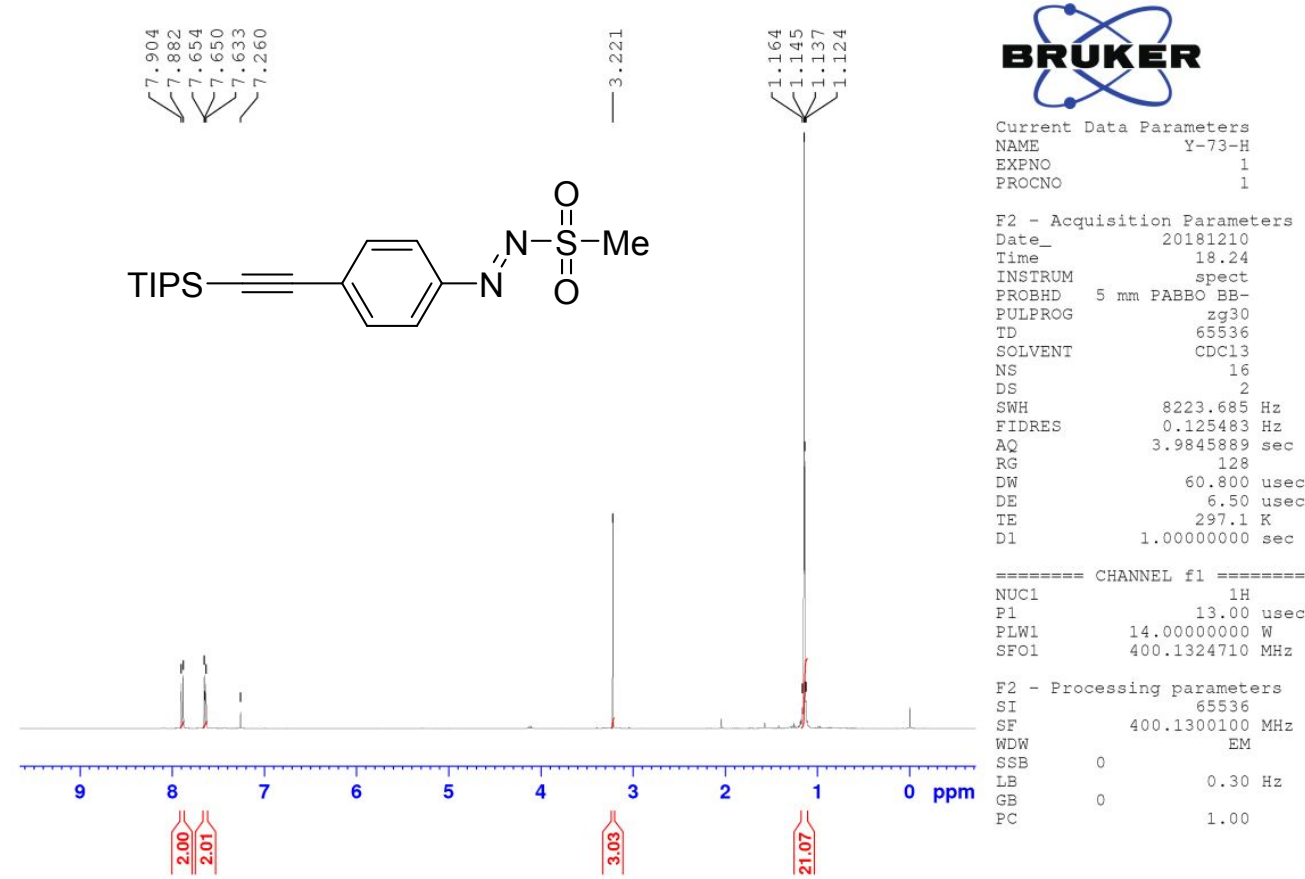


${ }^{1} \mathrm{H}$ NMR spectra of 1-(4-Bromophenyl)-2-(methylsulfonyl)diazene (1i) in $\mathrm{CDCl}_{3}$

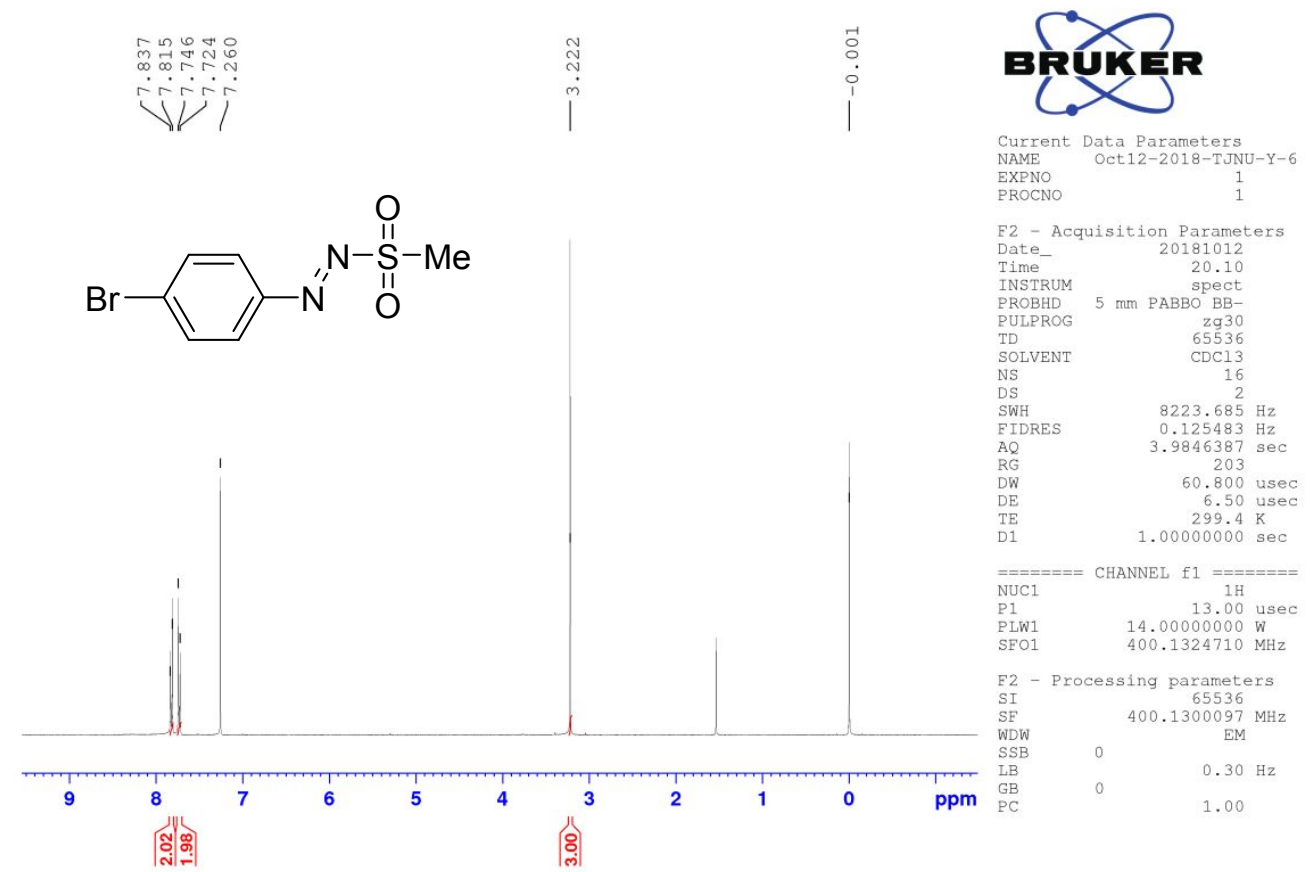

${ }^{1} \mathrm{H}$ NMR spectra of 4-((Methylsulfonyl)diazenyl)benzonitrile (1j) in $\mathrm{CDCl}_{3}$

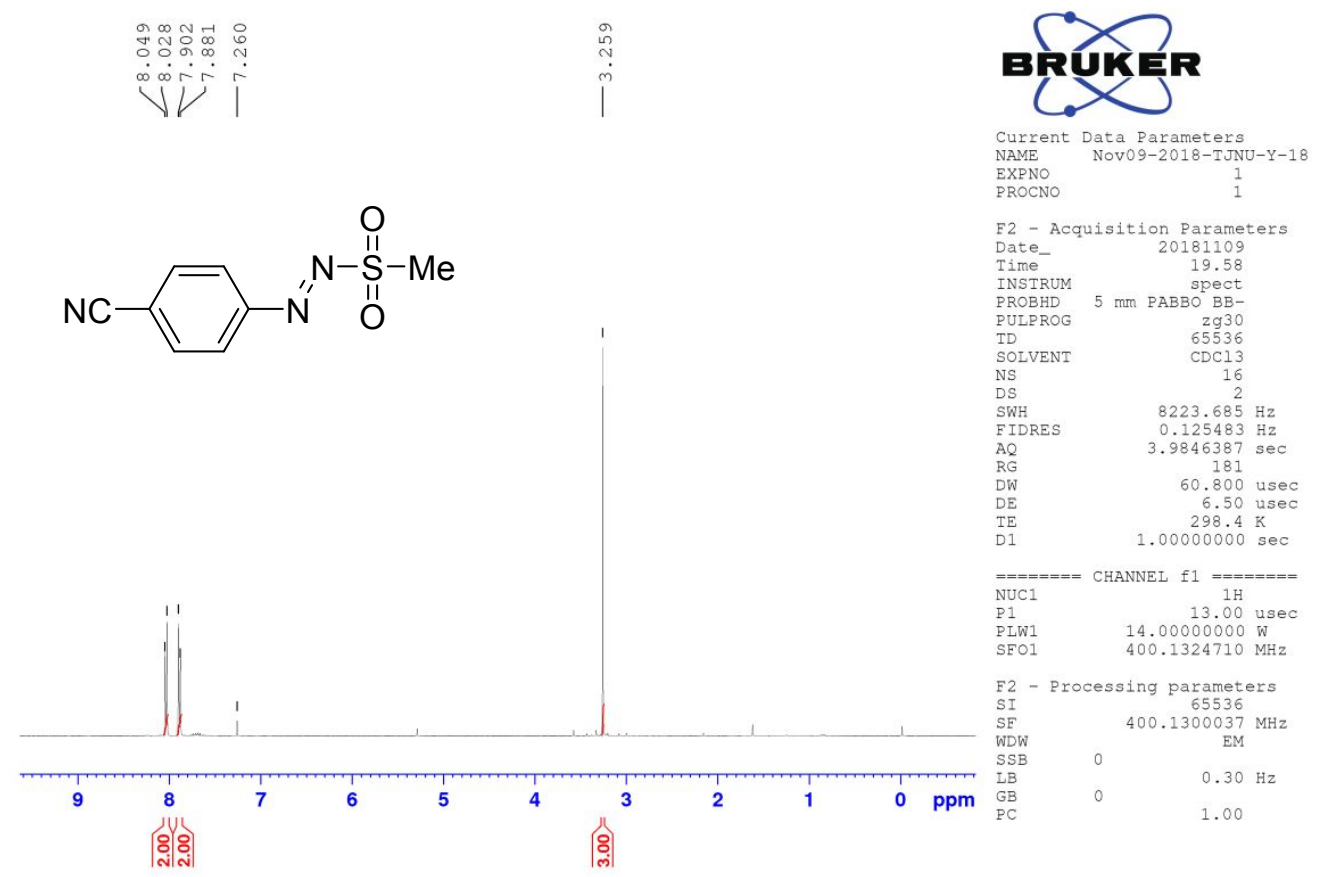


${ }^{1} \mathrm{H}$ NMR spectra of Ethyl 4 -((methylsulfonyl)diazenyl)benzoate (1k) in $\mathrm{CDCl}_{3}$

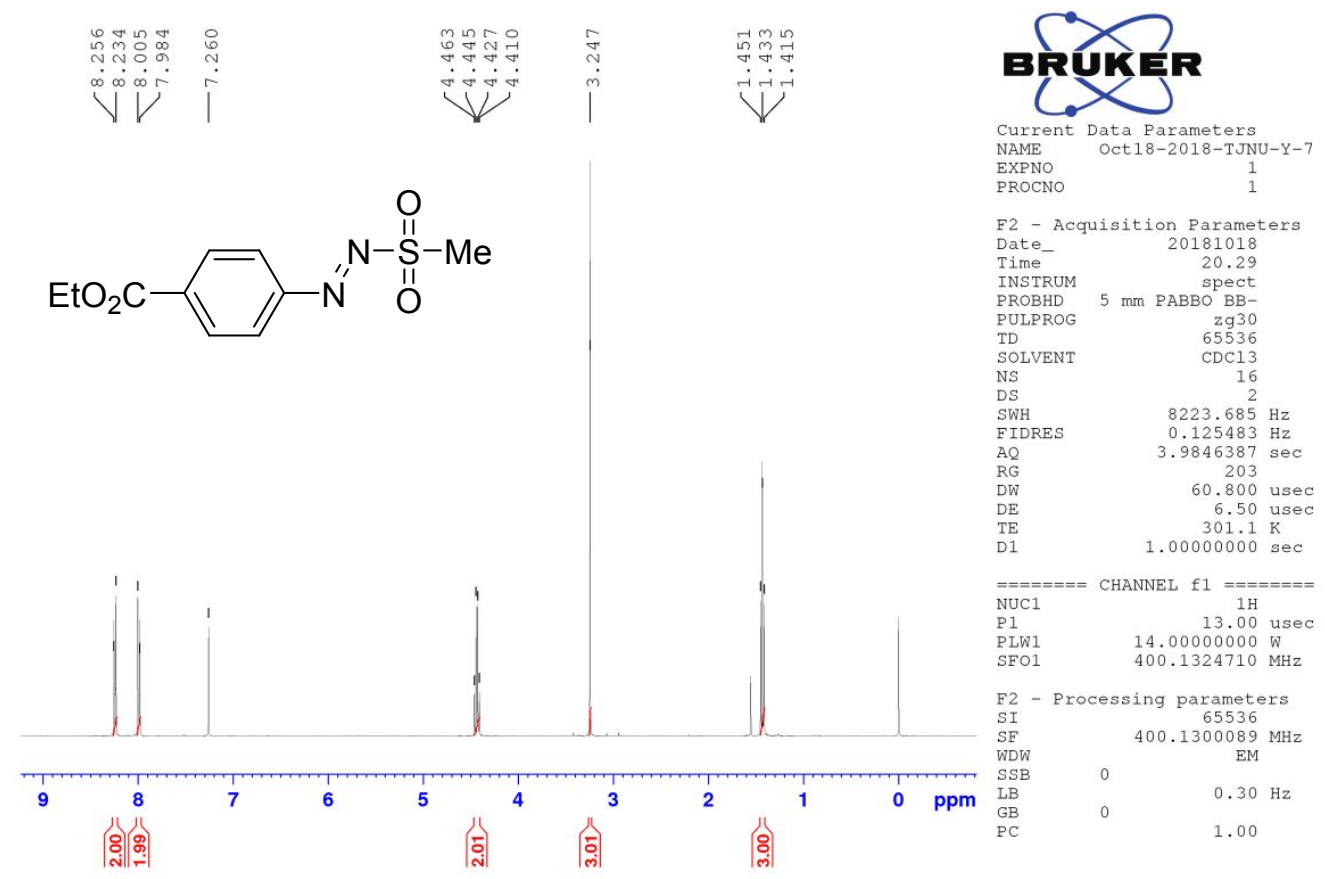

${ }^{1} \mathrm{H}$ NMR spectra of 1-(4-((Methylsulfonyl)diazenyl)phenyl)ethanone (1l) in $\mathrm{CDCl}_{3}$

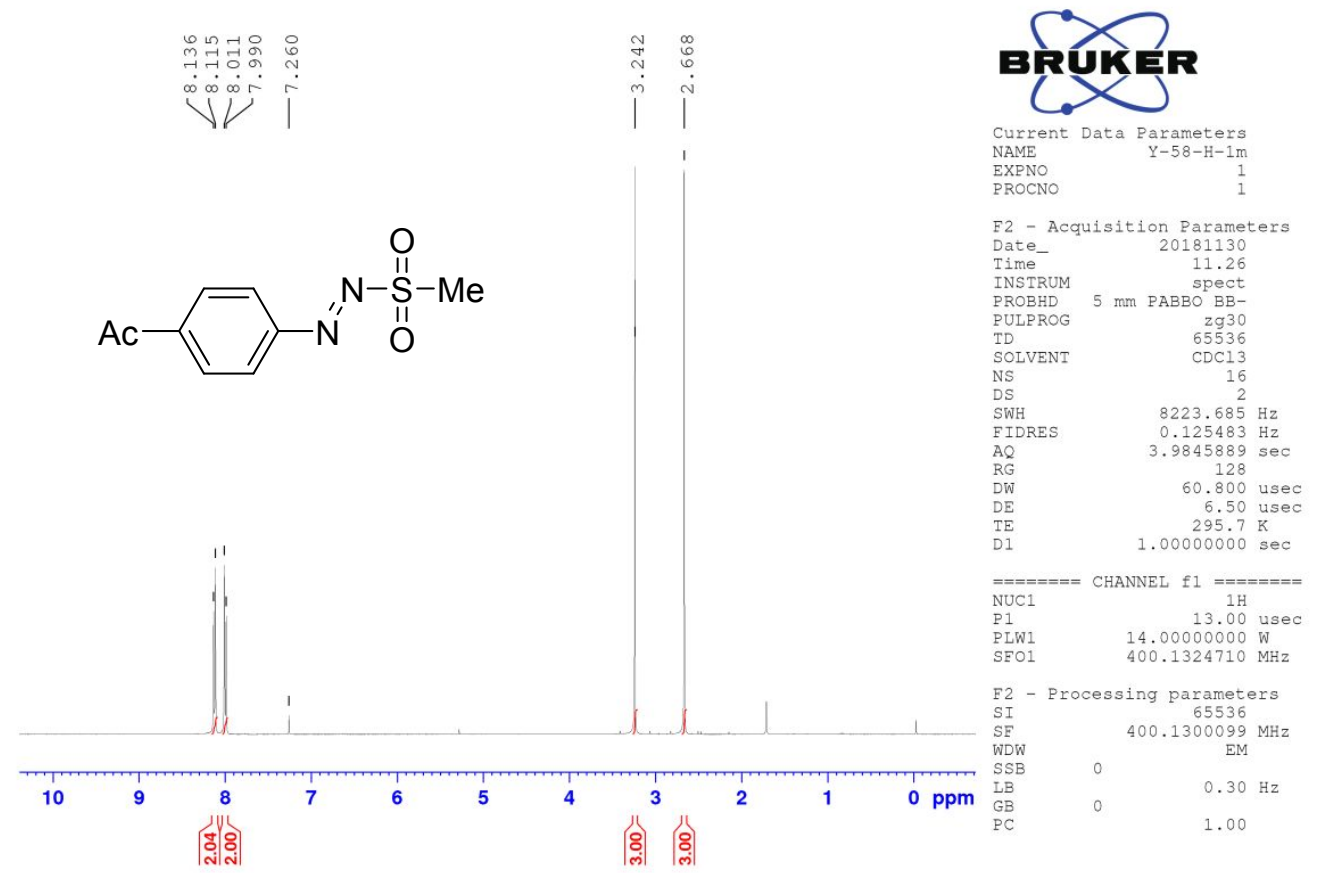


${ }^{1} \mathrm{H}$, and ${ }^{13} \mathrm{C}$ NMR spectra of (4-((methylsulfonyl)diazenyl)phenyl)(phenyl)methanone (1m) in $\mathrm{CDCl}_{3}$
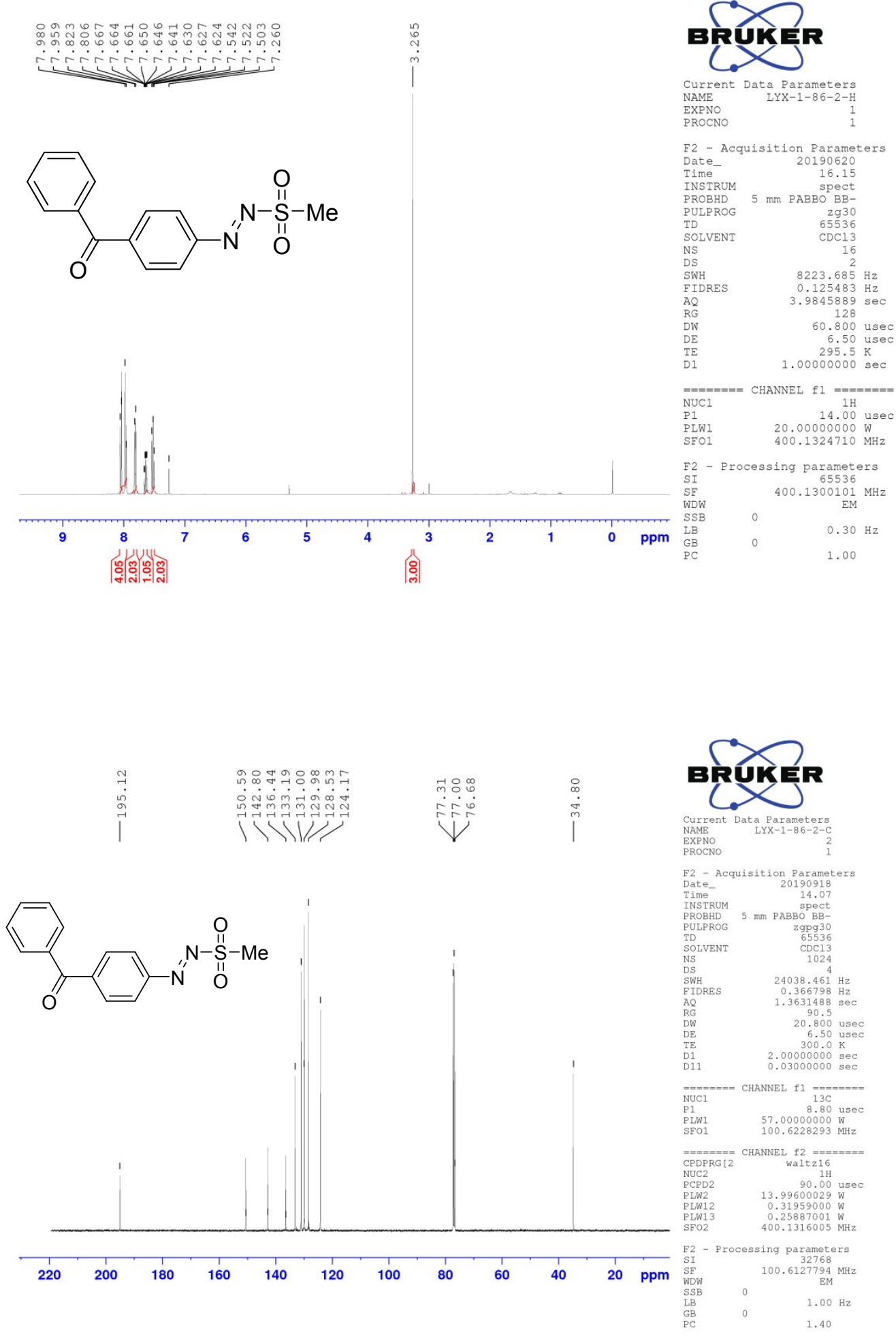
${ }^{1} \mathrm{H}$ NMR spectra of 1-(3-Bromophenyl)-2-(methylsulfonyl)diazene (1n) in $\mathrm{CDCl}_{3}$

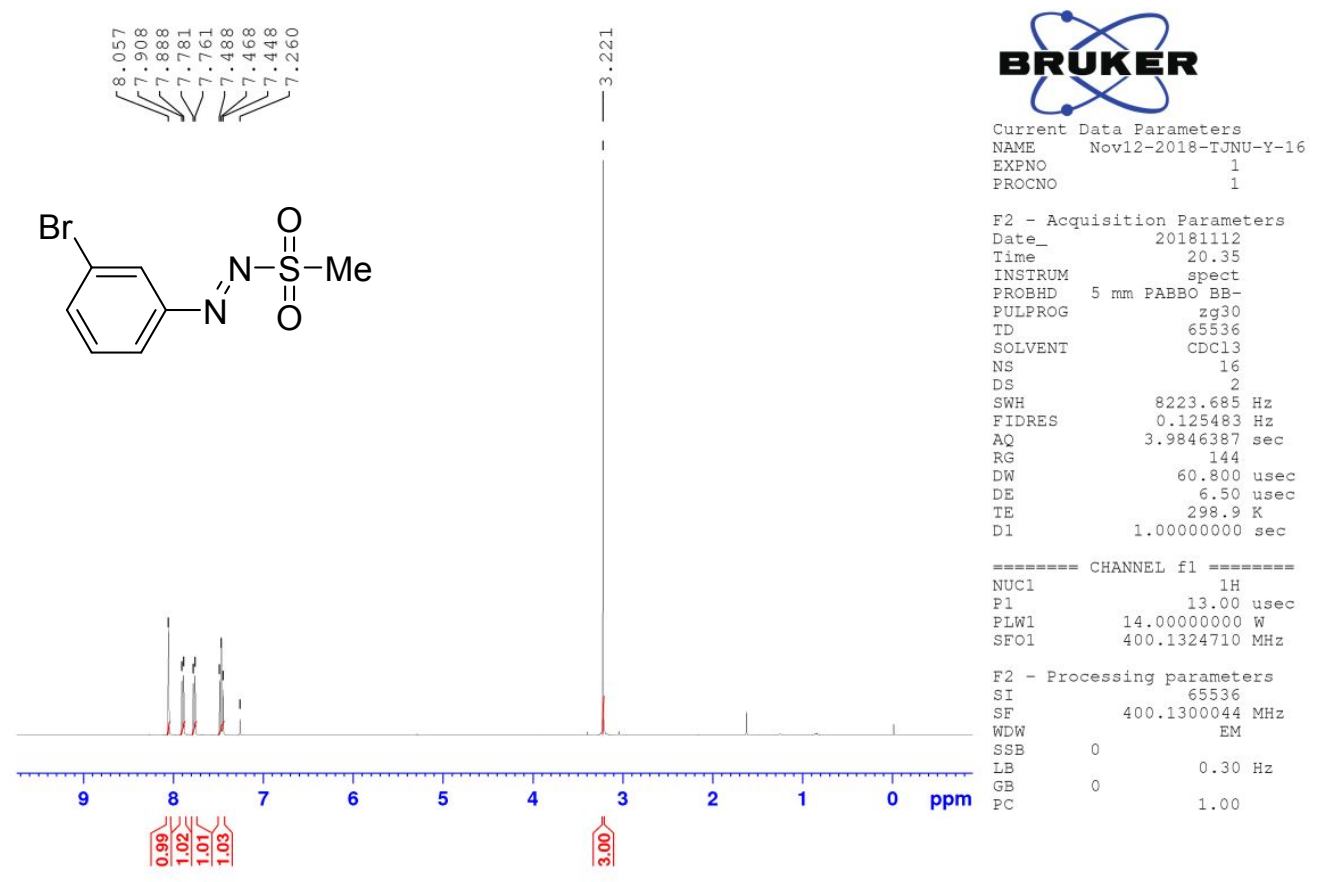

${ }^{1} \mathrm{H}$, and ${ }^{13} \mathrm{C}$ NMR spectra of 1-(methylsulfonyl)-2-(3,4,5-trimethoxyphenyl)diazene (1o) in $\mathrm{CDCl}_{3}$

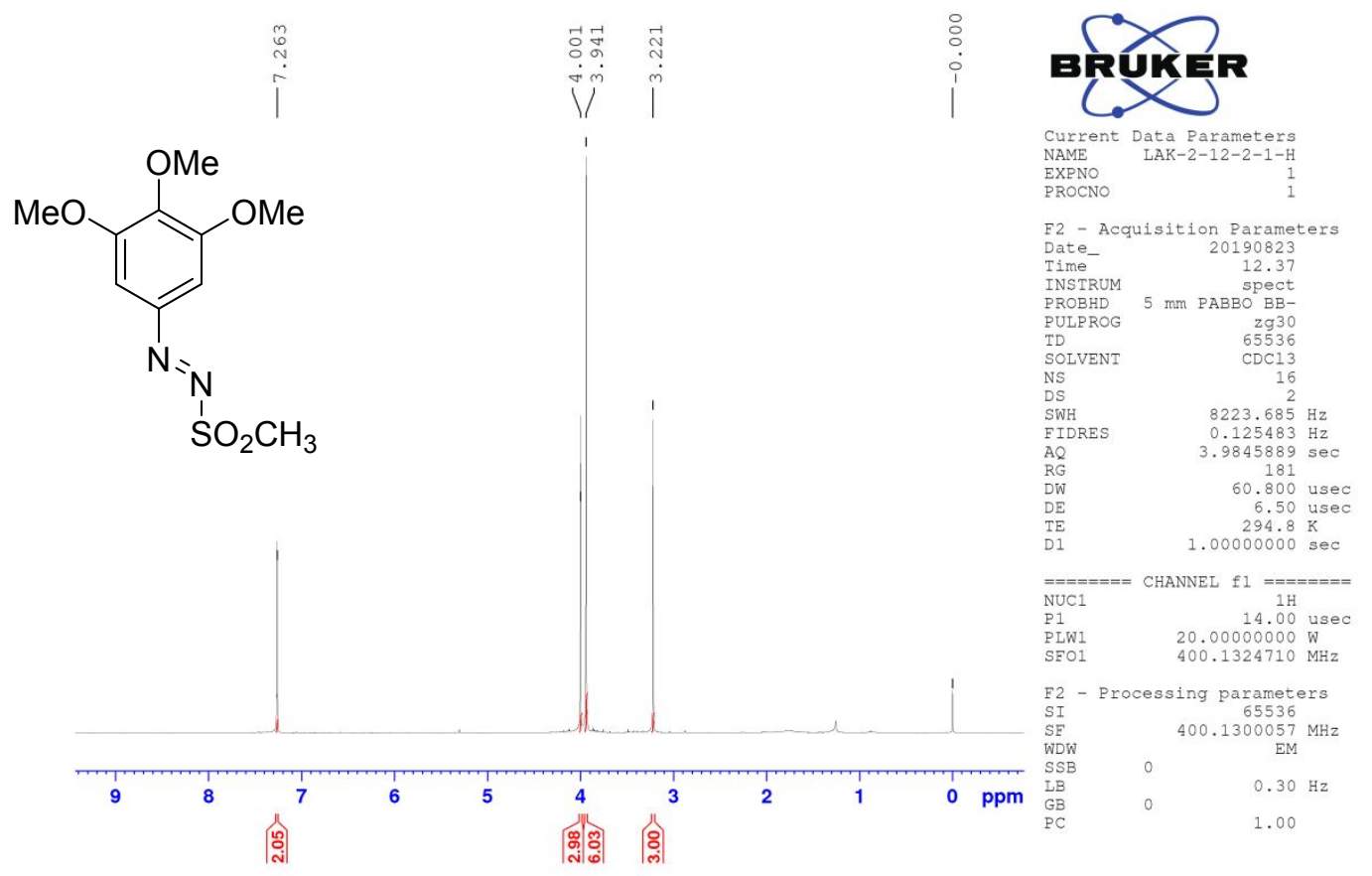




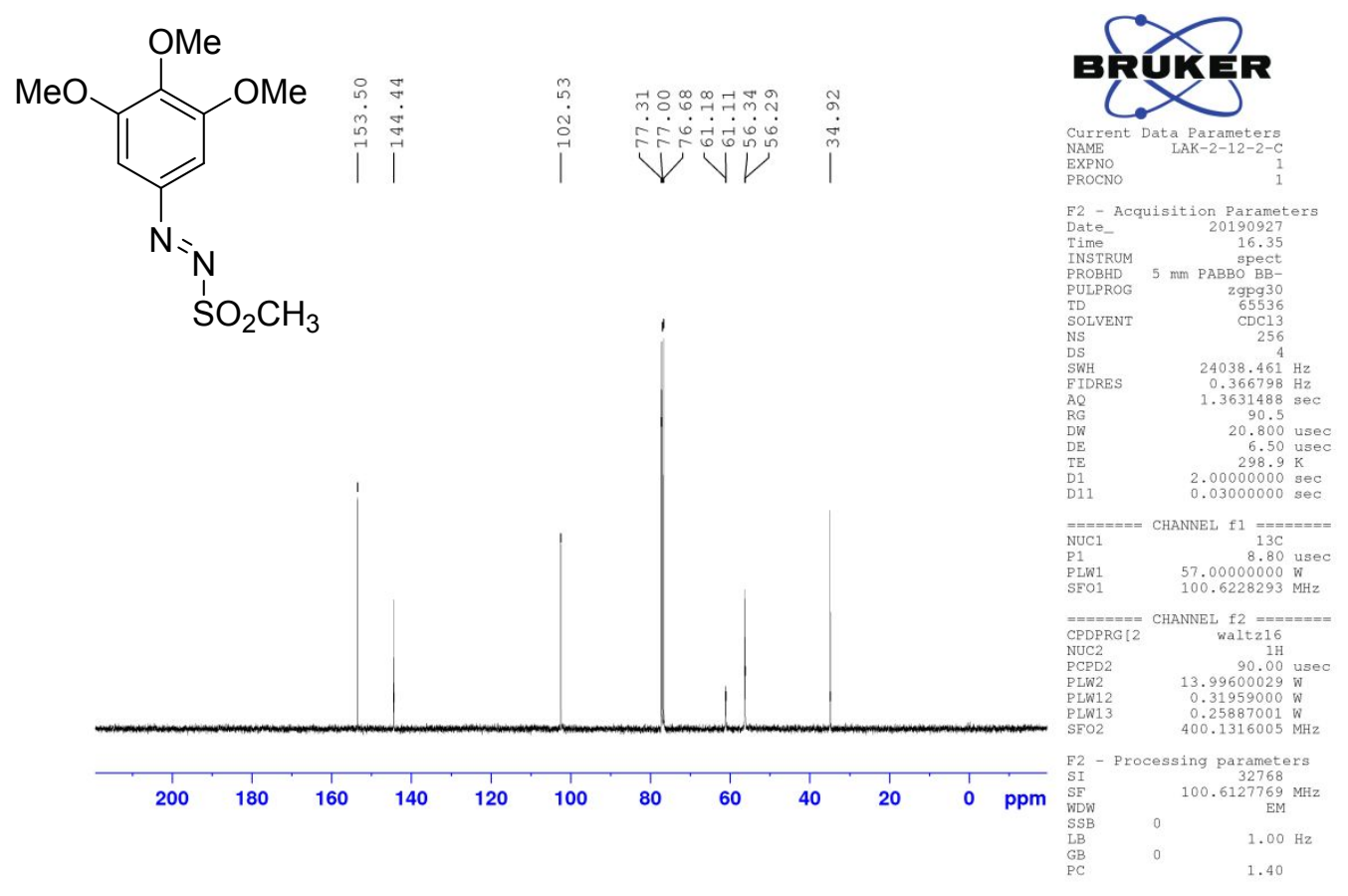

${ }^{1} \mathrm{H}$, and ${ }^{13} \mathrm{C}$ NMR spectra of 1-(benzo[d][1,3]dioxol-5-yl)-2-(methylsulfonyl)diazene (1p) in $\mathrm{CDCl}_{3}$

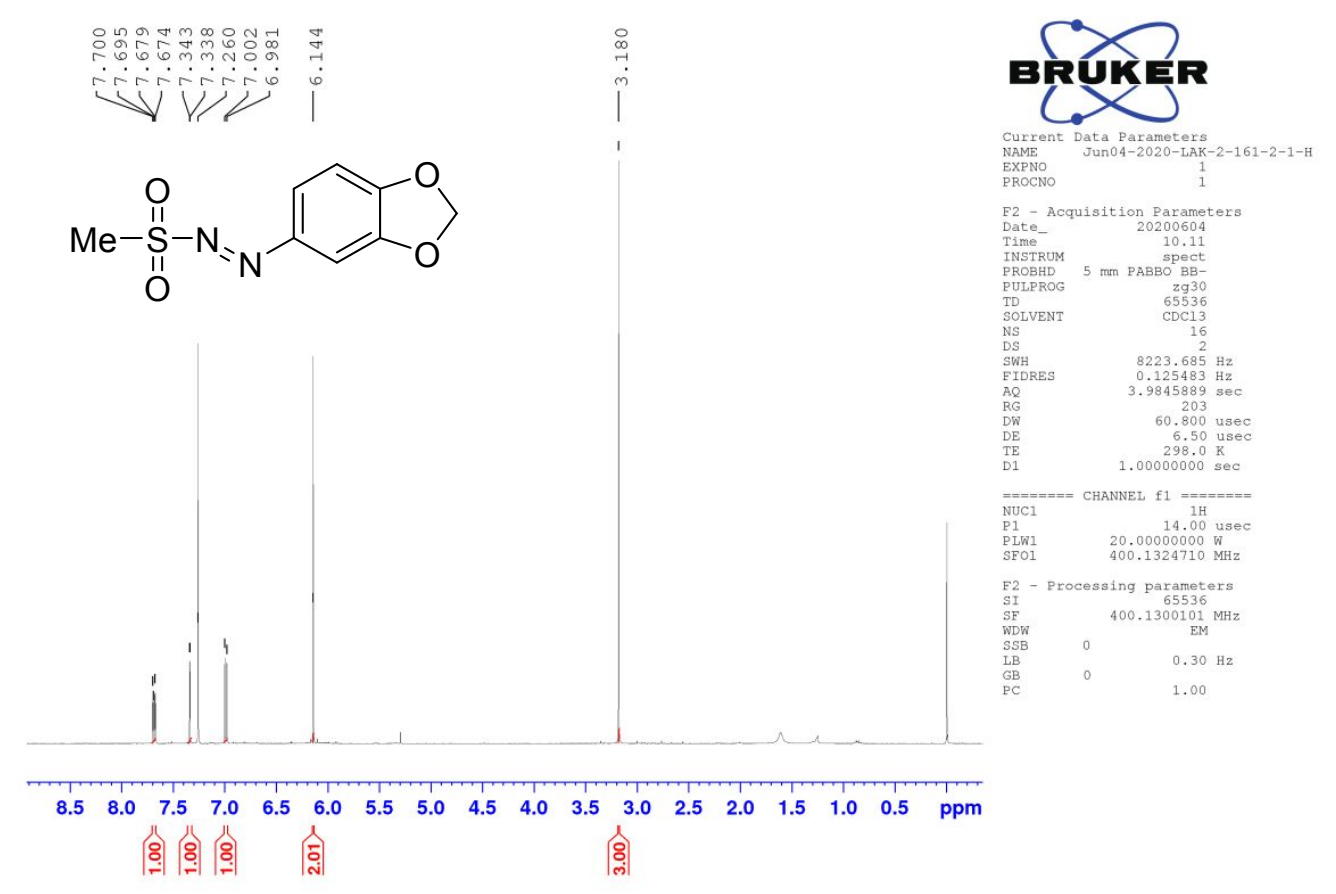




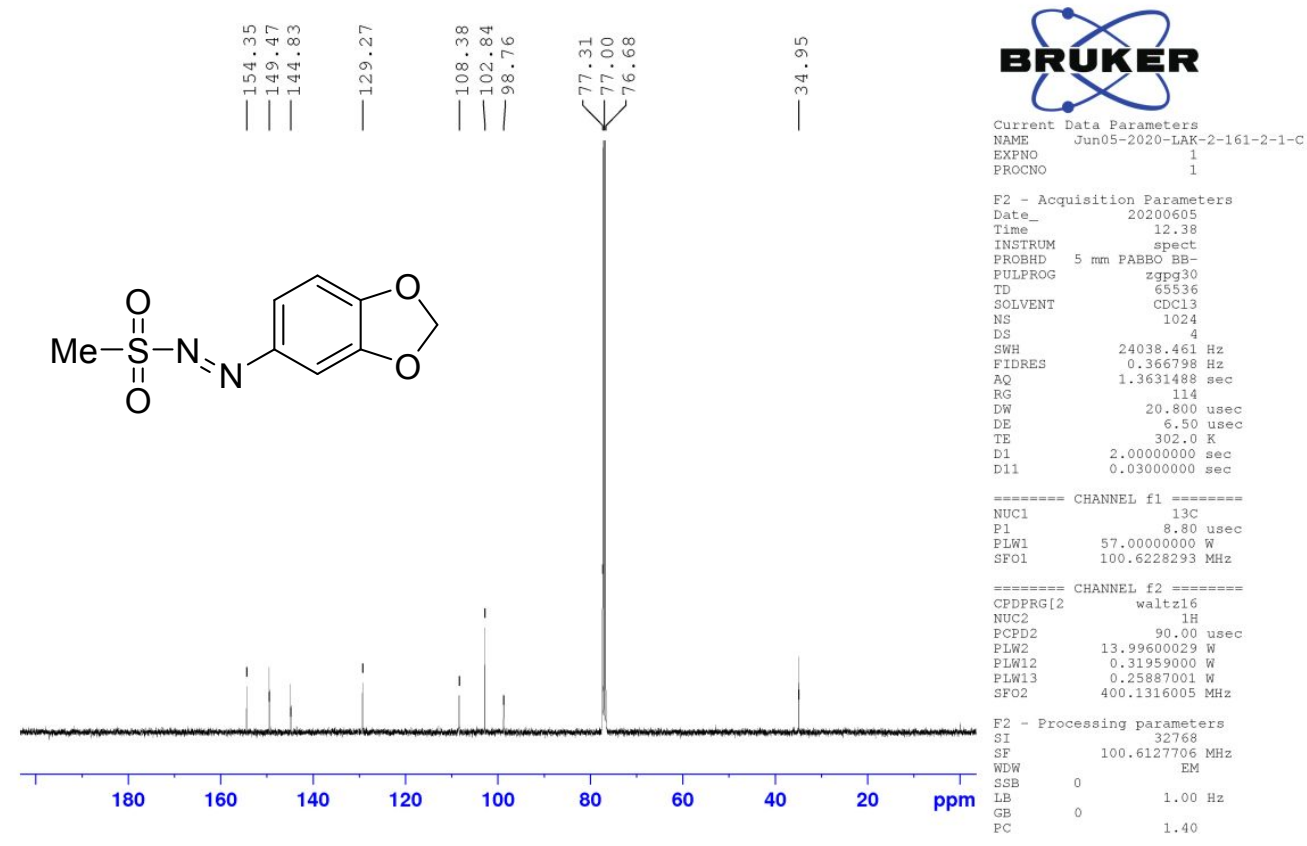

${ }^{1} \mathrm{H}$ NMR spectra of 1-(Methylsulfonyl)-2-(naphthalen-2-yl)diazene (1q) in $\mathrm{CDCl}_{3}$

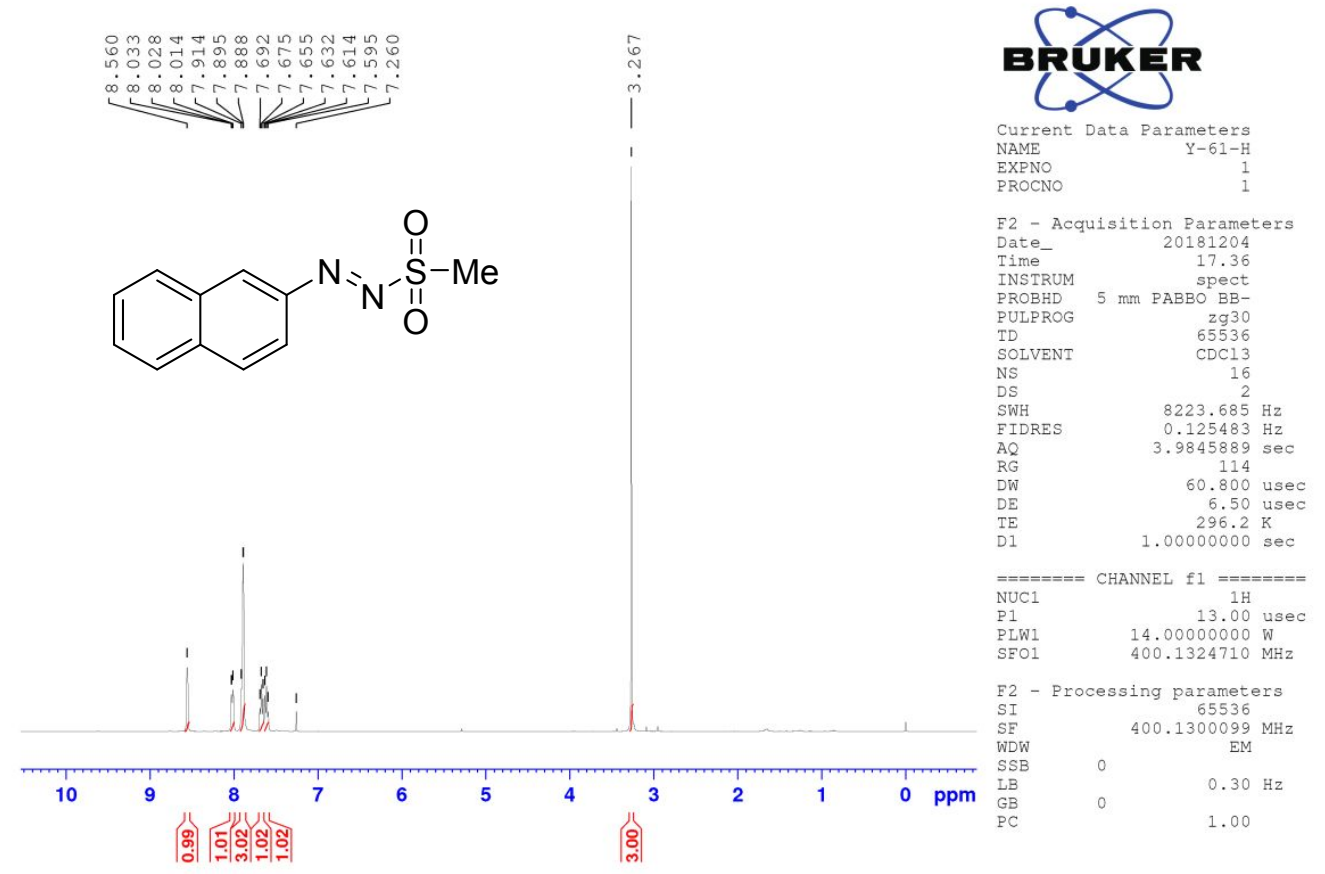


${ }^{1} \mathrm{H}$ NMR spectra of Ethyl 5-((methylsulfonyl)diazenyl)benzofuran-2-carboxylate (1r) in $\mathrm{CDCl}_{3}$

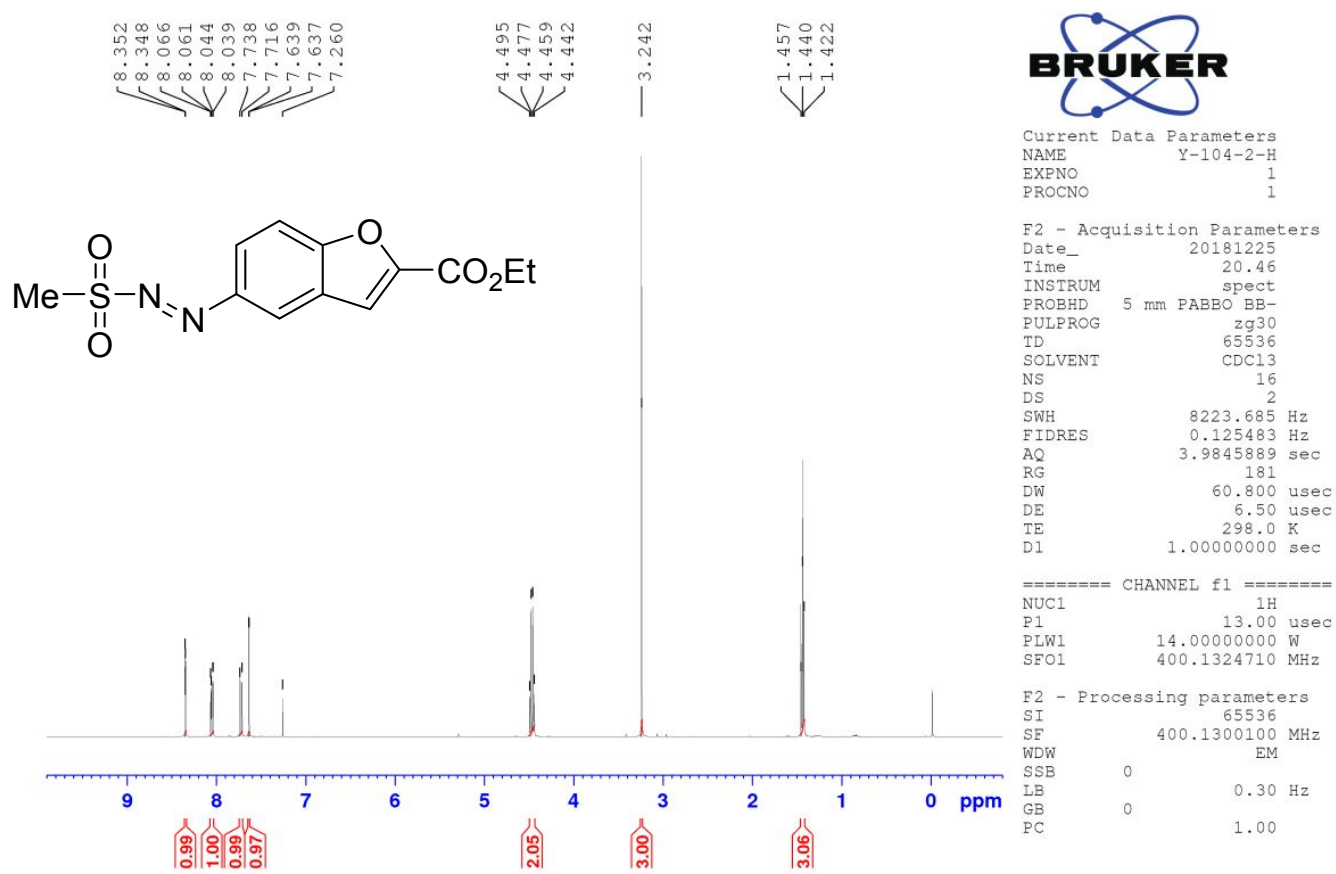

${ }^{1} \mathrm{H}$ NMR spectra of 2-Methyl-5-((methylsulfonyl)diazenyl)benzo[d]thiazole (1s) in $\mathrm{CDCl}_{3}$

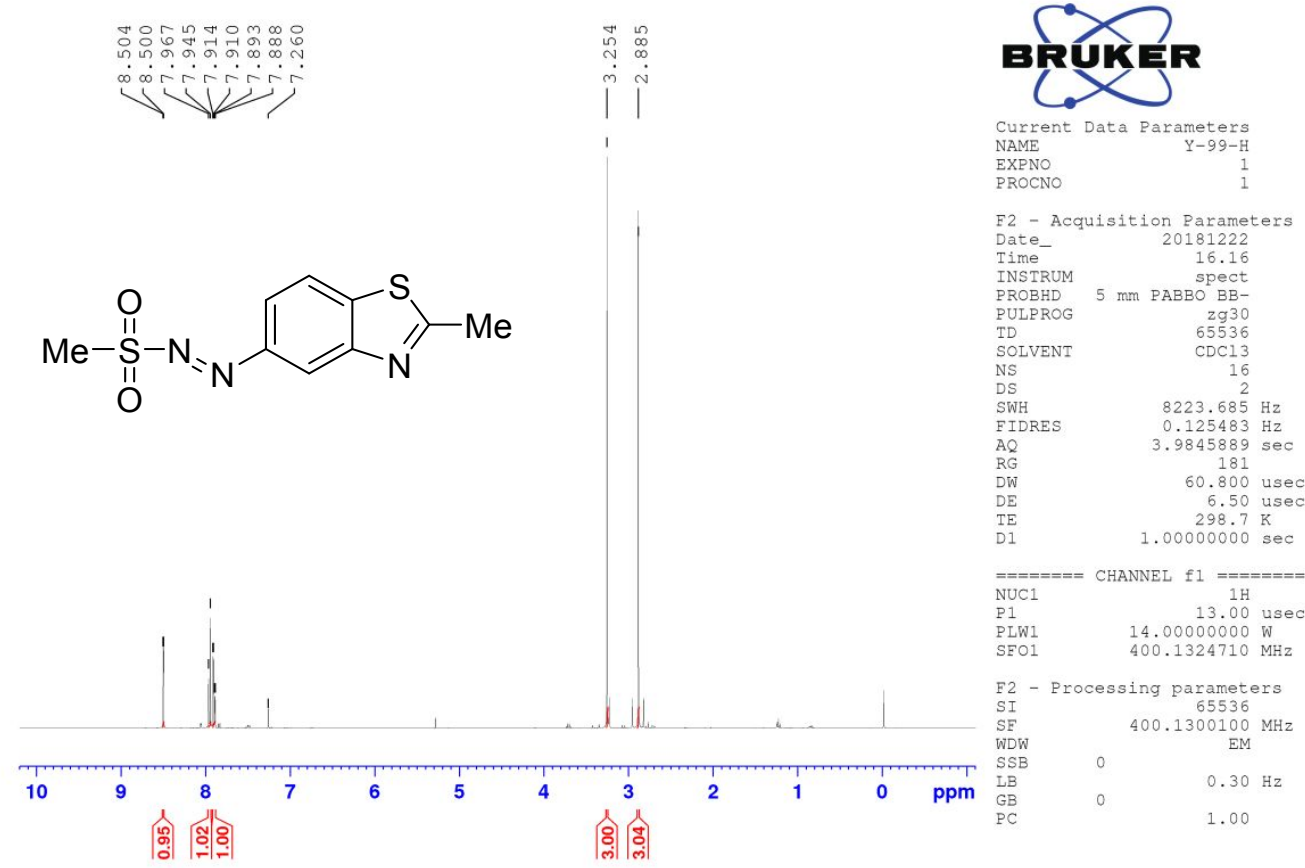


${ }^{1} \mathrm{H}$ NMR spectra of Methyl 5-((methylsulfonyl)diazenyl)nicotinate (1t) in $\mathrm{CDCl}_{3}$

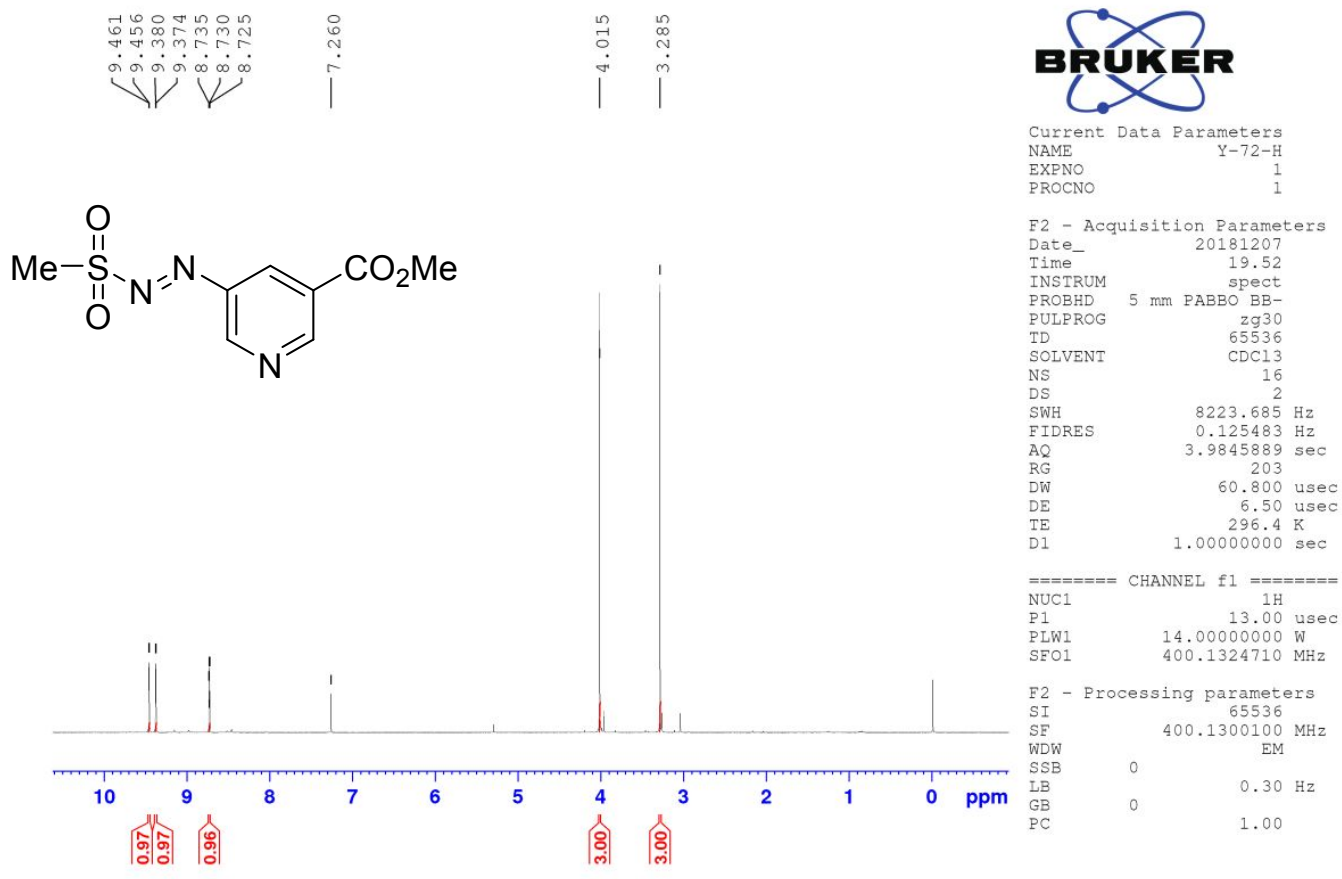

${ }^{1} \mathrm{H}$, and ${ }^{13} \mathrm{C} \mathrm{NMR}$ spectra of 7-((methylsulfonyl)diazenyl)quinoline (1u) in $\mathrm{CDCl}_{3}$

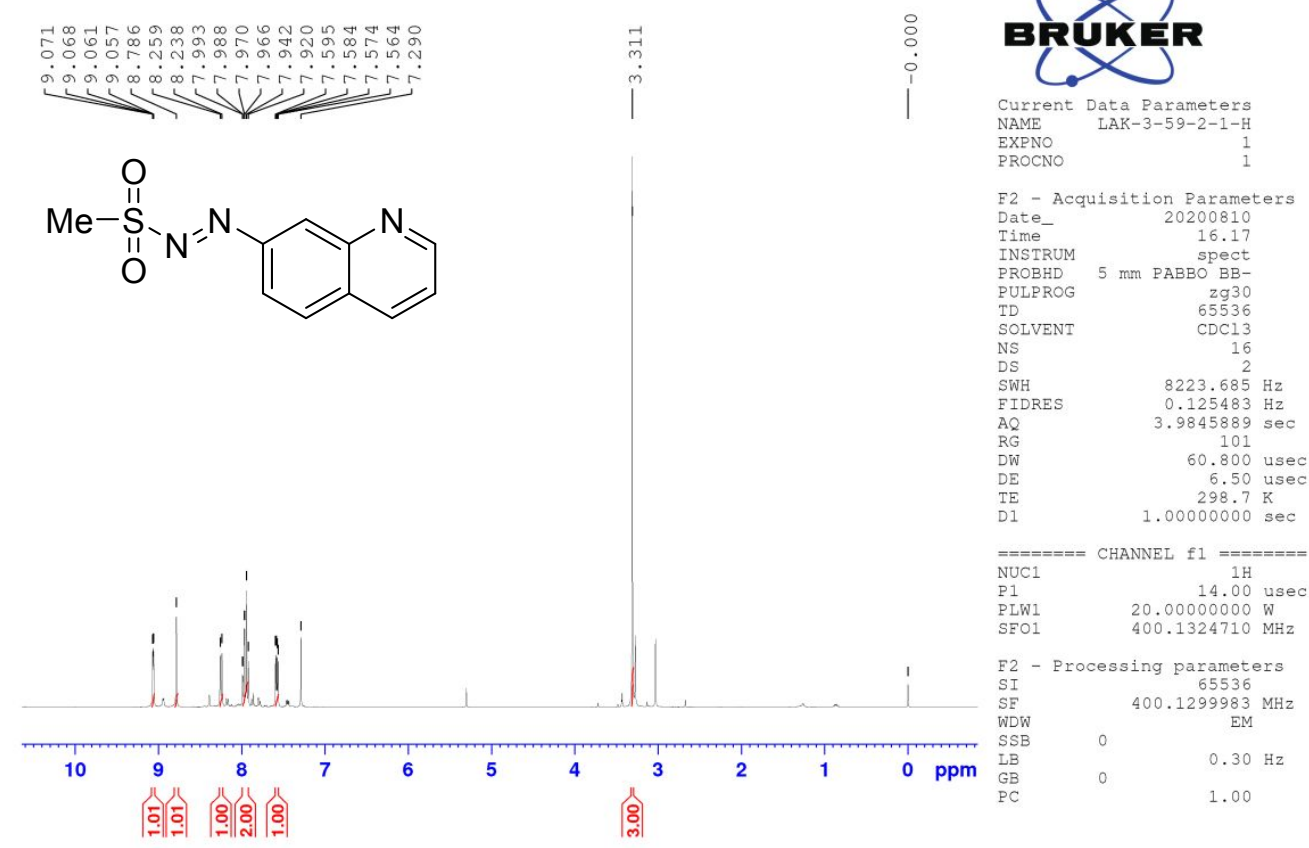




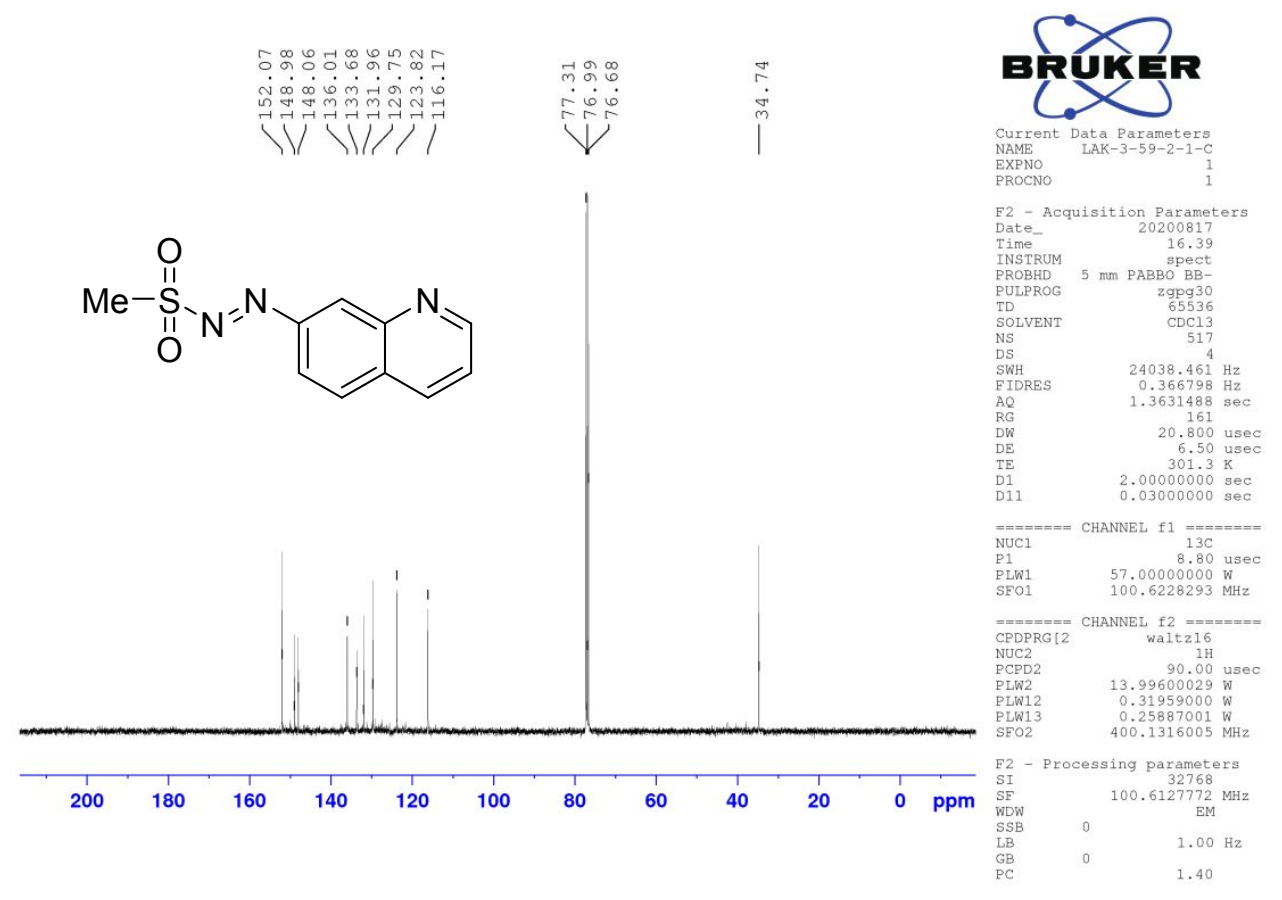

${ }^{1} \mathrm{H}$, and ${ }^{13} \mathrm{C}$ NMR spectra of 4-methyl-7-((methylsulfonyl)diazenyl)-2H-chromen-2one (1v) in $\mathrm{CDCl}_{3}$

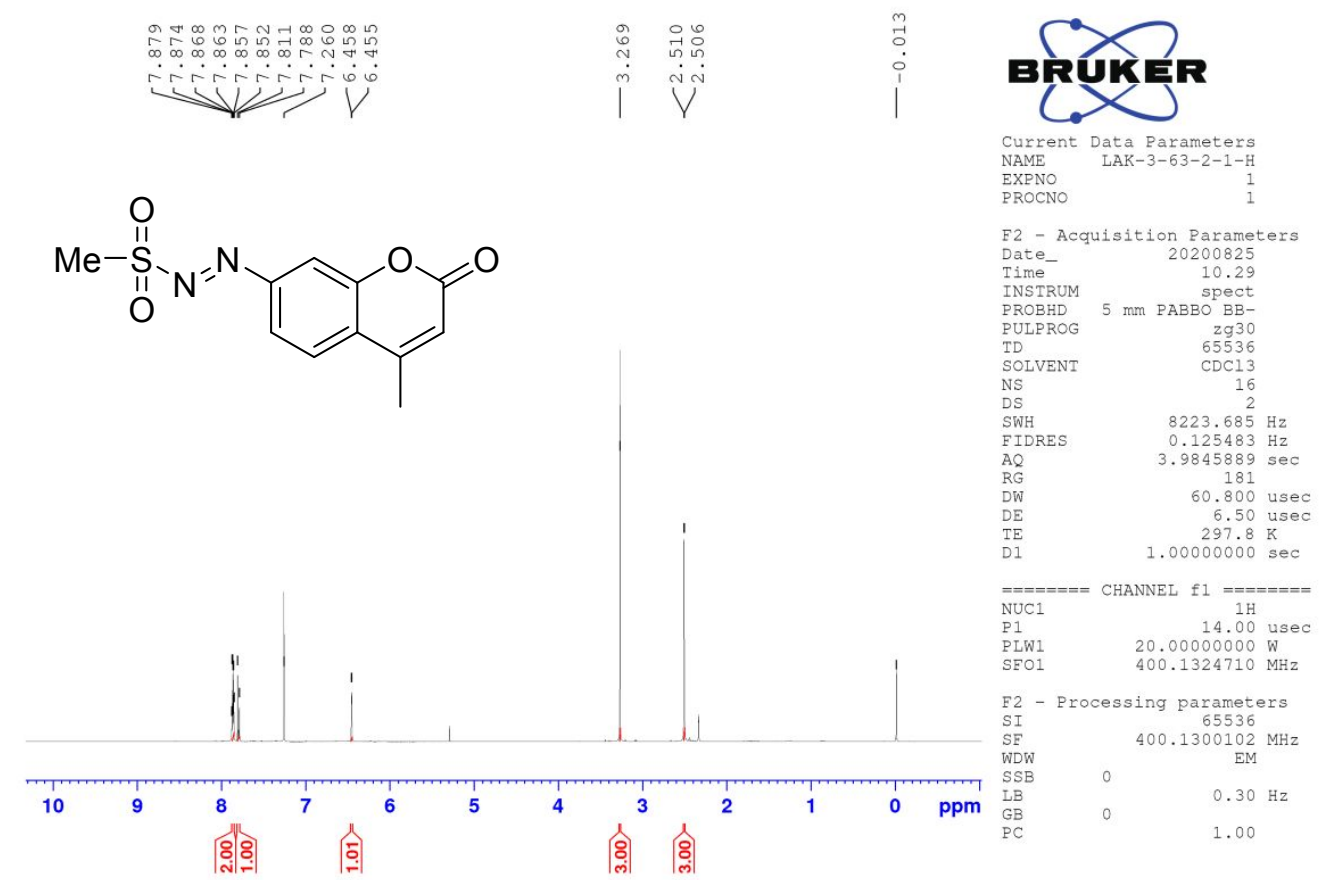




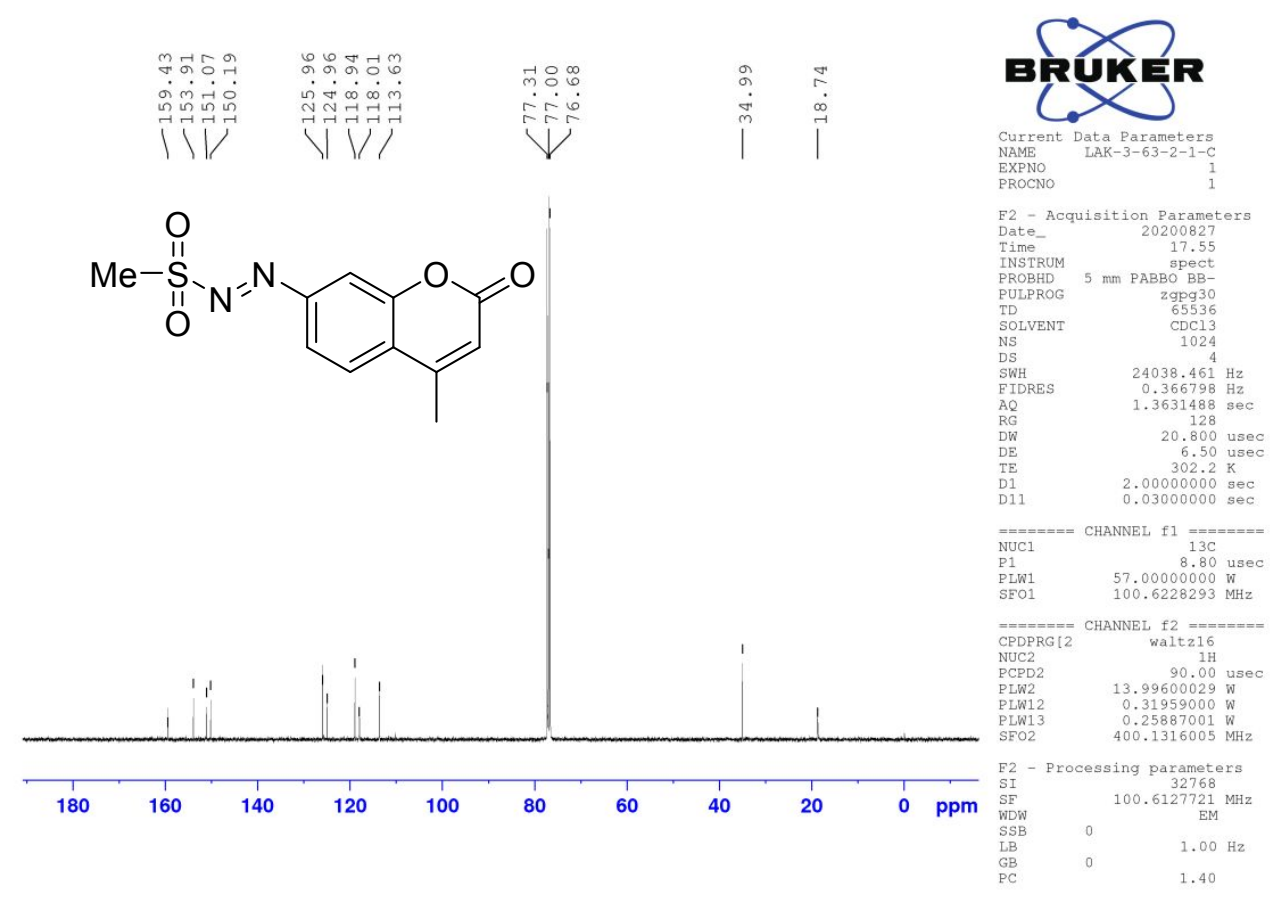

${ }^{1} \mathrm{H}$, and ${ }^{13} \mathrm{C}$ NMR spectra of 9-ethyl-3-((methylsulfonyl)diazenyl)-9H-carbazole (1w) in $\mathrm{CDCl}_{3}$

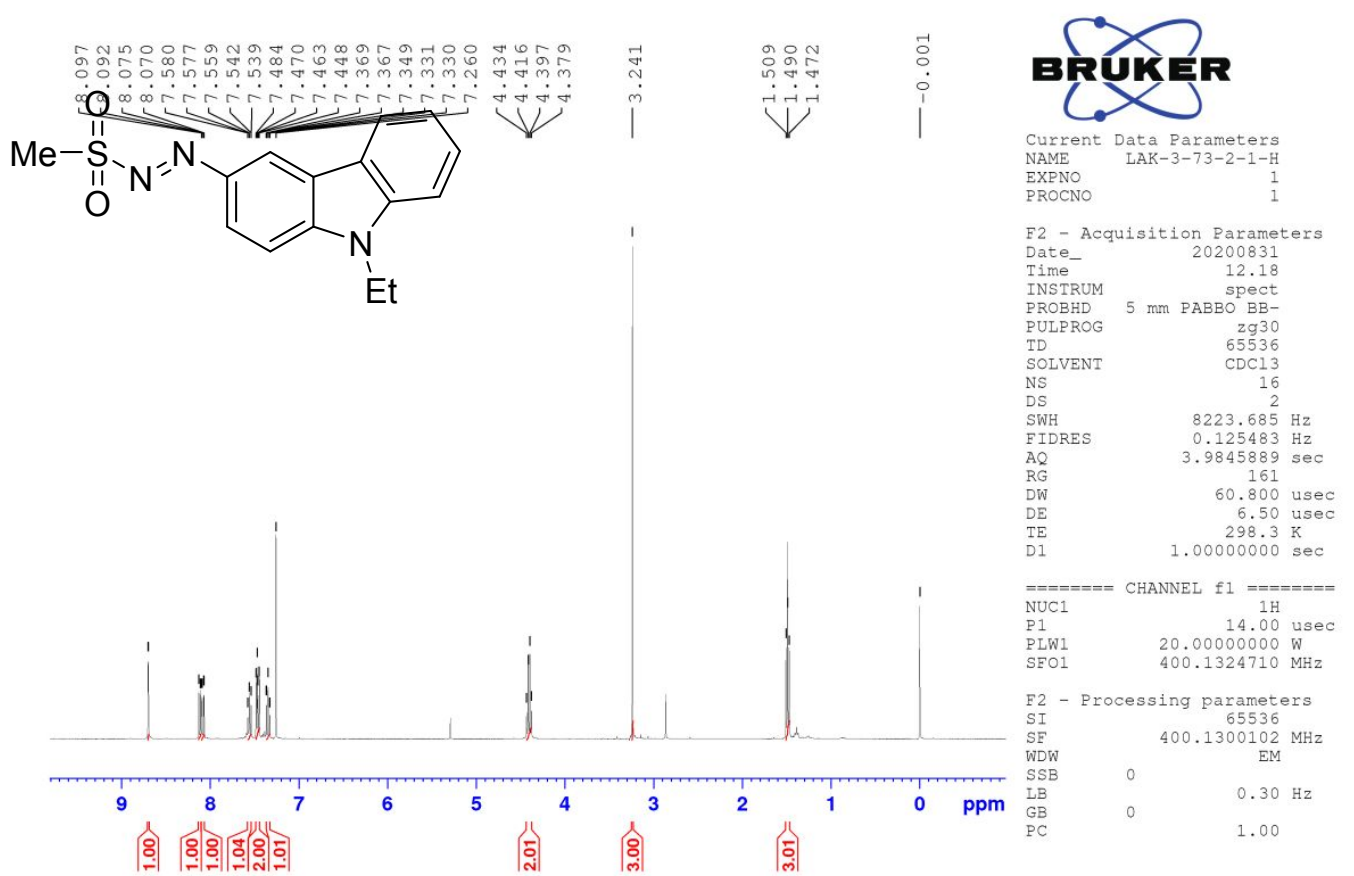




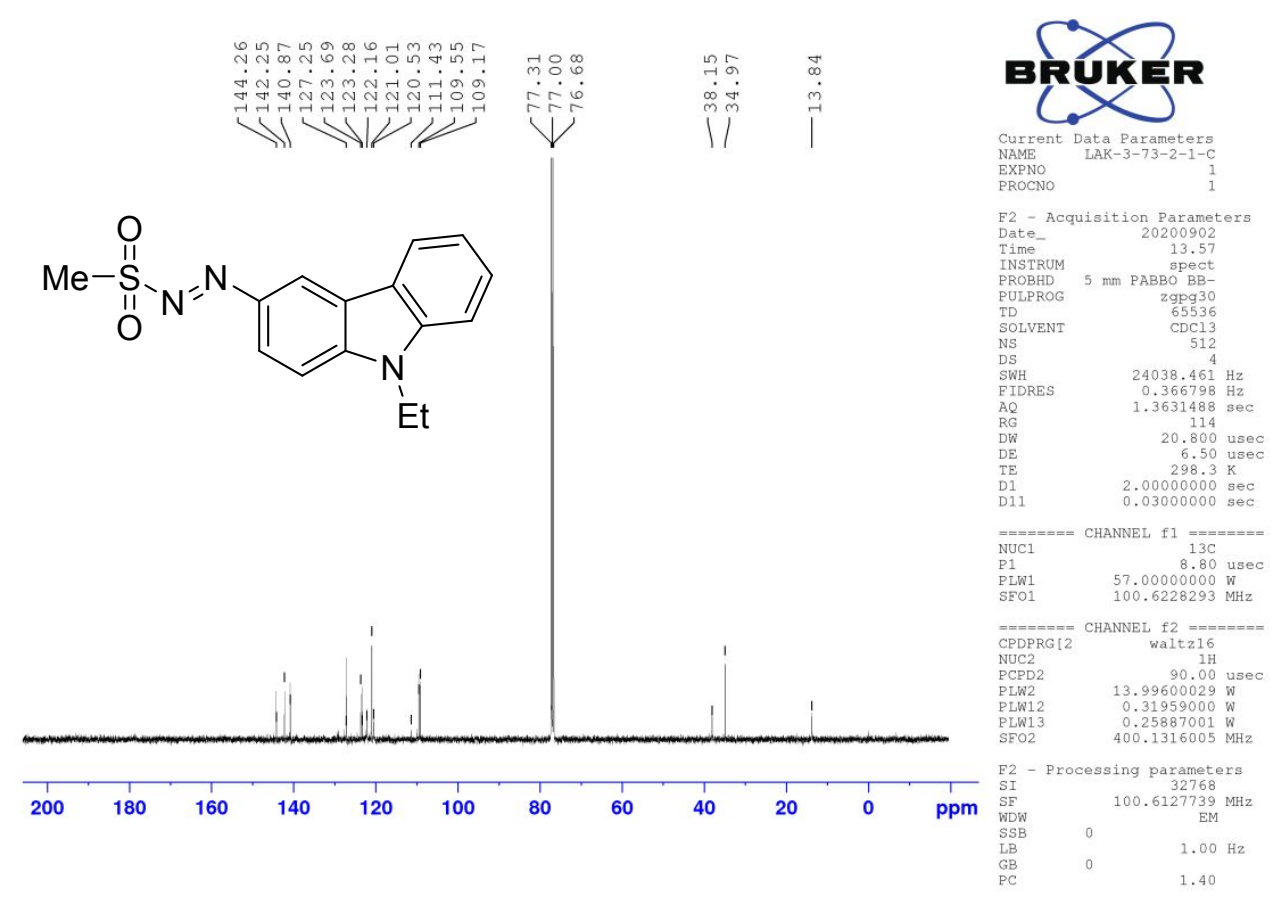

${ }^{1} \mathrm{H}$, and ${ }^{13} \mathrm{C}$ NMR spectra of 5-((methylsulfonyl)diazenyl)benzo[d]thiazole (1x) in $\mathrm{CDCl}_{3}$

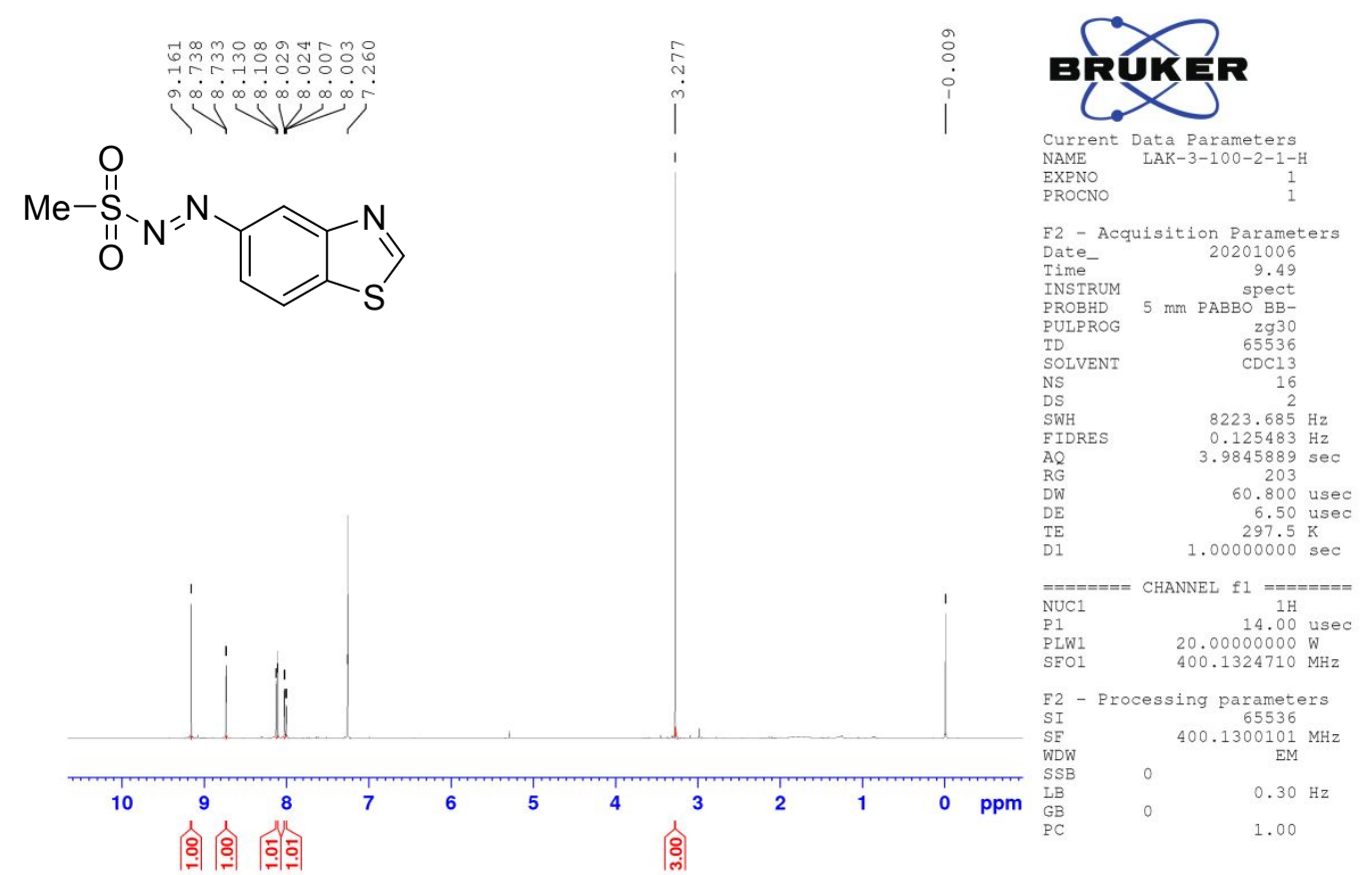




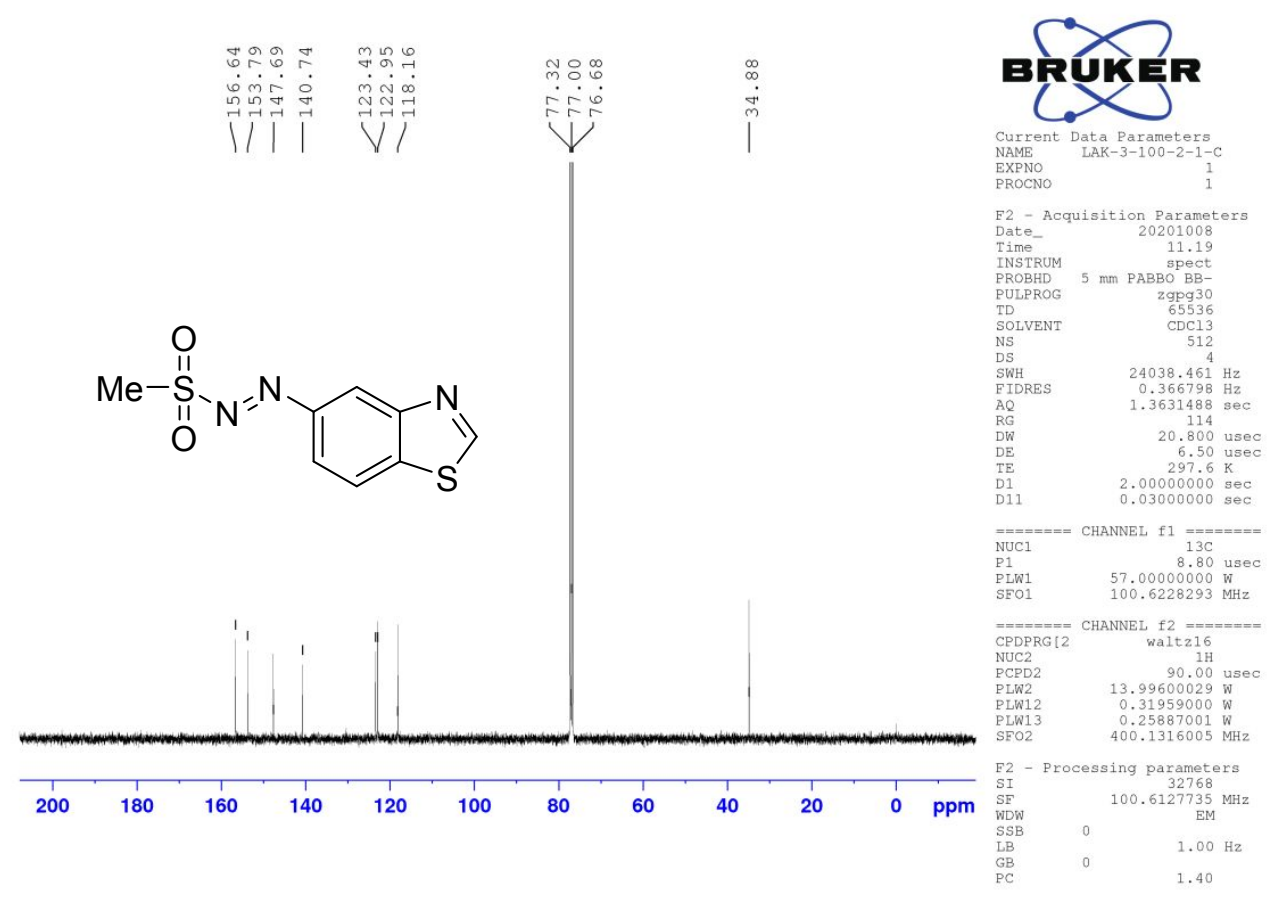


${ }^{1} \mathrm{H}, \quad{ }^{13} \mathrm{C} \quad$ and $\quad{ }^{19} \mathrm{~F} \quad \mathrm{NMR} \quad$ spectra of $\boldsymbol{S}$-(trifluoromethyl) 3,5 difluorobenzenesulfonothioate (2c) in $\mathrm{CDCl}_{3}$
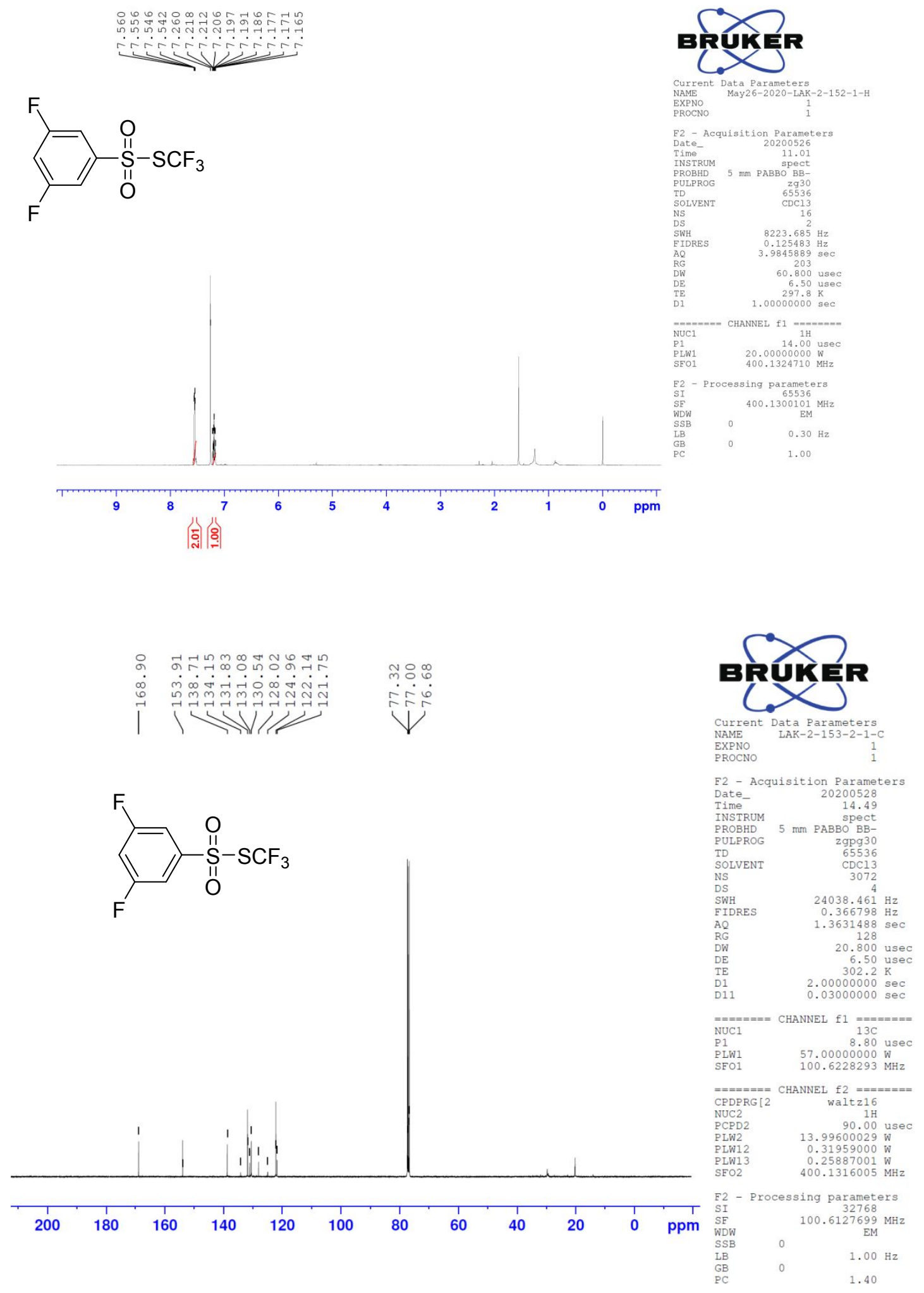


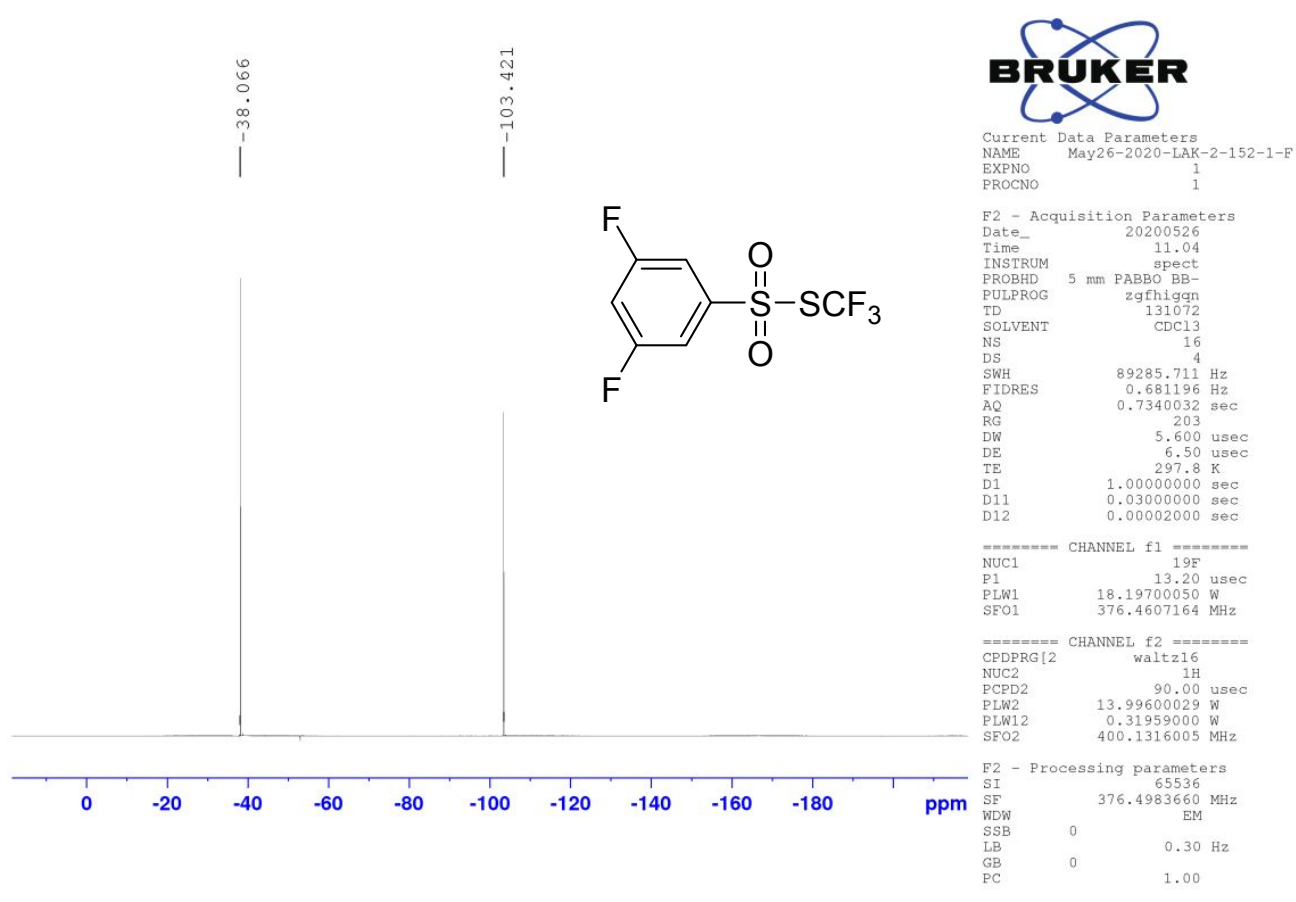


${ }^{1} \mathrm{H},{ }^{13} \mathrm{C}$ and ${ }^{19} \mathrm{~F}$ NMR spectra of $\left[1,1^{\prime}\right.$-biphenyl]-4-yl(trifluoromethyl)sulfane (3a) in $\mathrm{CDCl}_{3}$
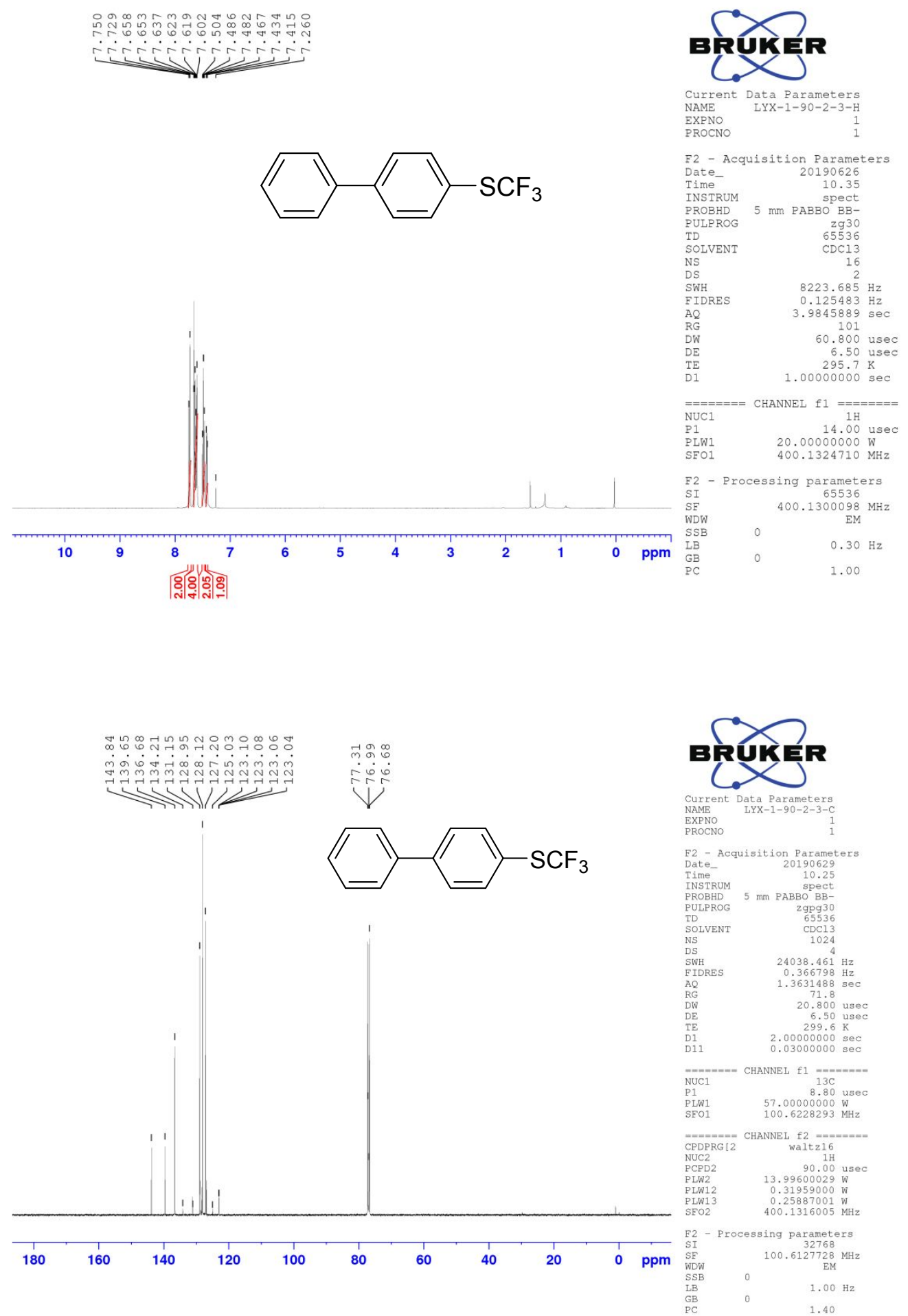


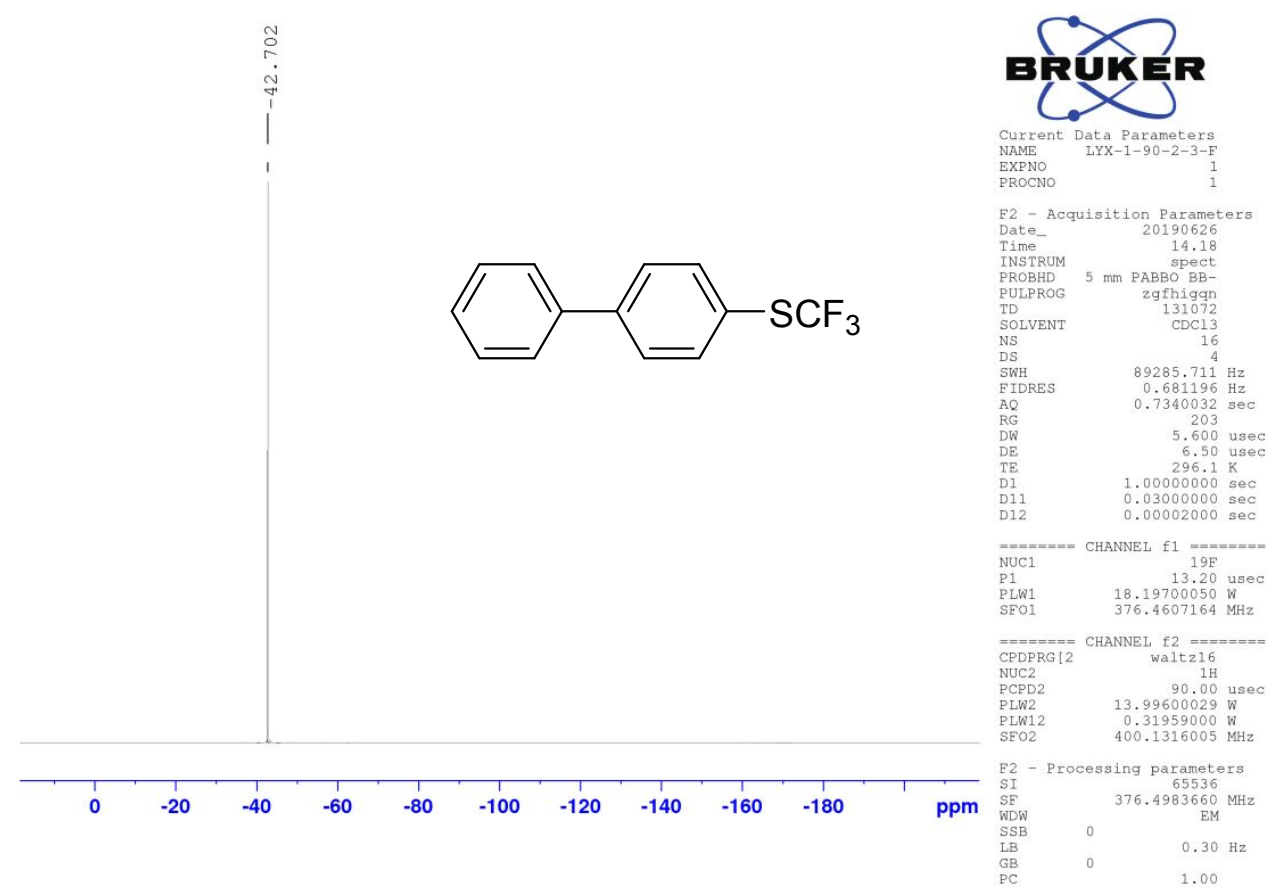

${ }^{1} \mathrm{H},{ }^{13} \mathrm{C}$ and ${ }^{19} \mathrm{~F}$ NMR spectra of 4-(4-((trifluoromethyl)thio)phenyl)morpholine (3b) in $\mathrm{CDCl}_{3}$

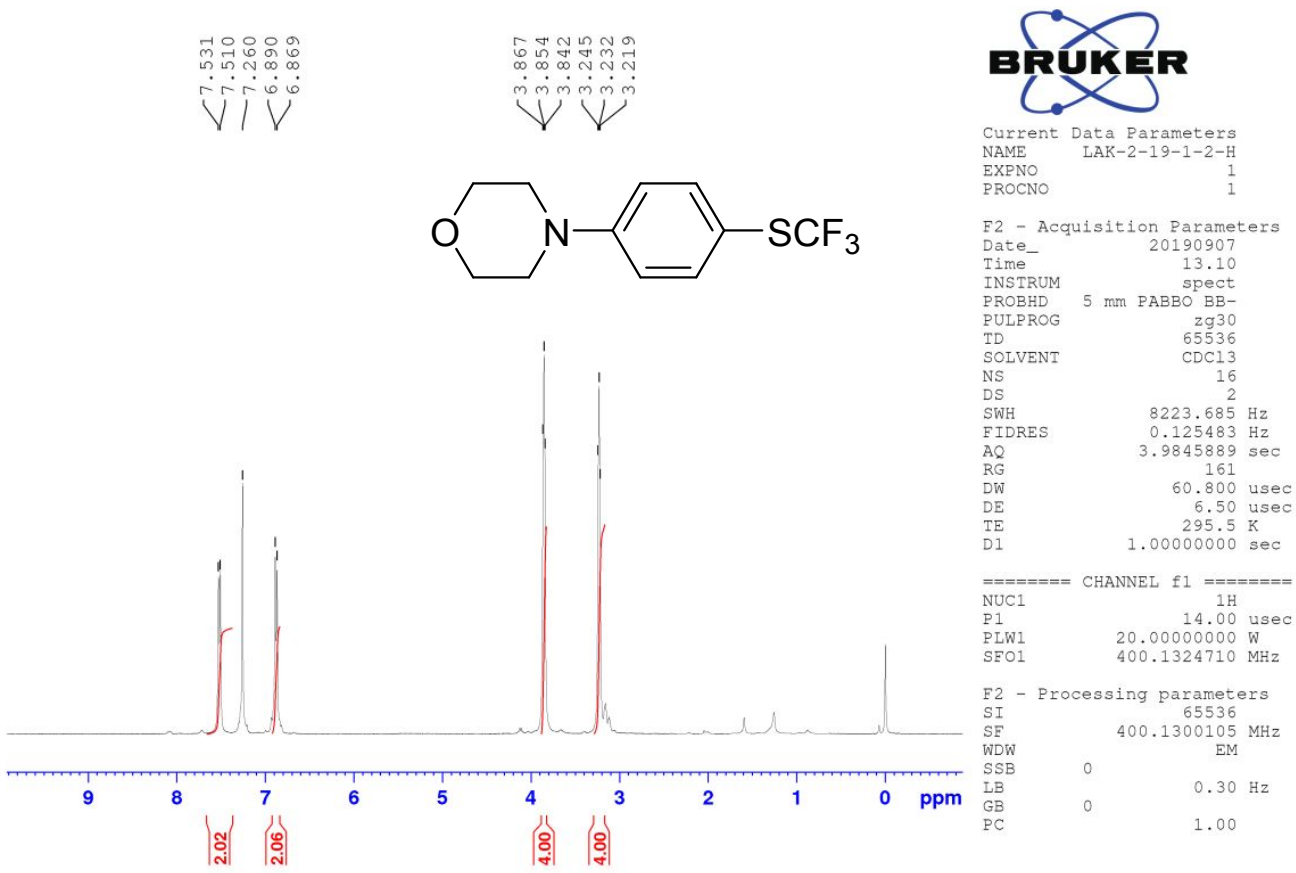



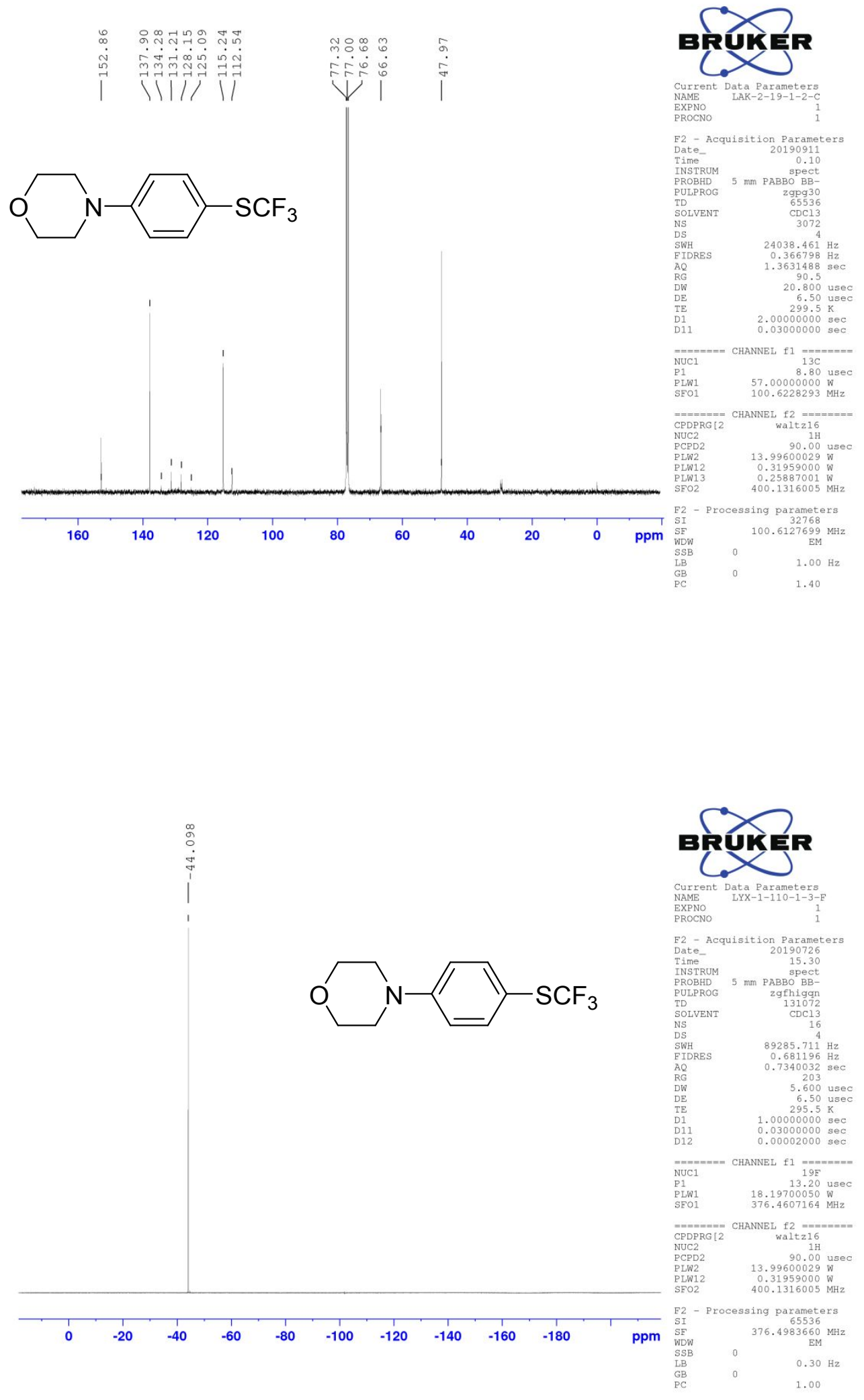
${ }^{1} \mathrm{H},{ }^{13} \mathrm{C}$ and ${ }^{19} \mathrm{~F}$ NMR spectra of (4-phenoxyphenyl)(trifluoromethyl)sulfane (3c) in $\mathrm{CDCl}_{3}$
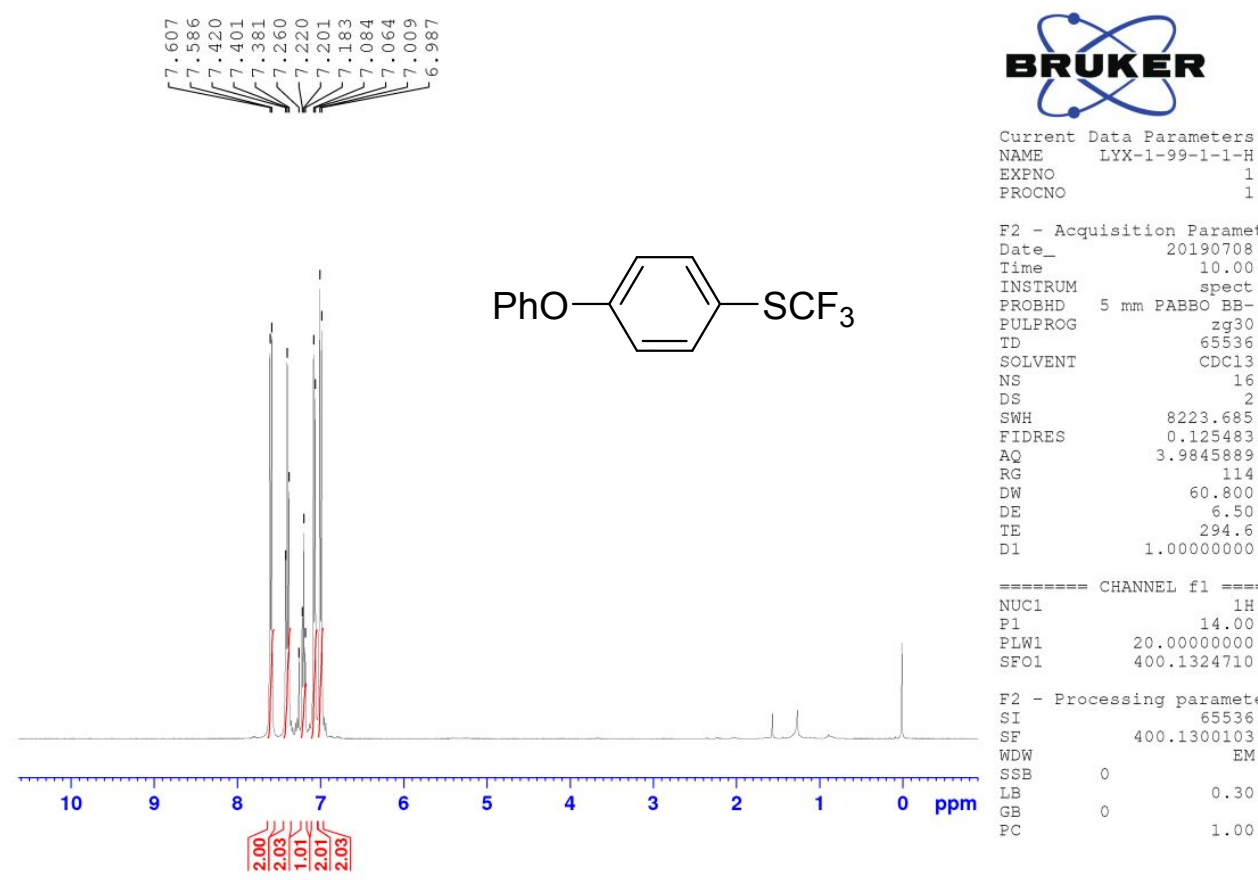

F2 - Acquisition Parameters

Date_ 20190708

$\begin{array}{ll}\text { Time } & 10.00 \\ \text { INSTRUM } & \text { spect }\end{array}$

PROBHD
PULPROG

TD

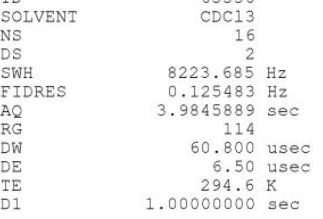

$=======$ CHANNEI $\mathrm{f} 1=======$
NUC1 $1 \mathrm{H}$
$14.00 \mathrm{usec}$

LW1 $20.00000000 \mathrm{~W}$

$\begin{array}{lr}\text { F2 - } & \text { Processing parameters } \\ \text { SI } & 65536 \\ \text { SE } & 400.1300103 \mathrm{MHz} \\ \text { WDW } & \mathrm{EM}\end{array}$

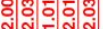
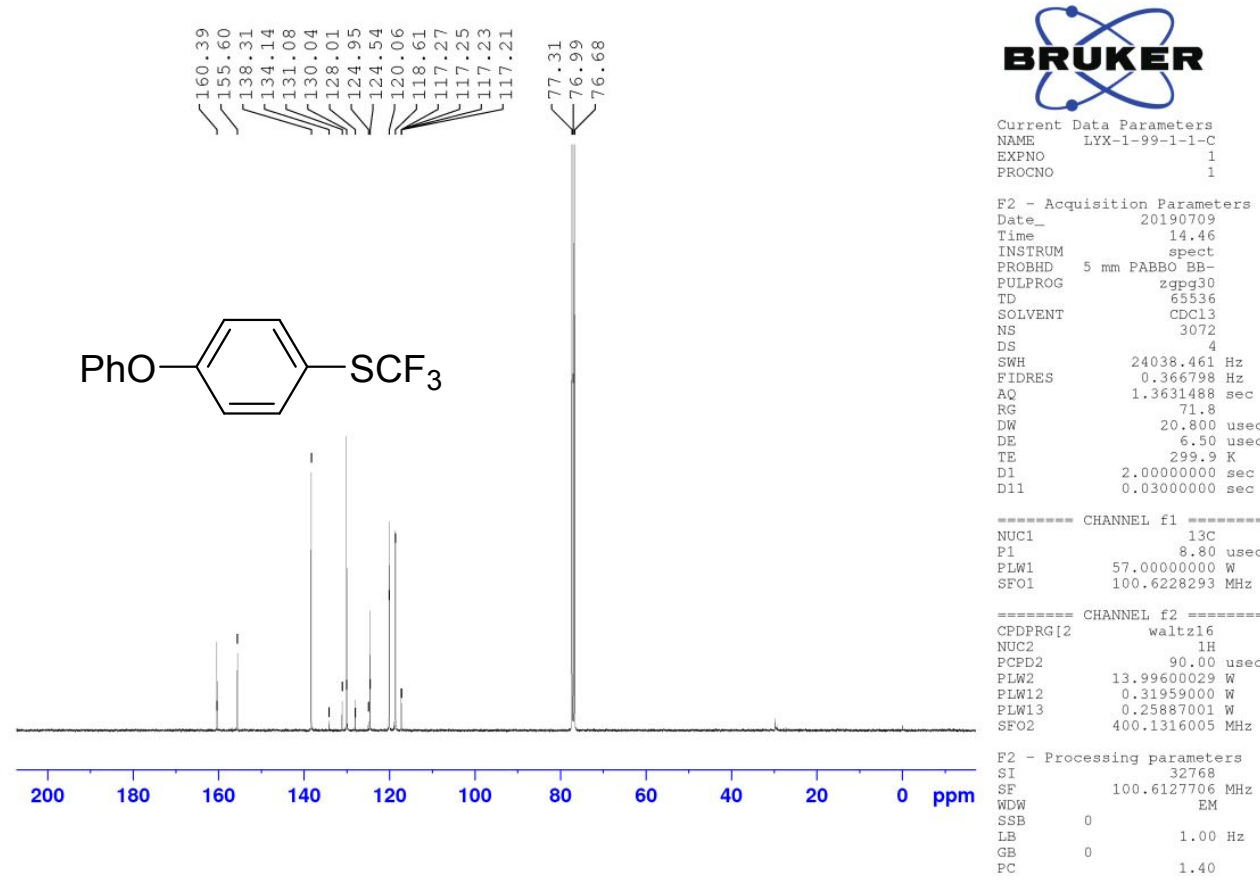


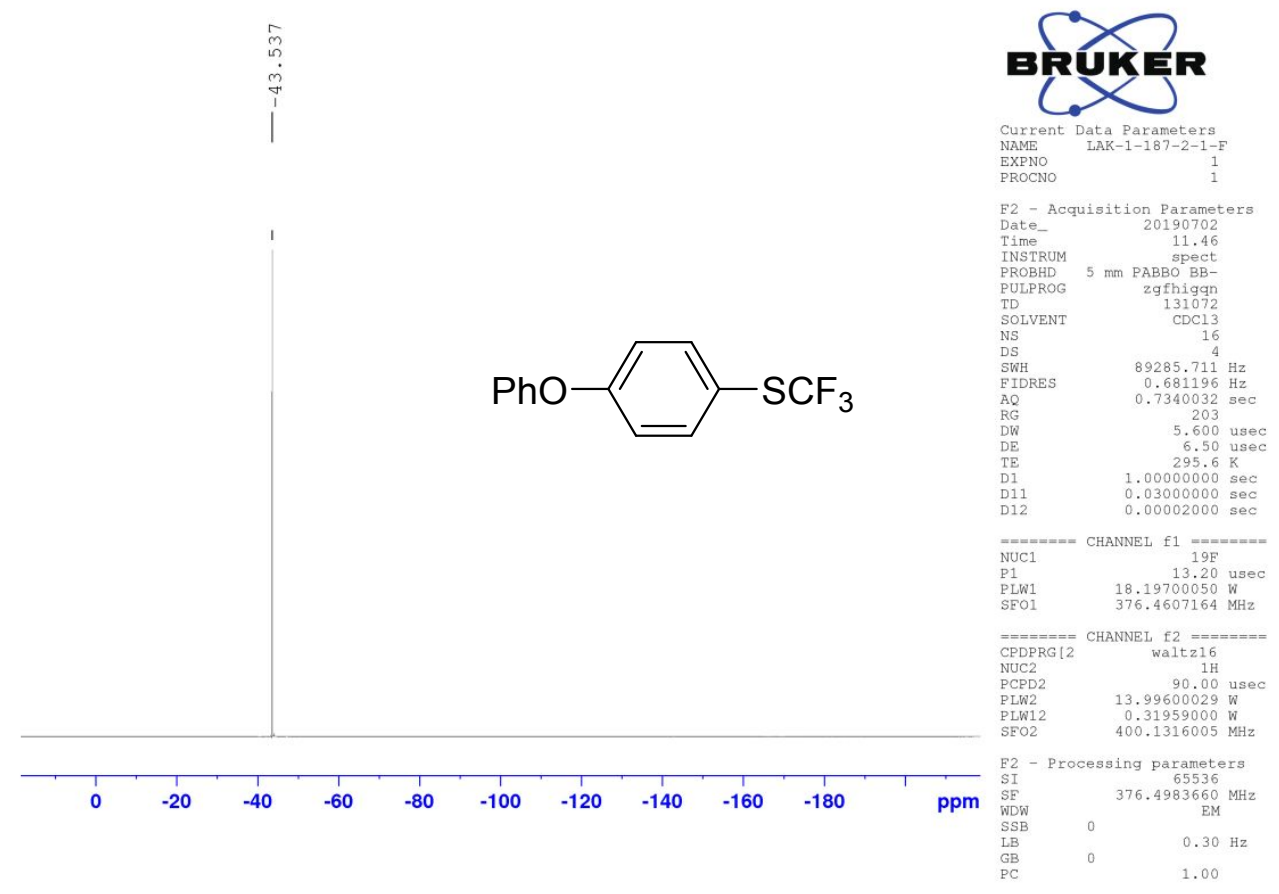

${ }^{1} \mathrm{H},{ }^{13} \mathrm{C}$ and ${ }^{19} \mathrm{~F}$ NMR spectra of (4-(benzyloxy)phenyl)(trifluoromethyl)sulfane (3d) in $\mathrm{CDCl}_{3}$

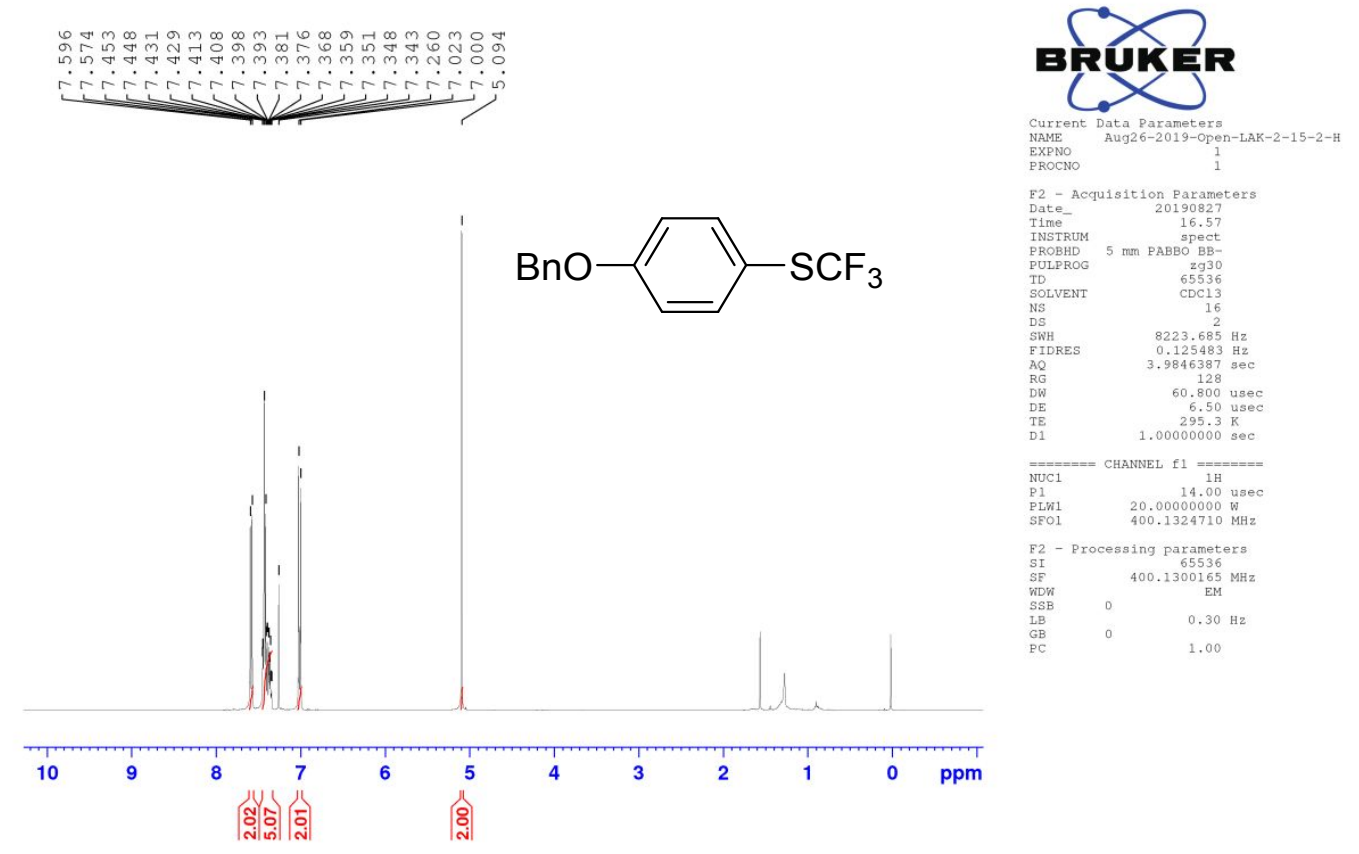



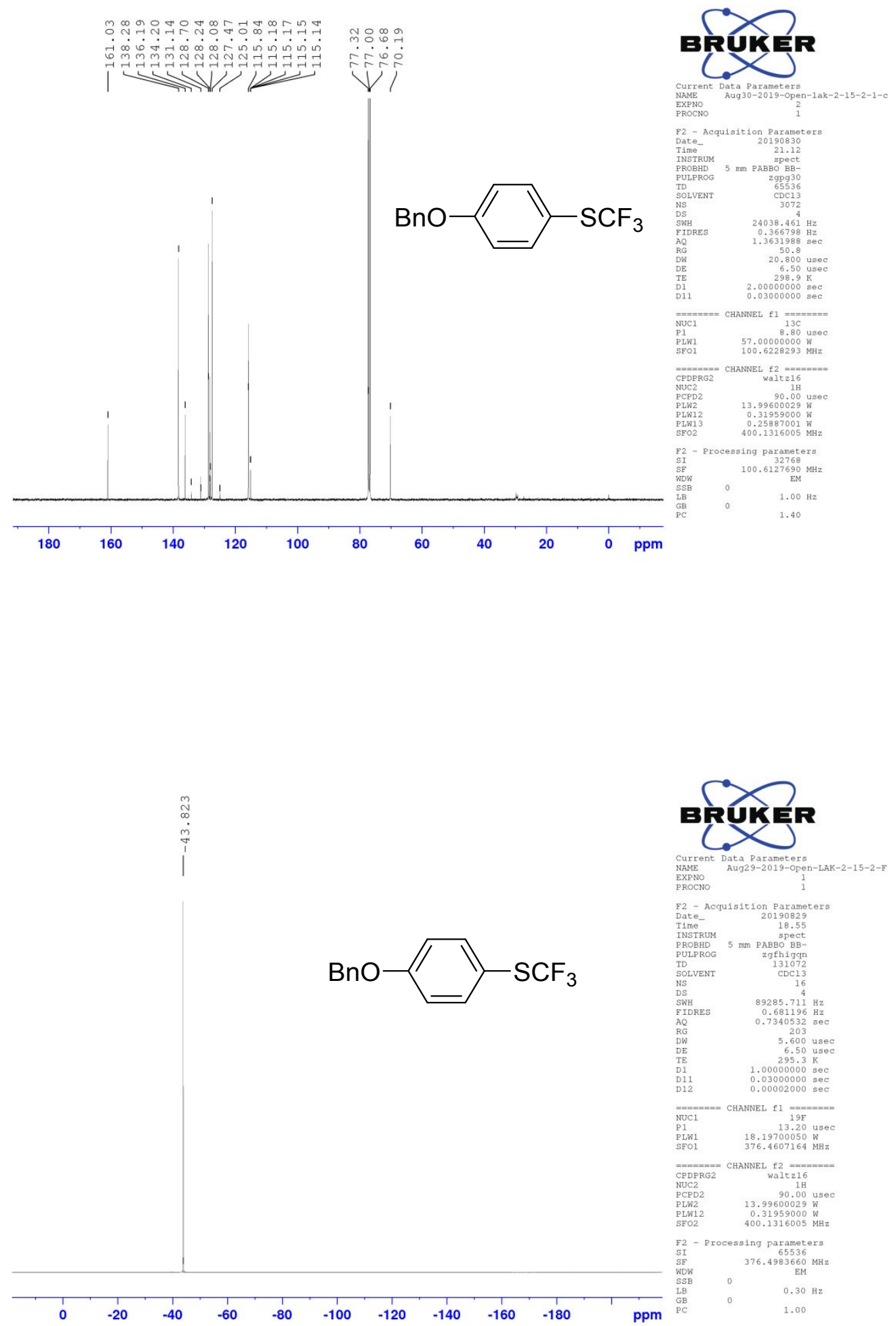
${ }^{1} \mathrm{H},{ }^{13} \mathrm{C}$ and ${ }^{19} \mathrm{~F}$ NMR spectra of methyl(4-((trifluoromethyl)thio)phenyl)sulfane (3e) in $\mathrm{CDCl}_{3}$
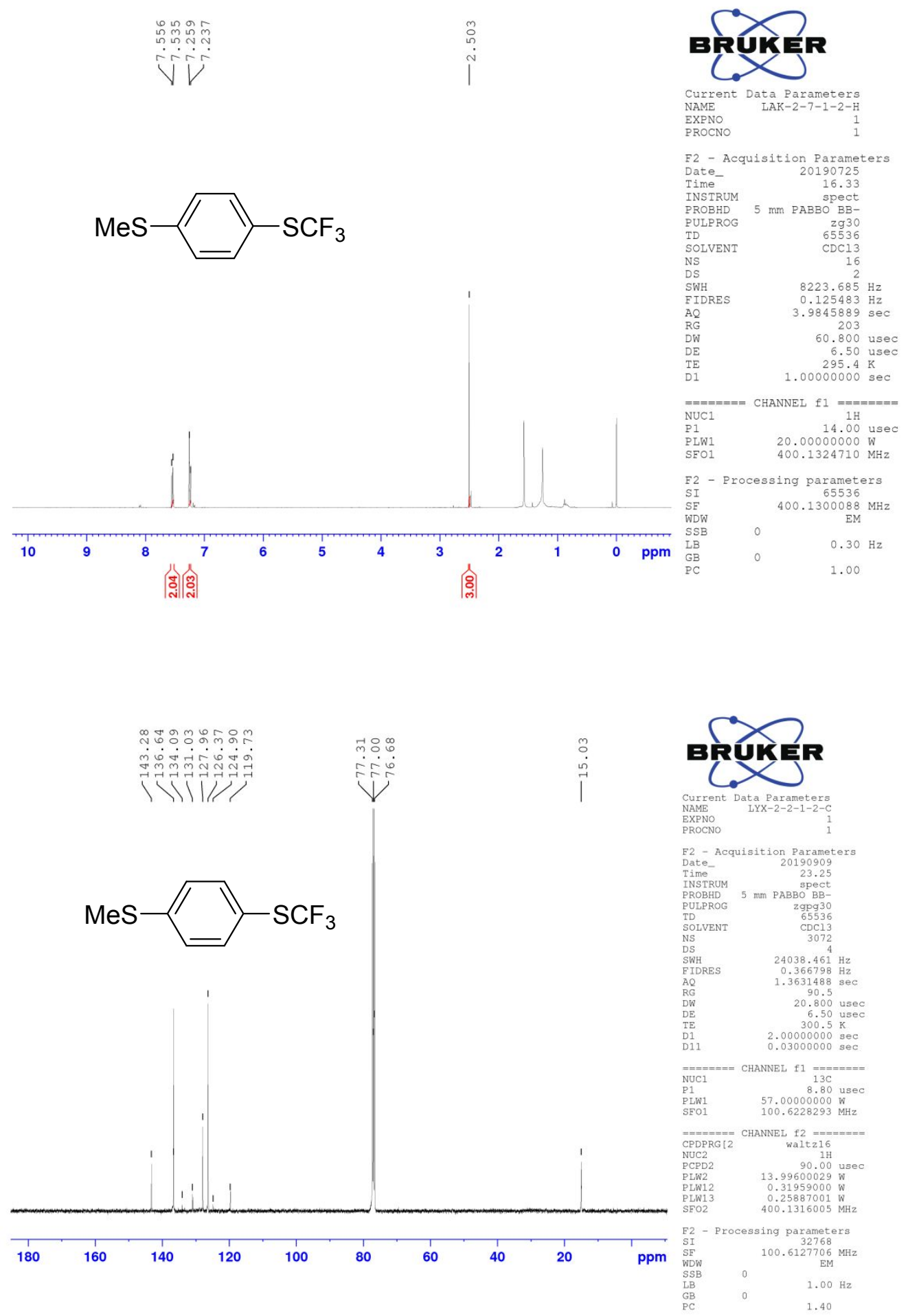


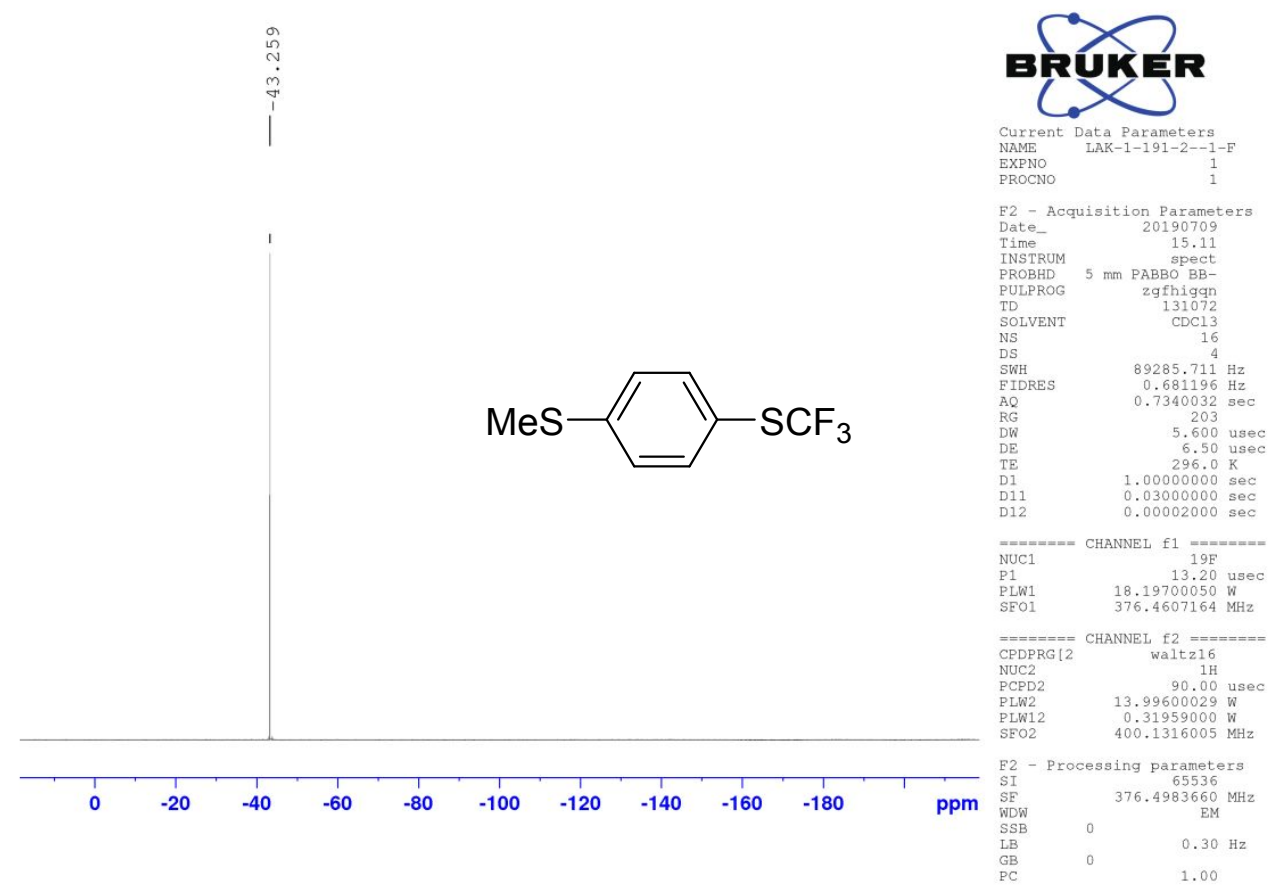

${ }^{1} \mathrm{H},{ }^{13} \mathrm{C}$ and ${ }^{19} \mathrm{~F}$ NMR spectra of (4-(tert-butyl)phenyl)(trifluoromethyl)sulfane (3f) in $\mathrm{CDCl}_{3}$

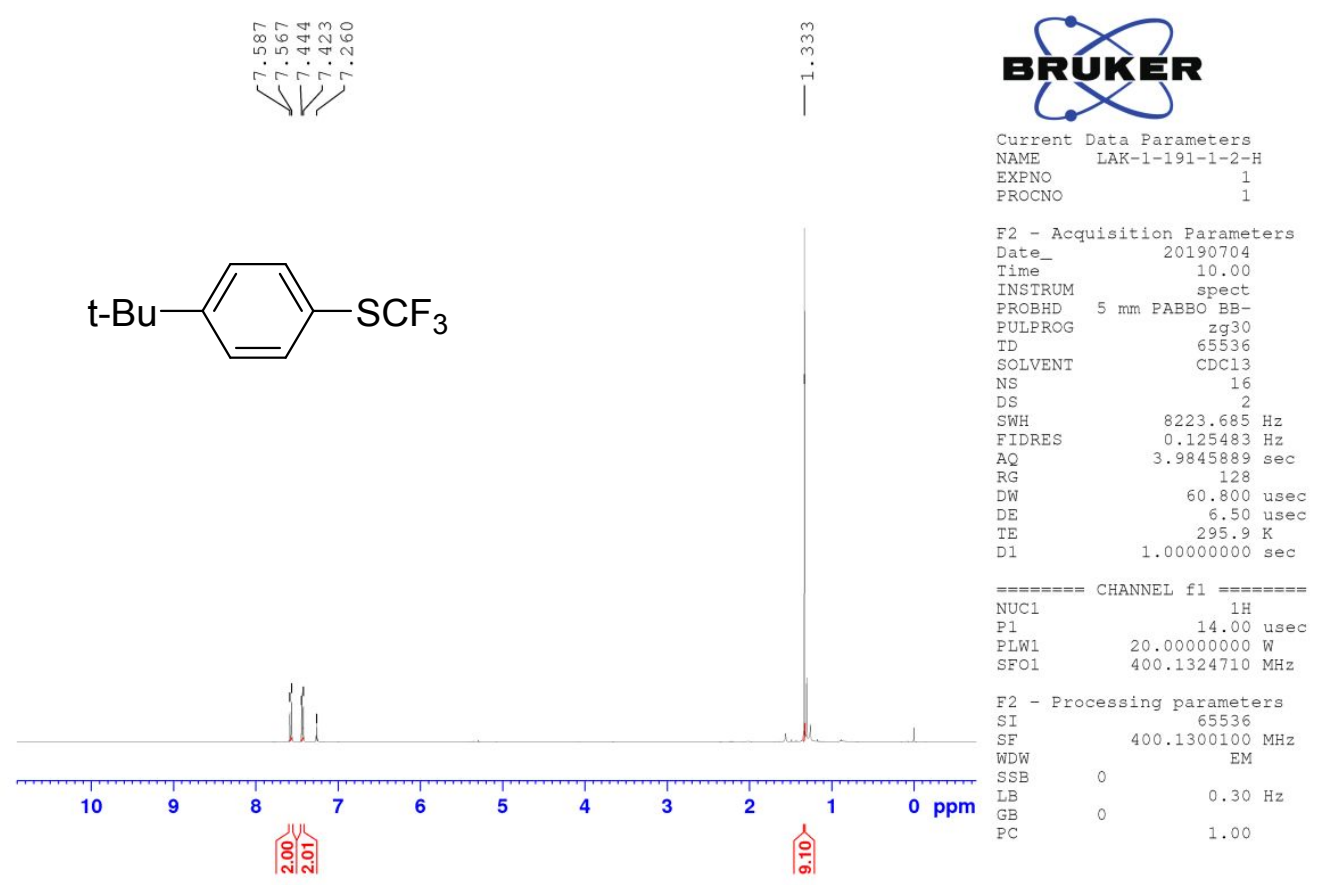



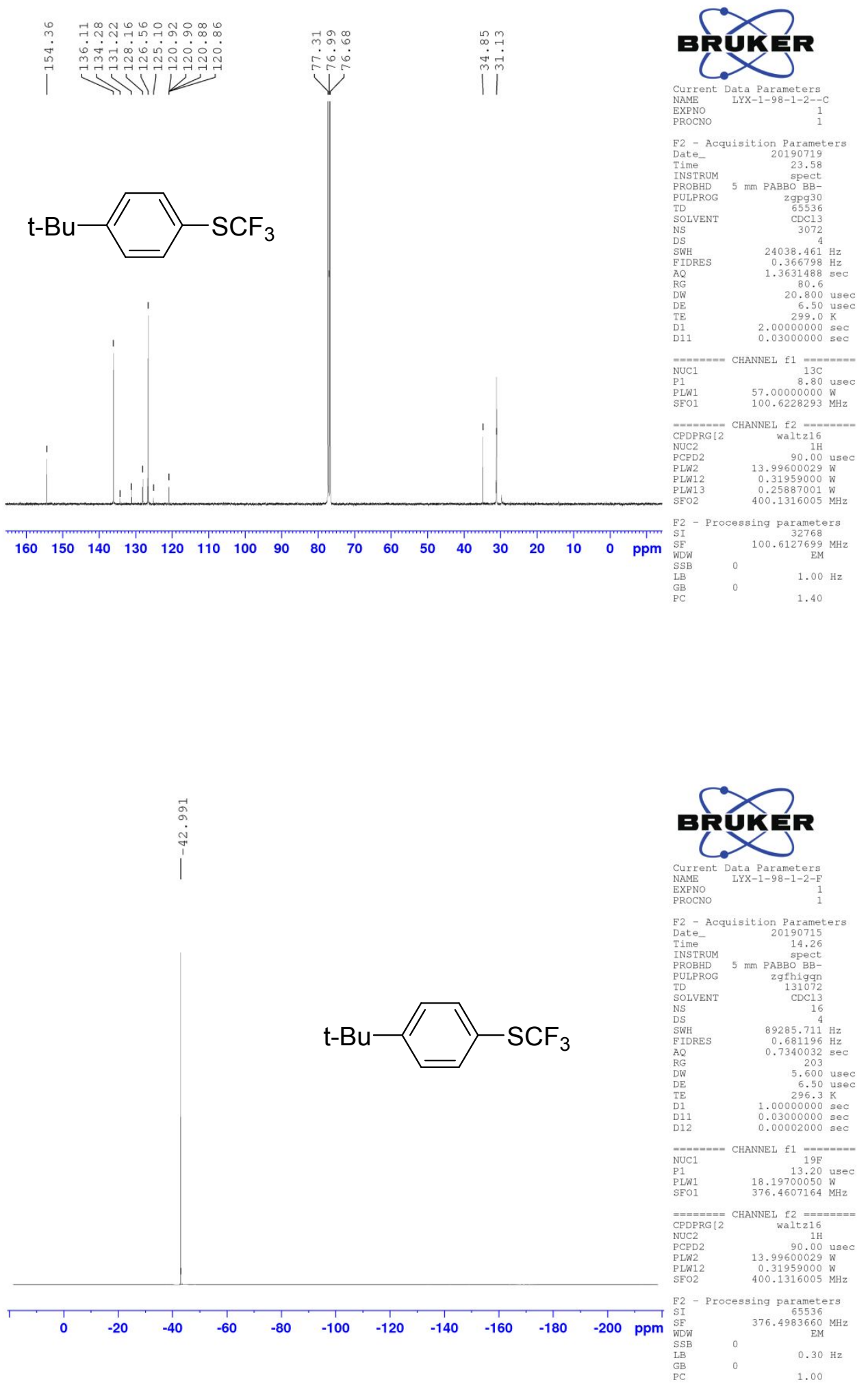
${ }^{1} \mathrm{H},{ }^{13} \mathrm{C}$ and ${ }^{19} \mathrm{~F}$ NMR spectra of ethyl (E)-3-(4-((trifluoromethyl)thio)phenyl)acrylate (3g) in $\mathrm{CDCl}_{3}$
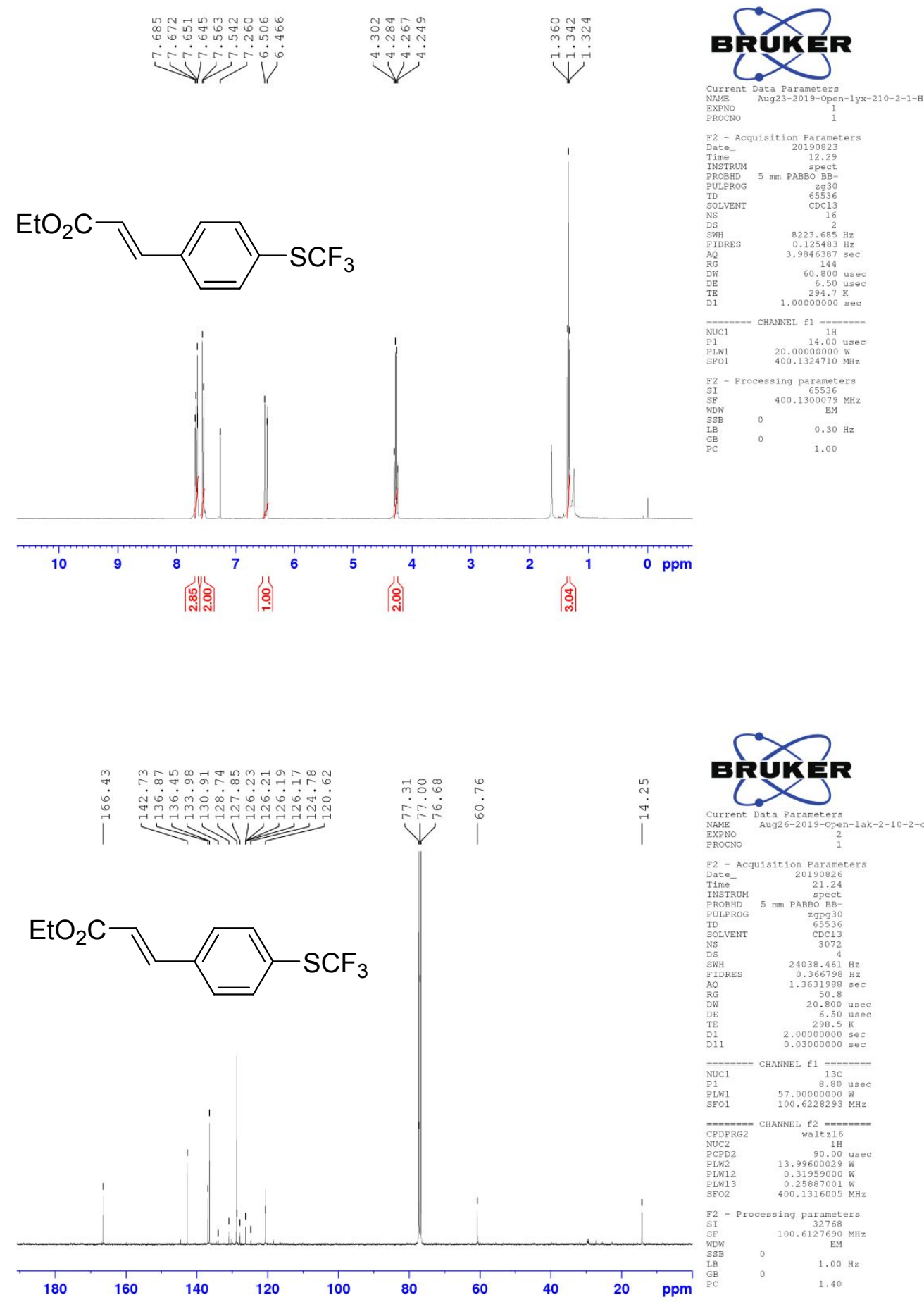

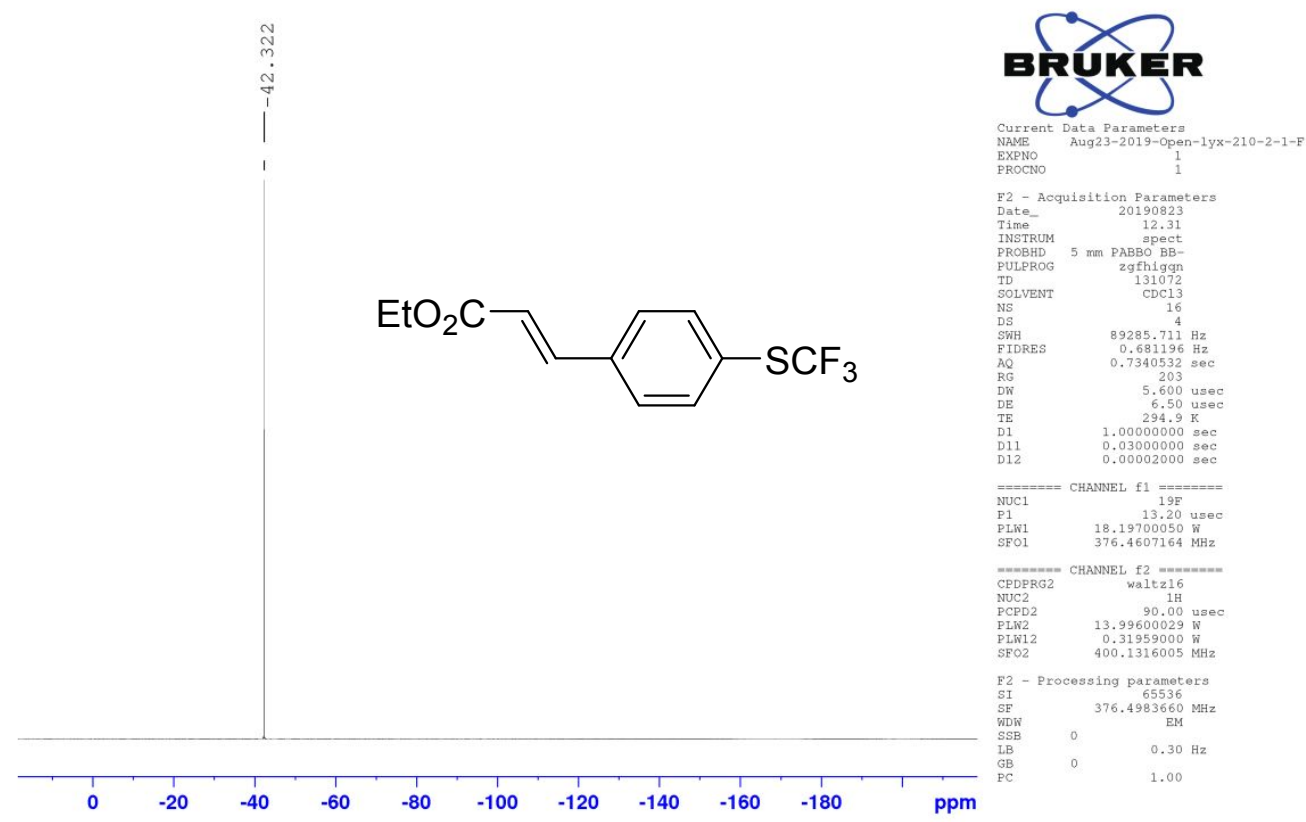

${ }^{1} \mathrm{H}, \quad{ }^{13} \mathrm{C}$ and $\quad{ }^{19} \mathrm{~F}$ NMR $\quad$ spectra of triisopropyl((4((trifluoromethyl)thio)phenyl)ethynyl)silane (3h) in $\mathrm{CDCl}_{3}$.

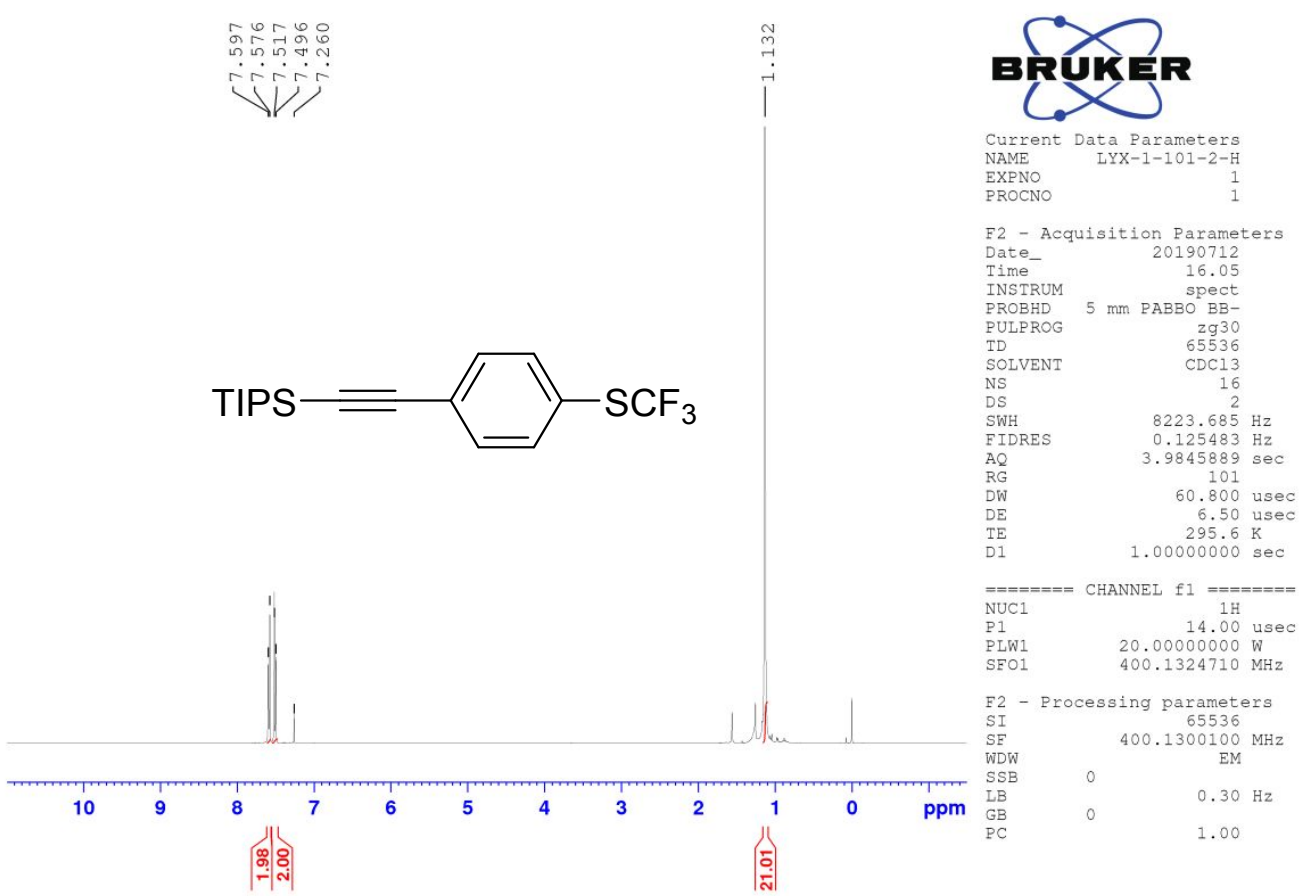



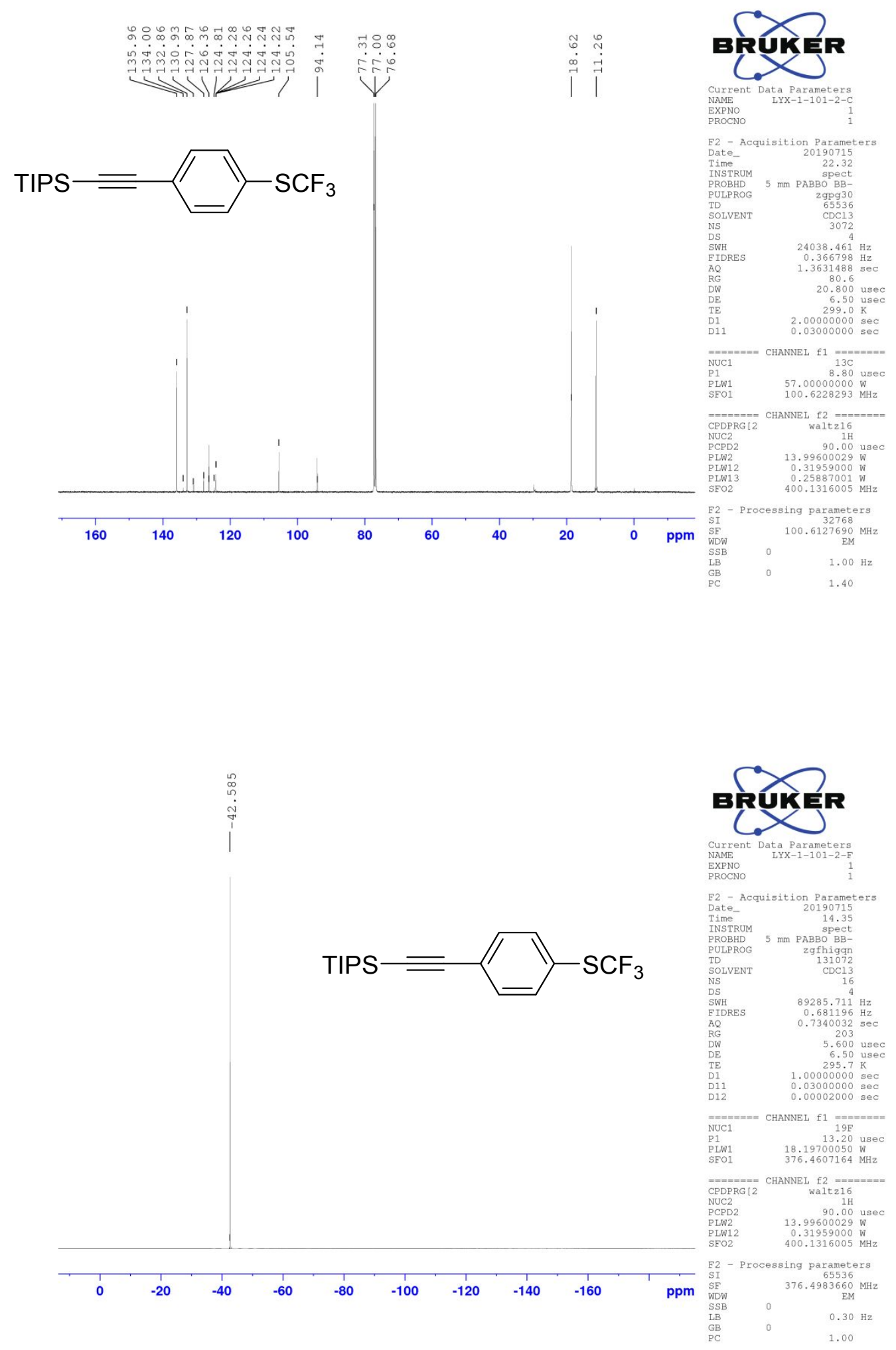
${ }^{1} \mathrm{H},{ }^{13} \mathrm{C}$ and ${ }^{19} \mathrm{~F}$ NMR spectra of (4-bromophenyl)(trifluoromethyl)sulfane (3i) in $\mathrm{CDCl}_{3}$
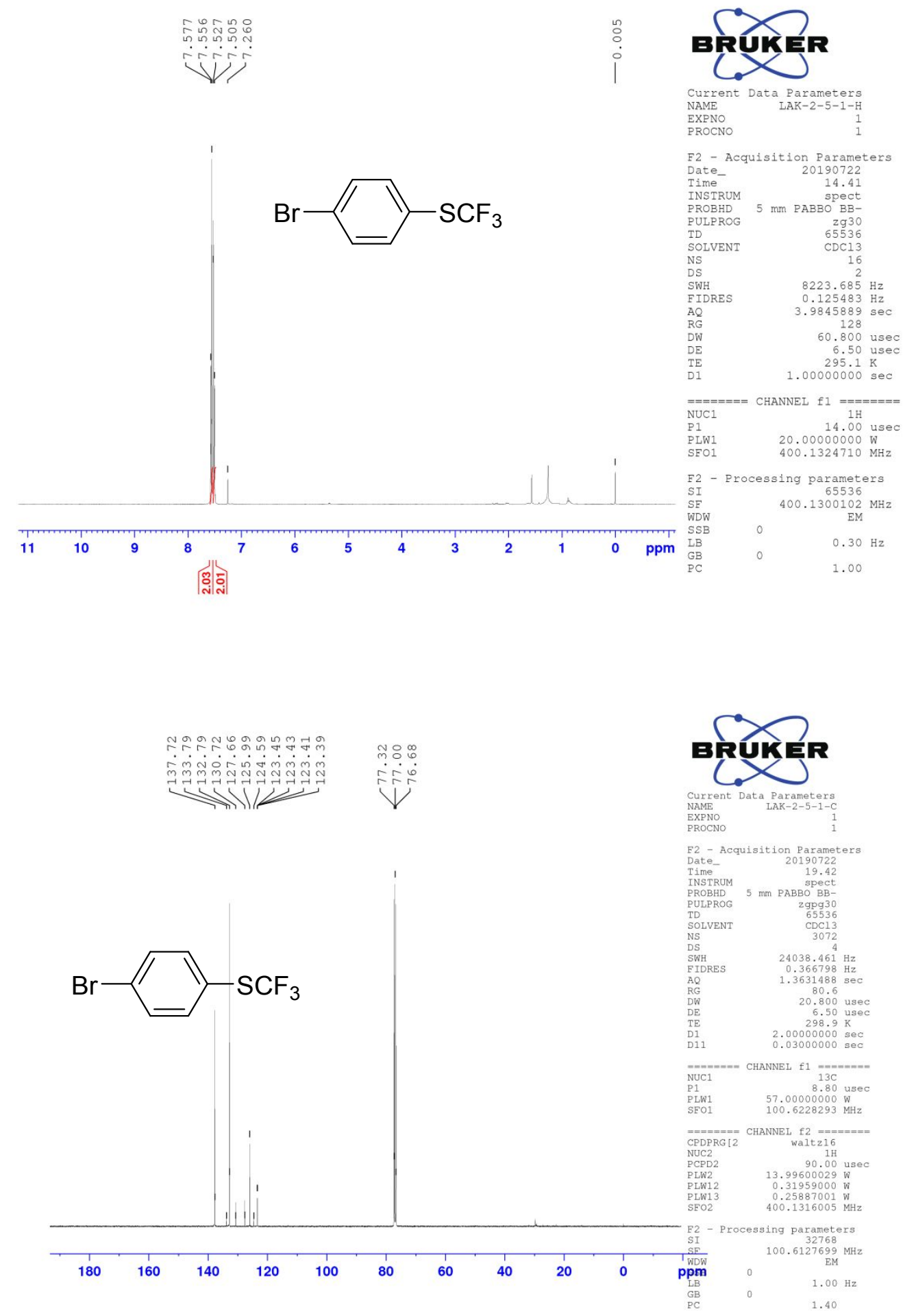


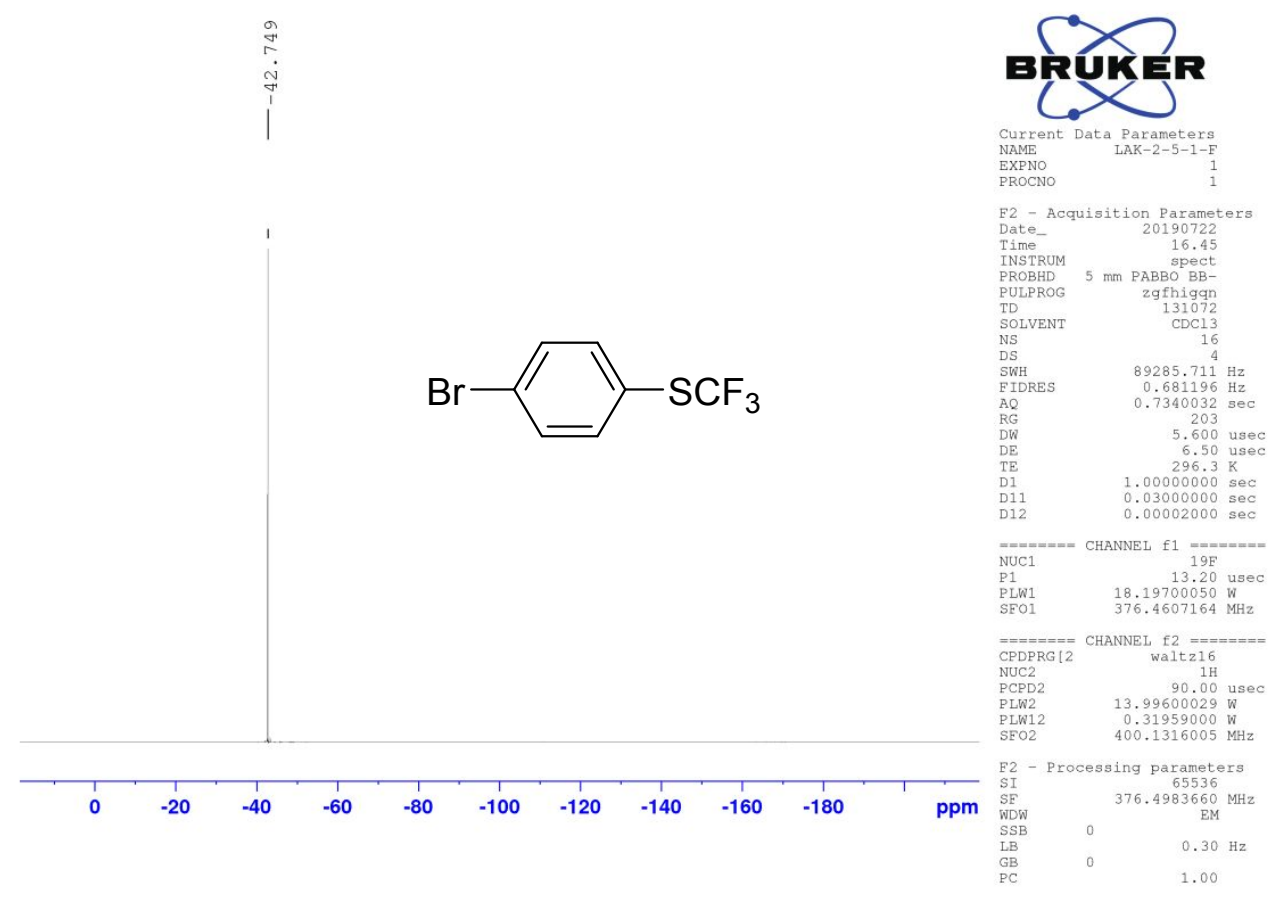

${ }^{1} \mathrm{H},{ }^{13} \mathrm{C}$ and ${ }^{19} \mathrm{~F}$ NMR spectra of 4-((trifluoromethyl)thio)benzonitrile (3j) in $\mathrm{CDCl}_{3}$

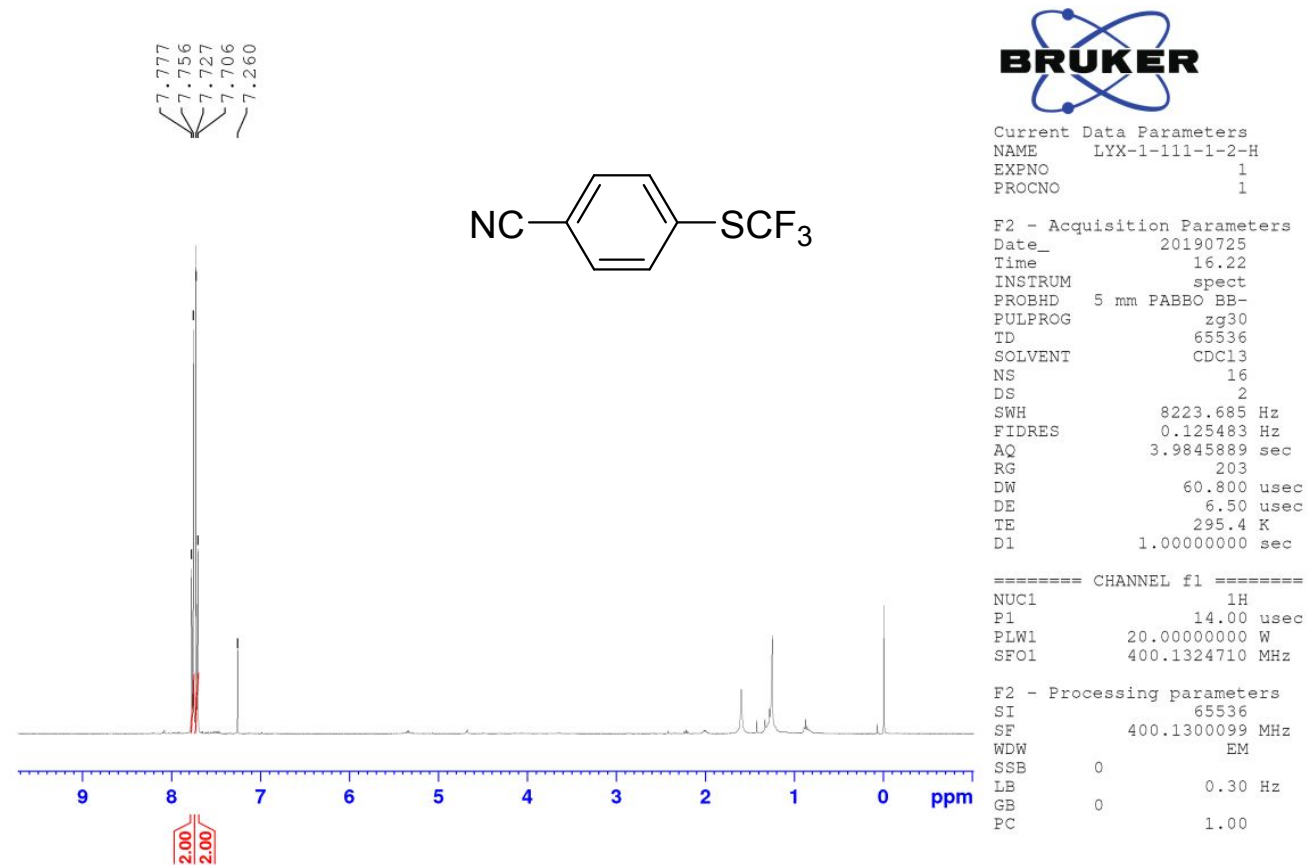



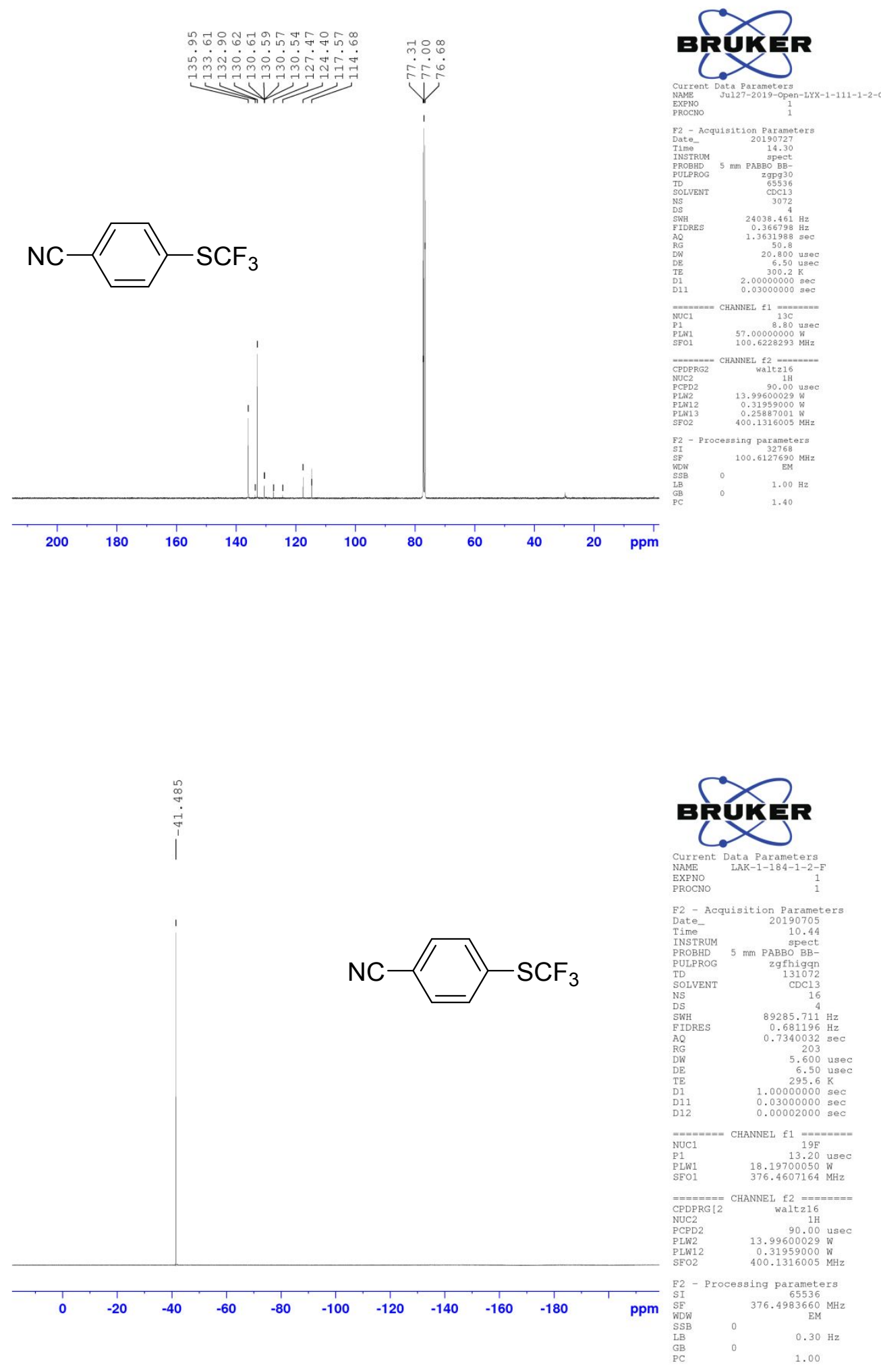
${ }^{1} \mathrm{H},{ }^{13} \mathrm{C}$ and ${ }^{19} \mathrm{~F}$ NMR spectra of 4-((trifluoromethyl)thio)benzoate (3k) in $\mathrm{CDCl}_{3}$
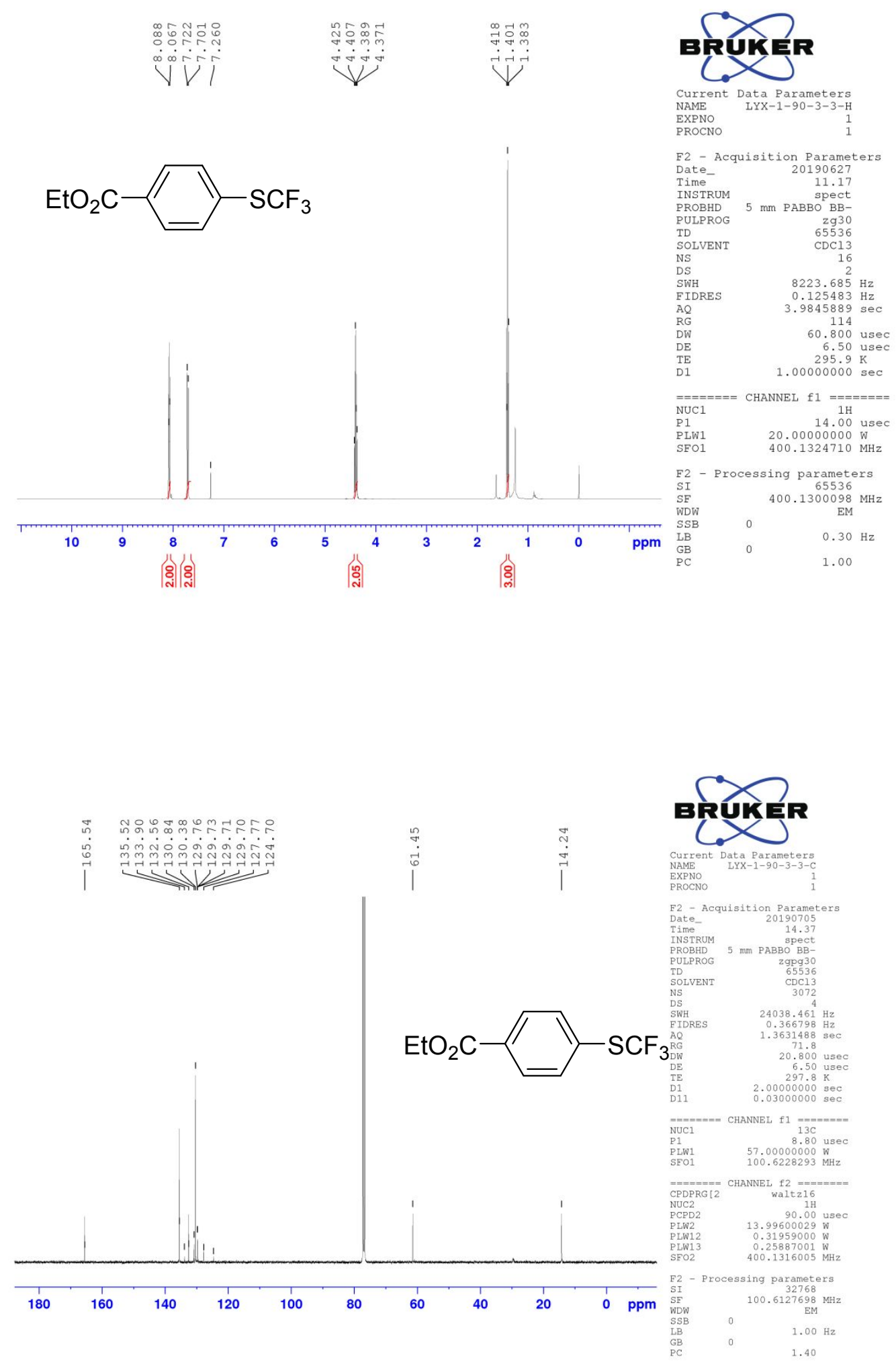


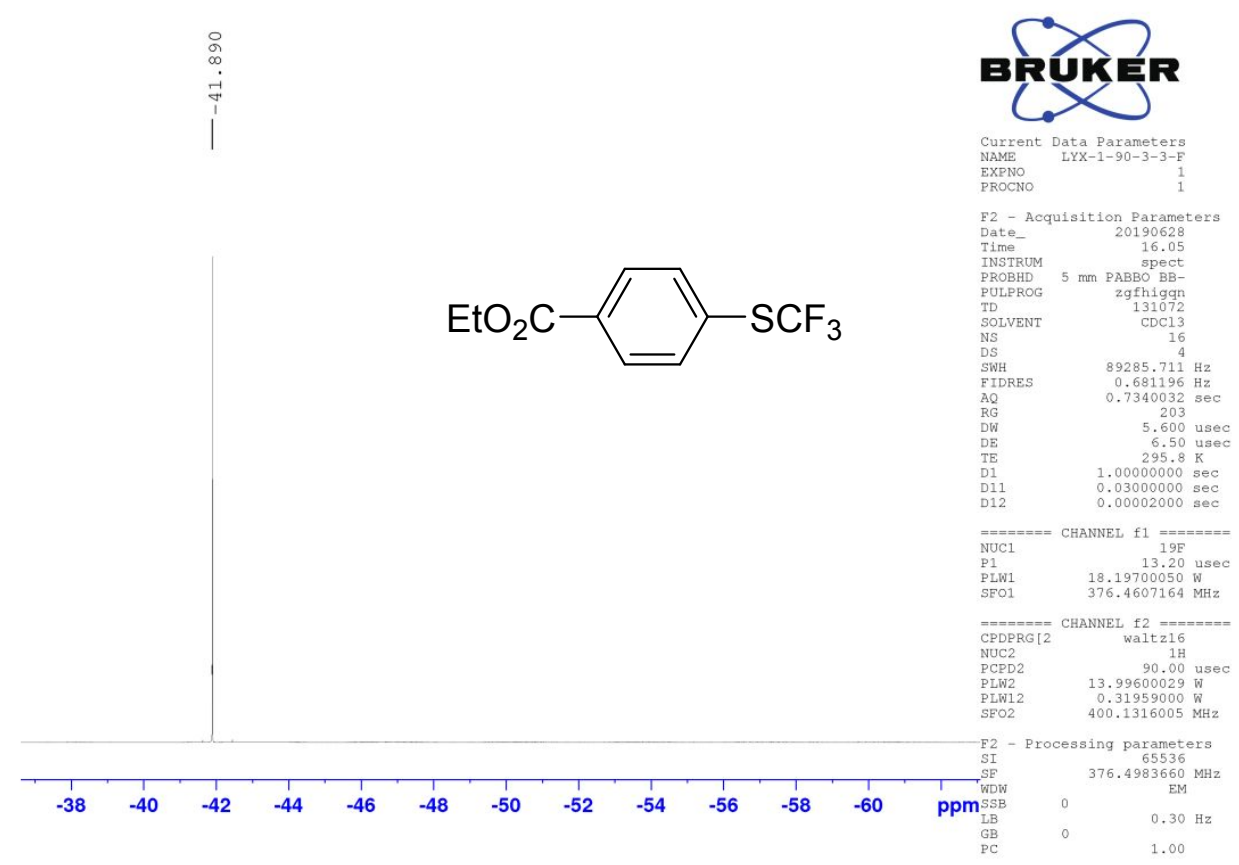

${ }^{1} \mathrm{H},{ }^{13} \mathrm{C}$ and ${ }^{19} \mathrm{~F}$ NMR spectra of 1-(4-((trifluoromethyl)thio)phenyl)ethanone (3l) in $\mathrm{CDCl}_{3}$

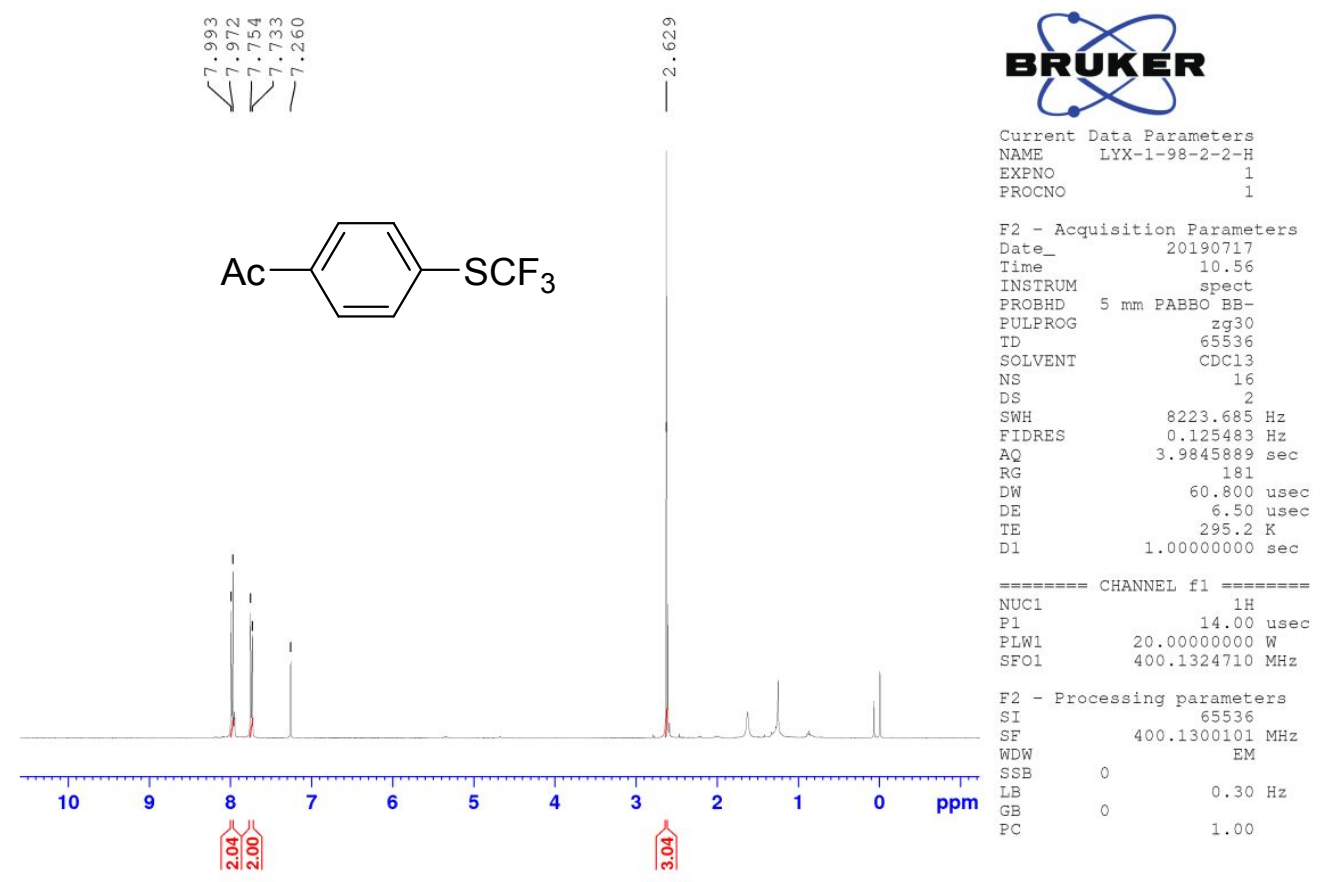



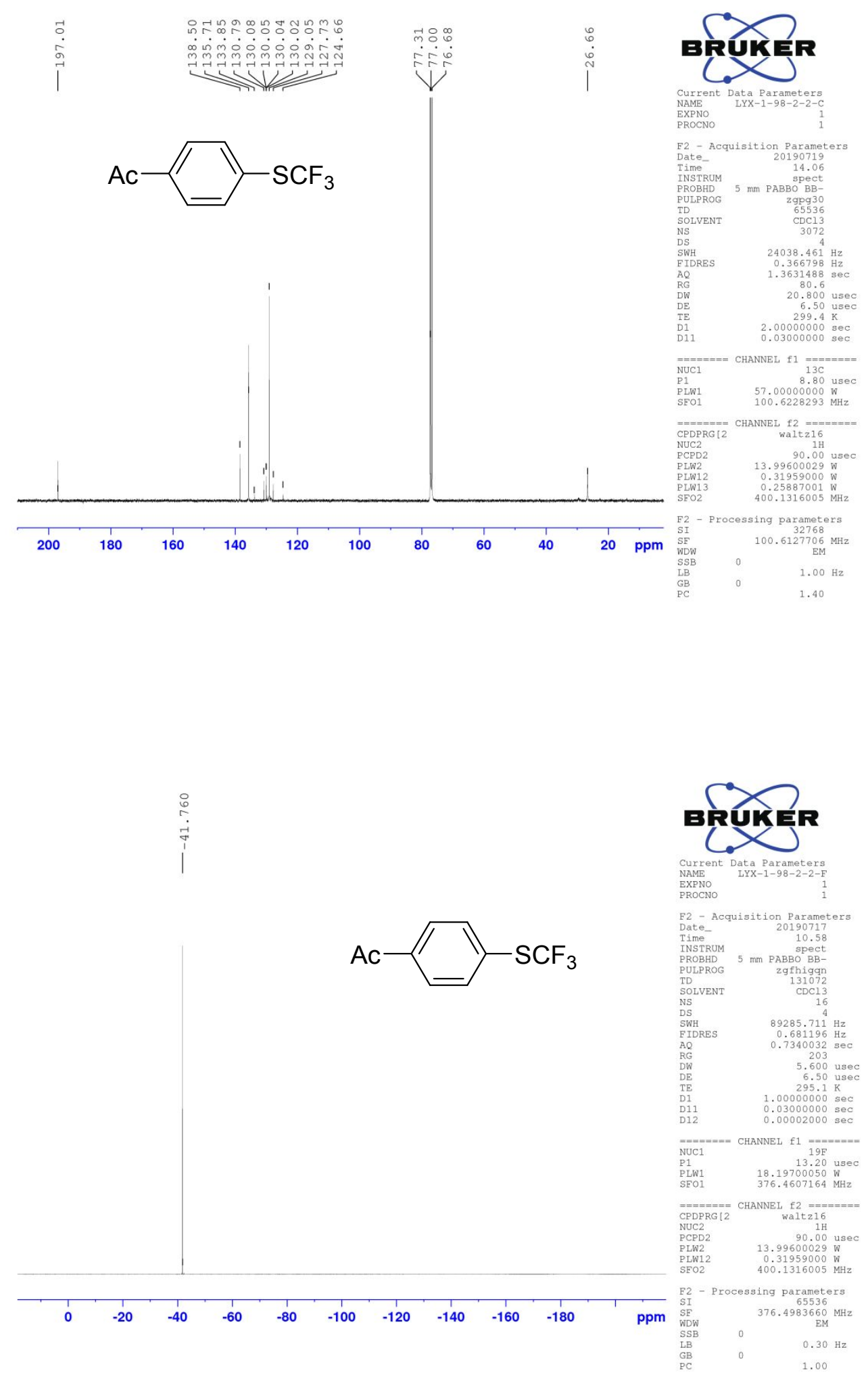
${ }^{1} \mathrm{H},{ }^{13} \mathrm{C}$ and ${ }^{19} \mathrm{~F}$ NMR spectra of phenyl(4-((trifluoromethyl)thio)phenyl)methanone (3m) in $\mathrm{CDCl}_{3}$
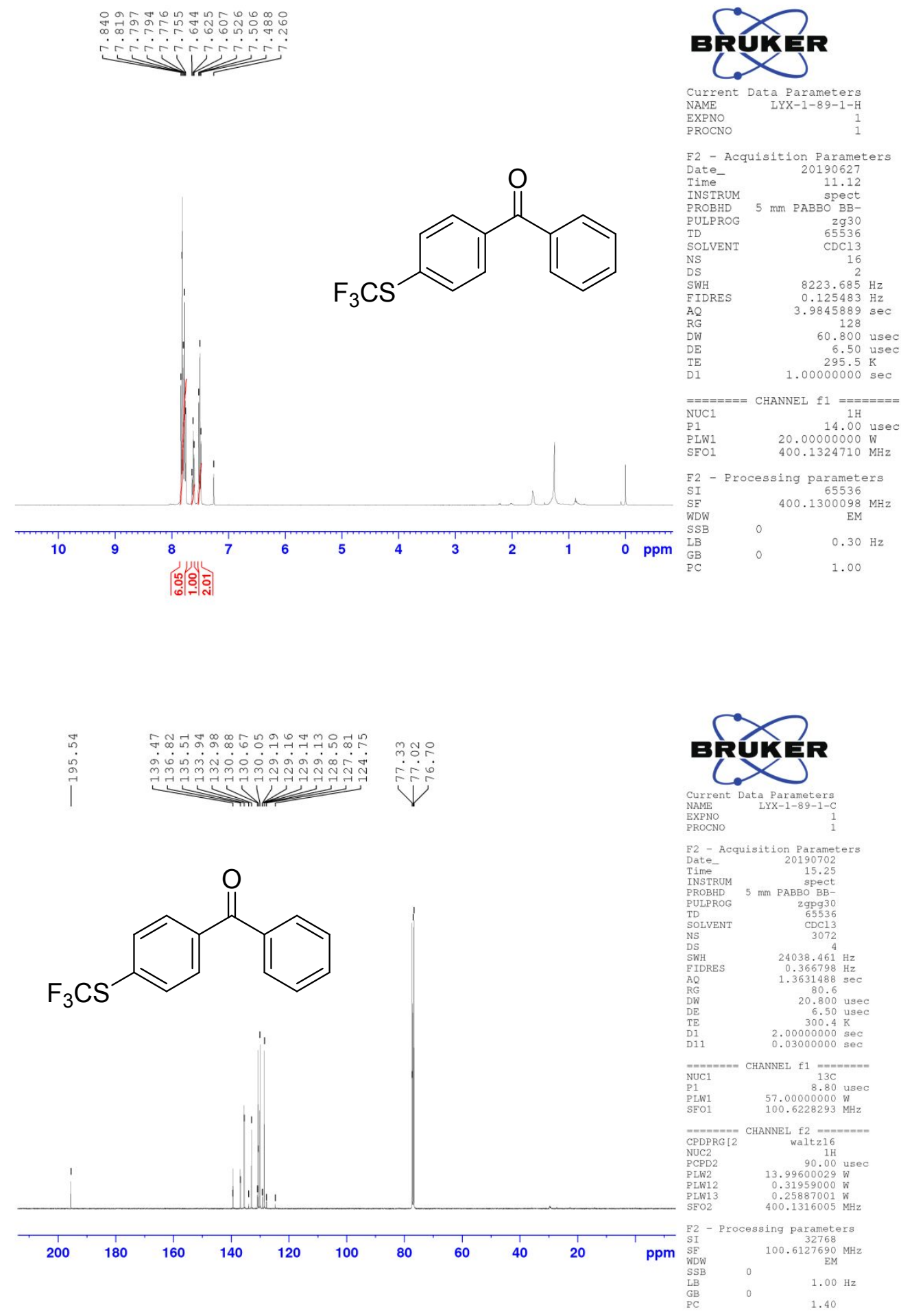


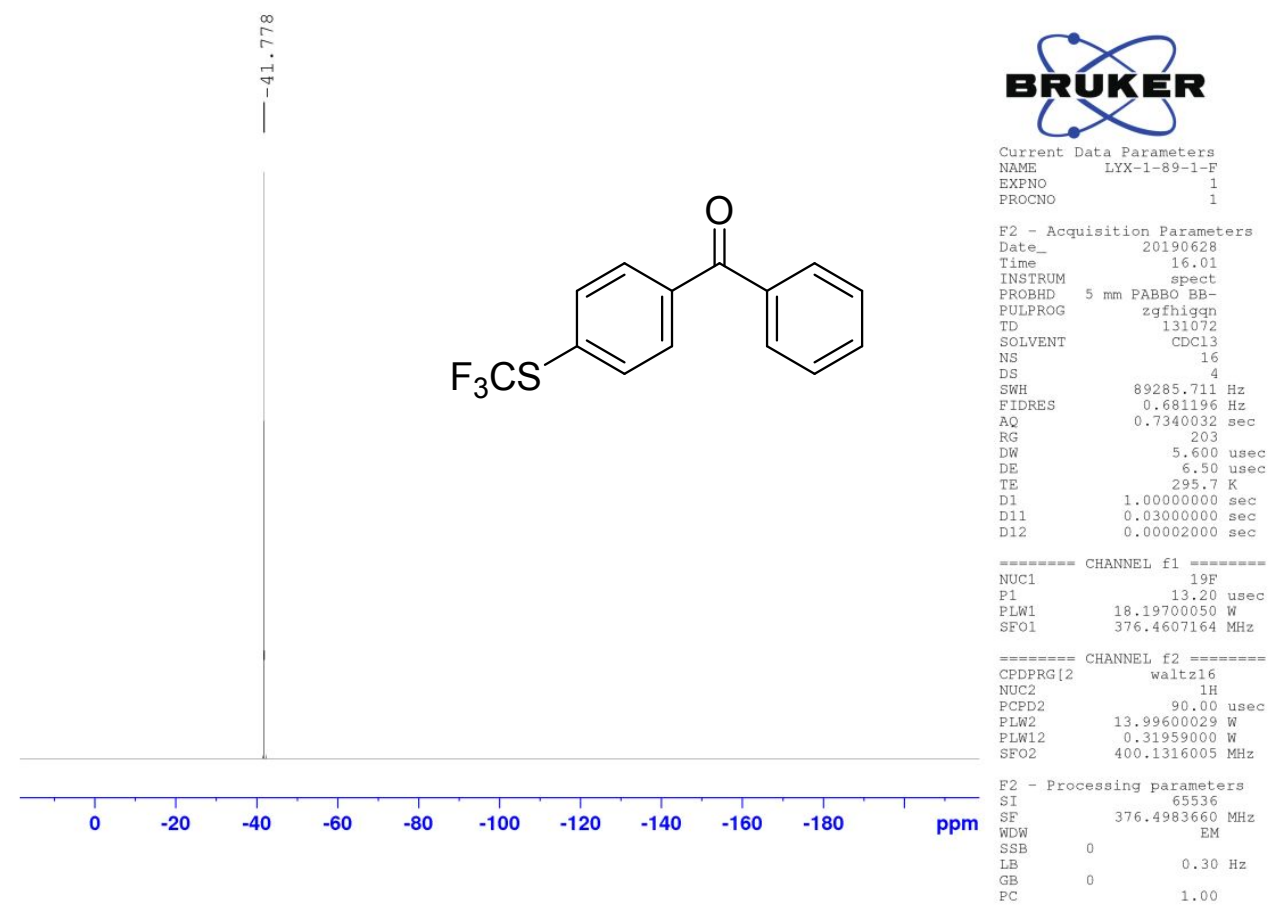

${ }^{1} \mathrm{H},{ }^{13} \mathrm{C}$ and ${ }^{19} \mathrm{~F}$ NMR spectra of (3-bromophenyl)(trifluoromethyl)sulfane (3n) in $\mathrm{CDCl}_{3}$

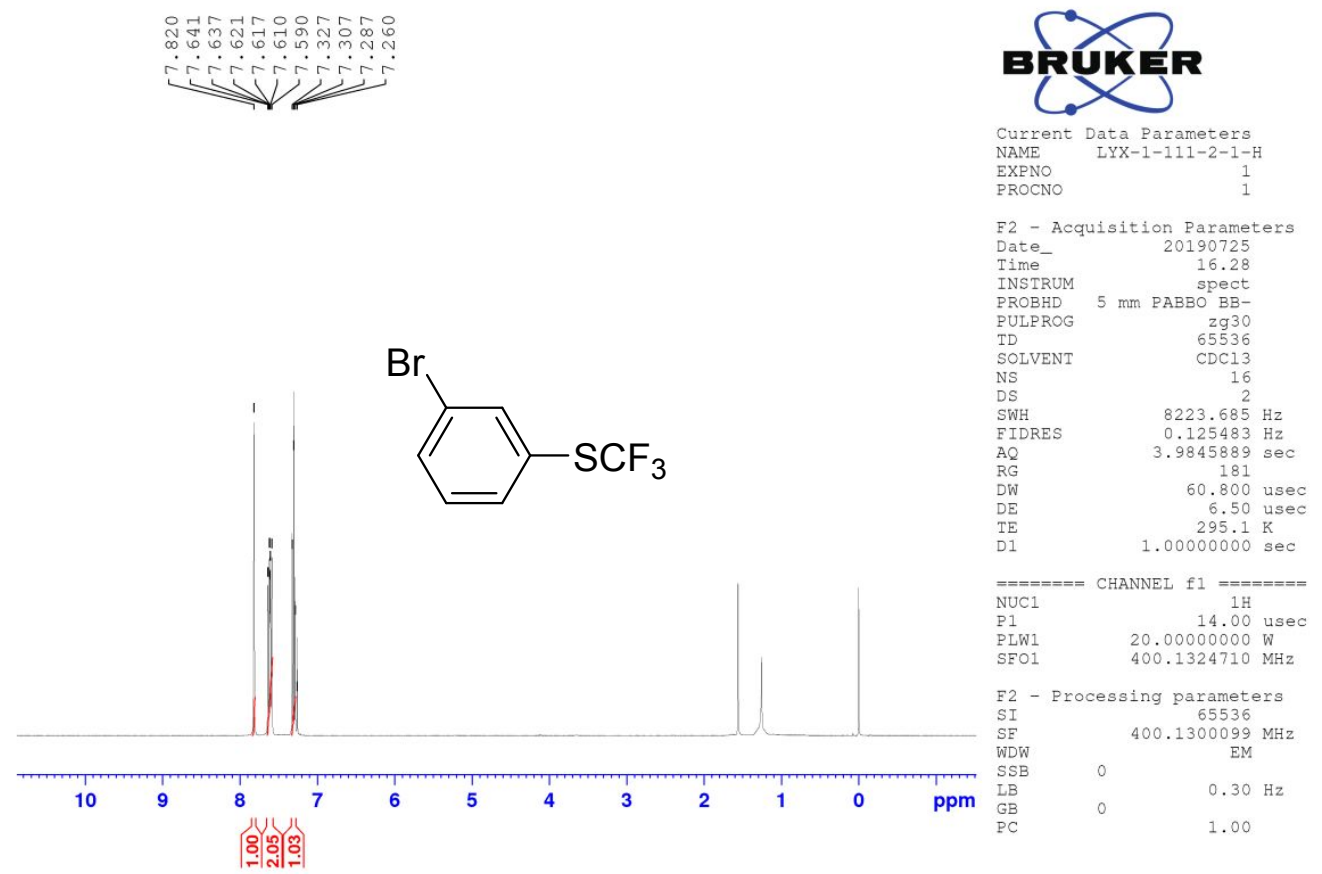



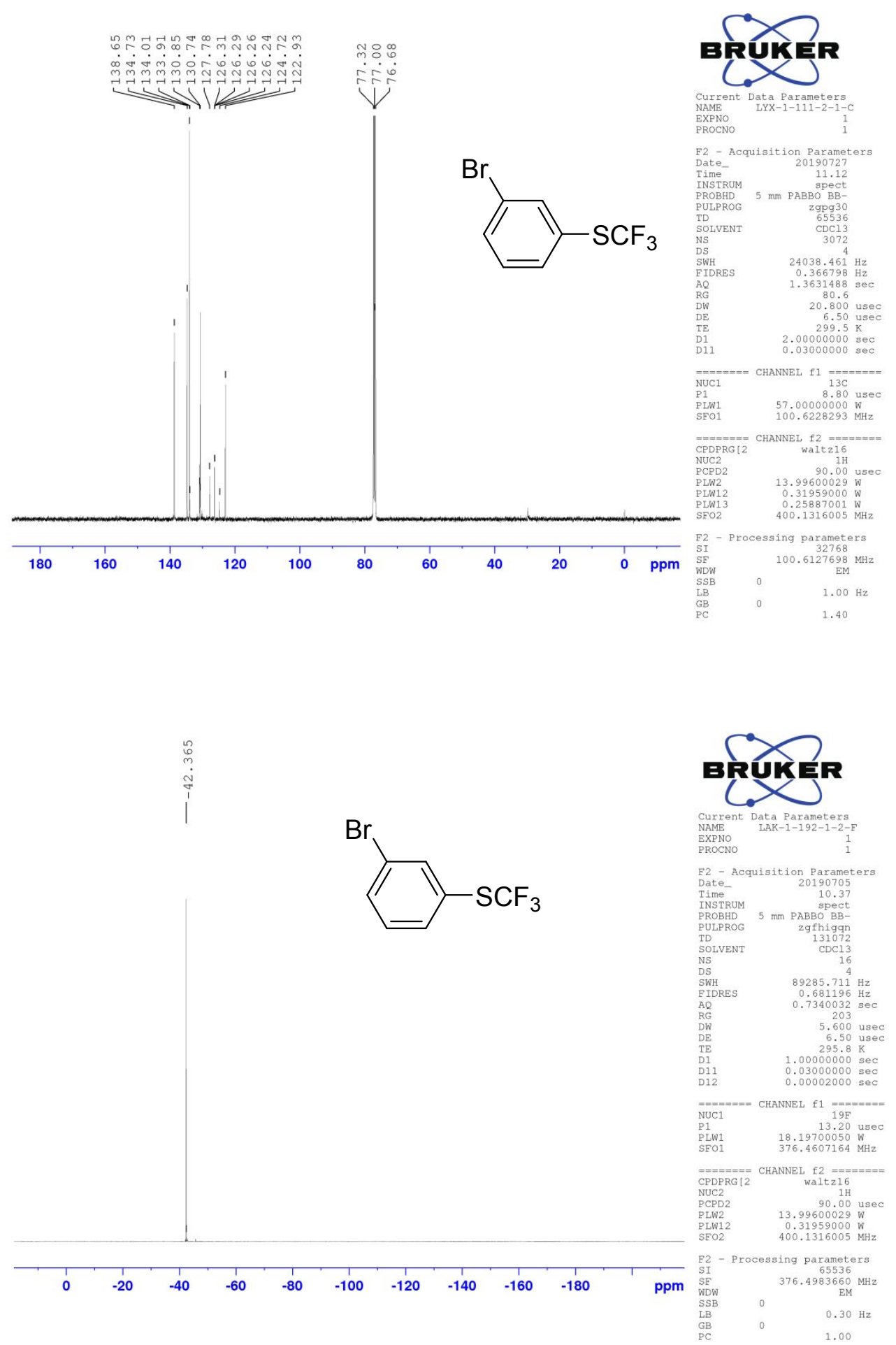
${ }^{1} \mathrm{H},{ }^{13} \mathrm{C}$ and ${ }^{19} \mathrm{~F}$ NMR spectra of (trifluoromethyl)(3,4,5-trimethoxyphenyl)sulfane (3o) in $\mathrm{CDCl}_{3}$
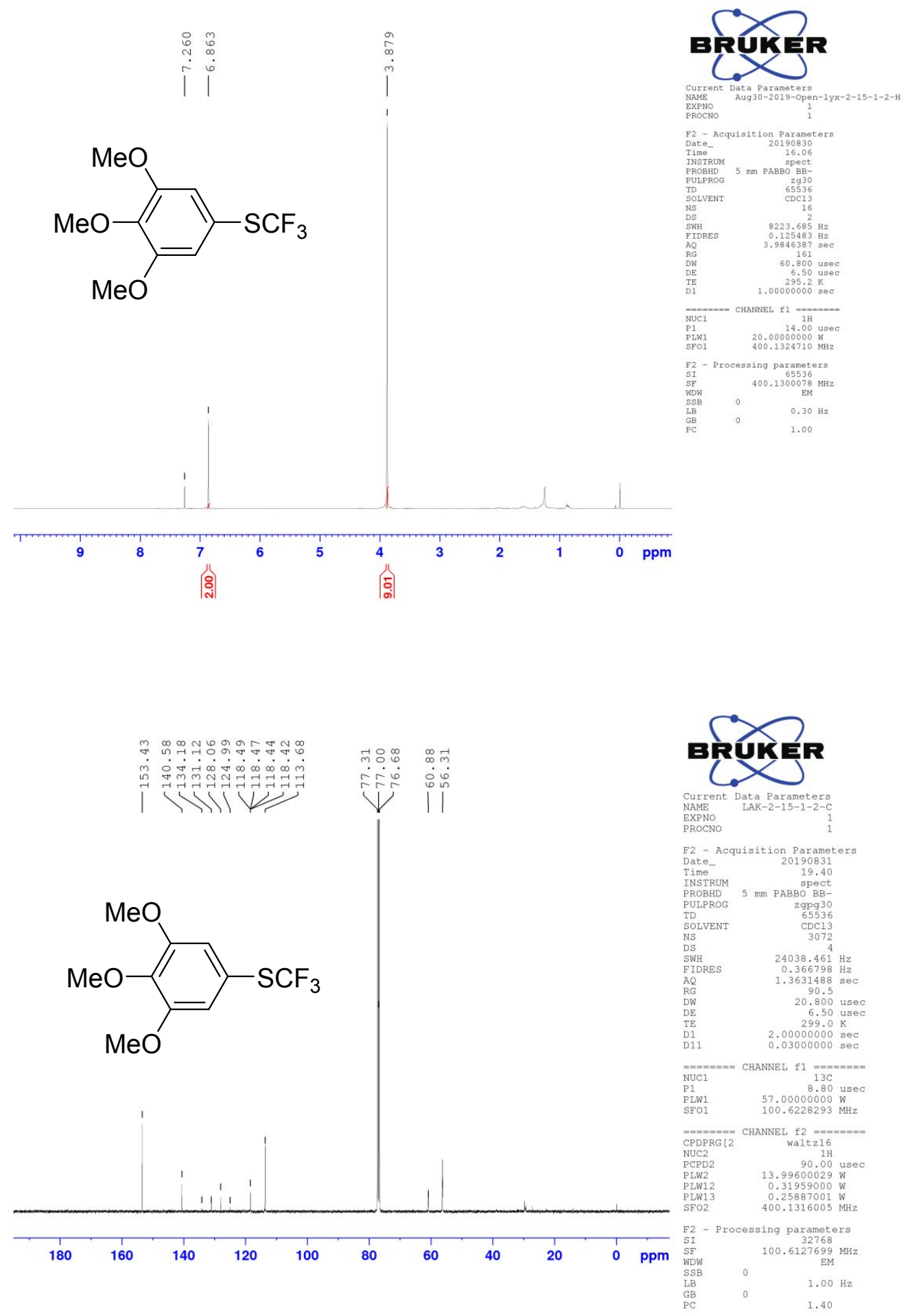


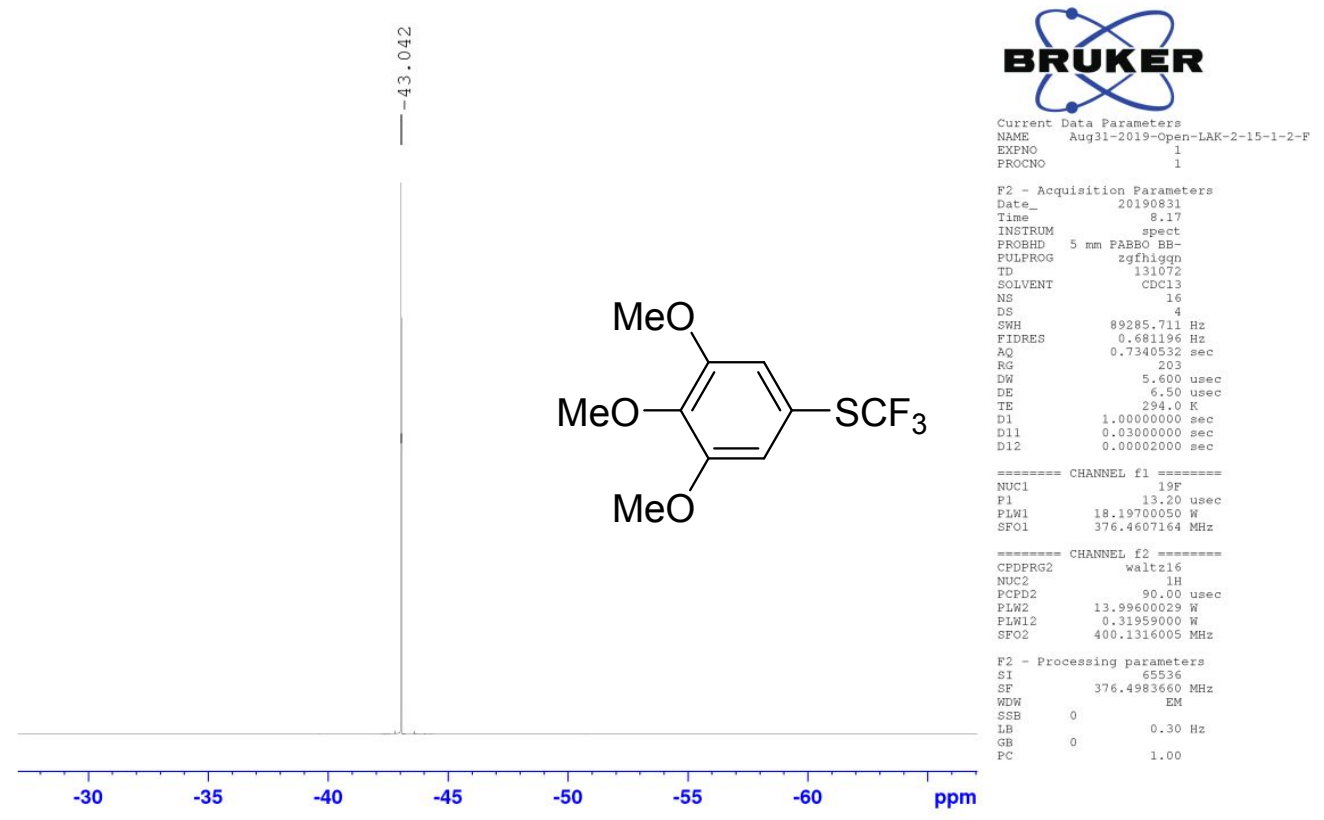

${ }^{1} \mathrm{H},{ }^{13} \mathrm{C}$ and ${ }^{19} \mathrm{~F}$ NMR spectra of 5-((trifluoromethyl)thio)benzo[d][1,3]dioxole (3p) in $\mathrm{CDCl}_{3}$
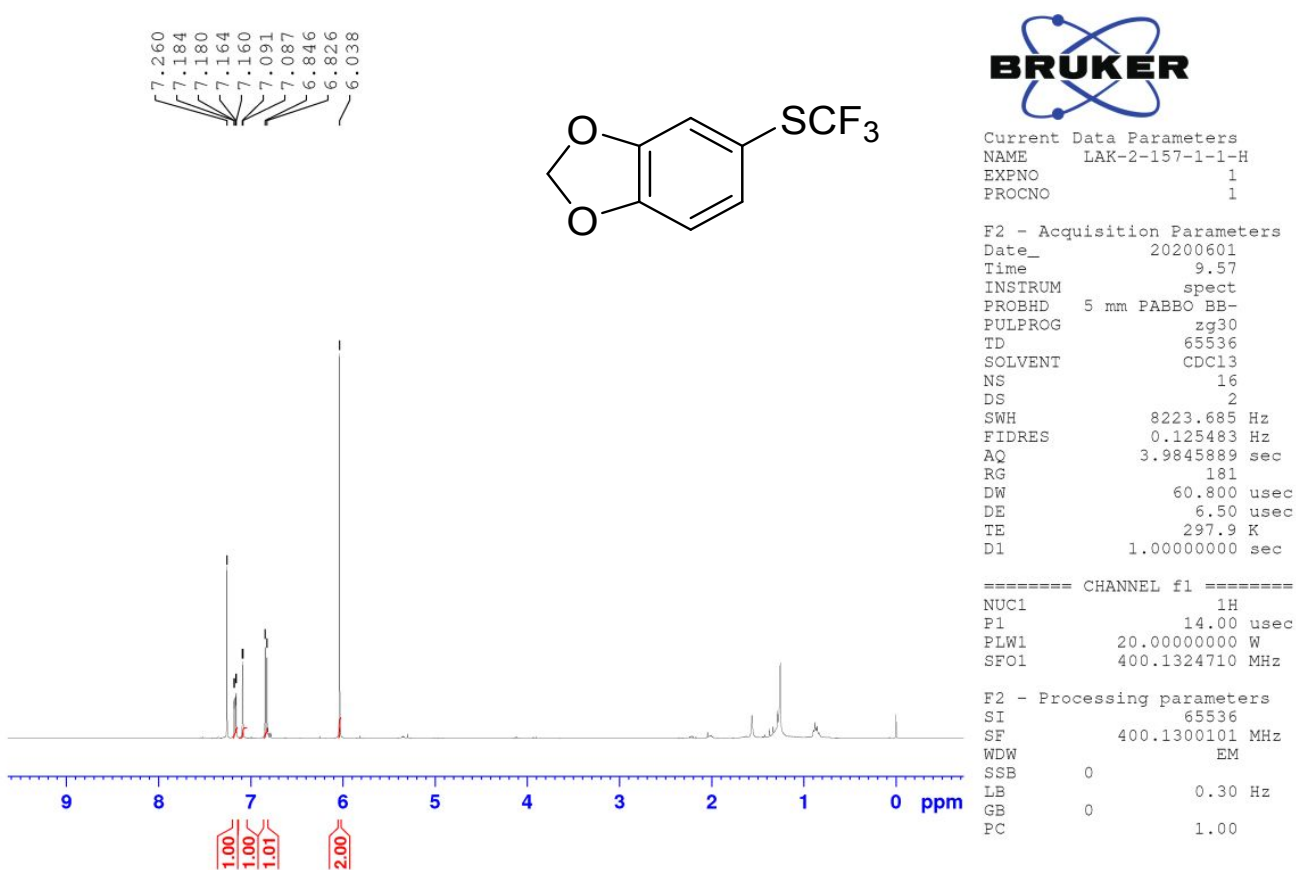

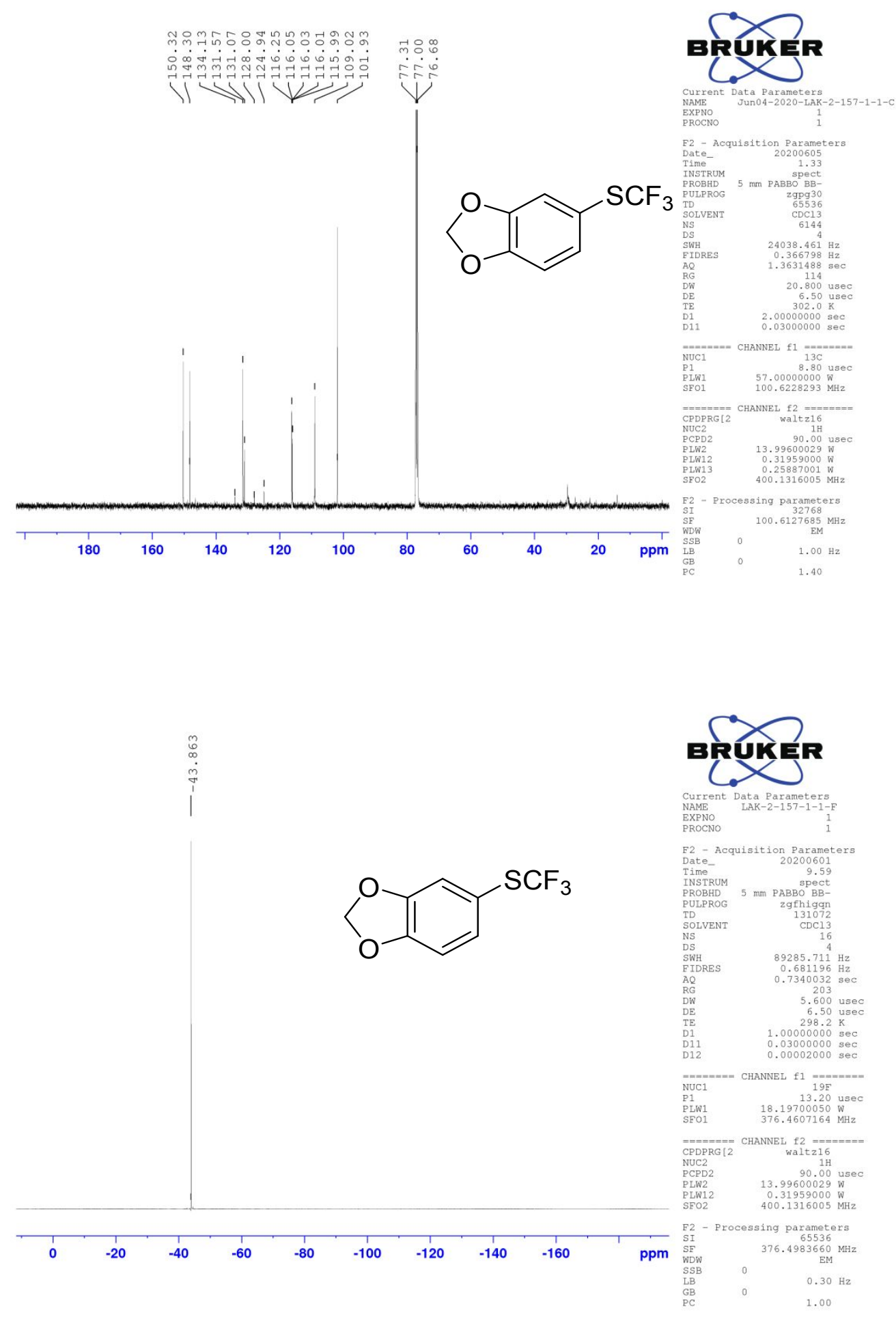
${ }^{1} \mathrm{H},{ }^{13} \mathrm{C}$ and ${ }^{19} \mathrm{~F}$ NMR spectra of naphthalen-2-yl(trifluoromethyl)sulfane (3q) in $\mathrm{CDCl}_{3}$
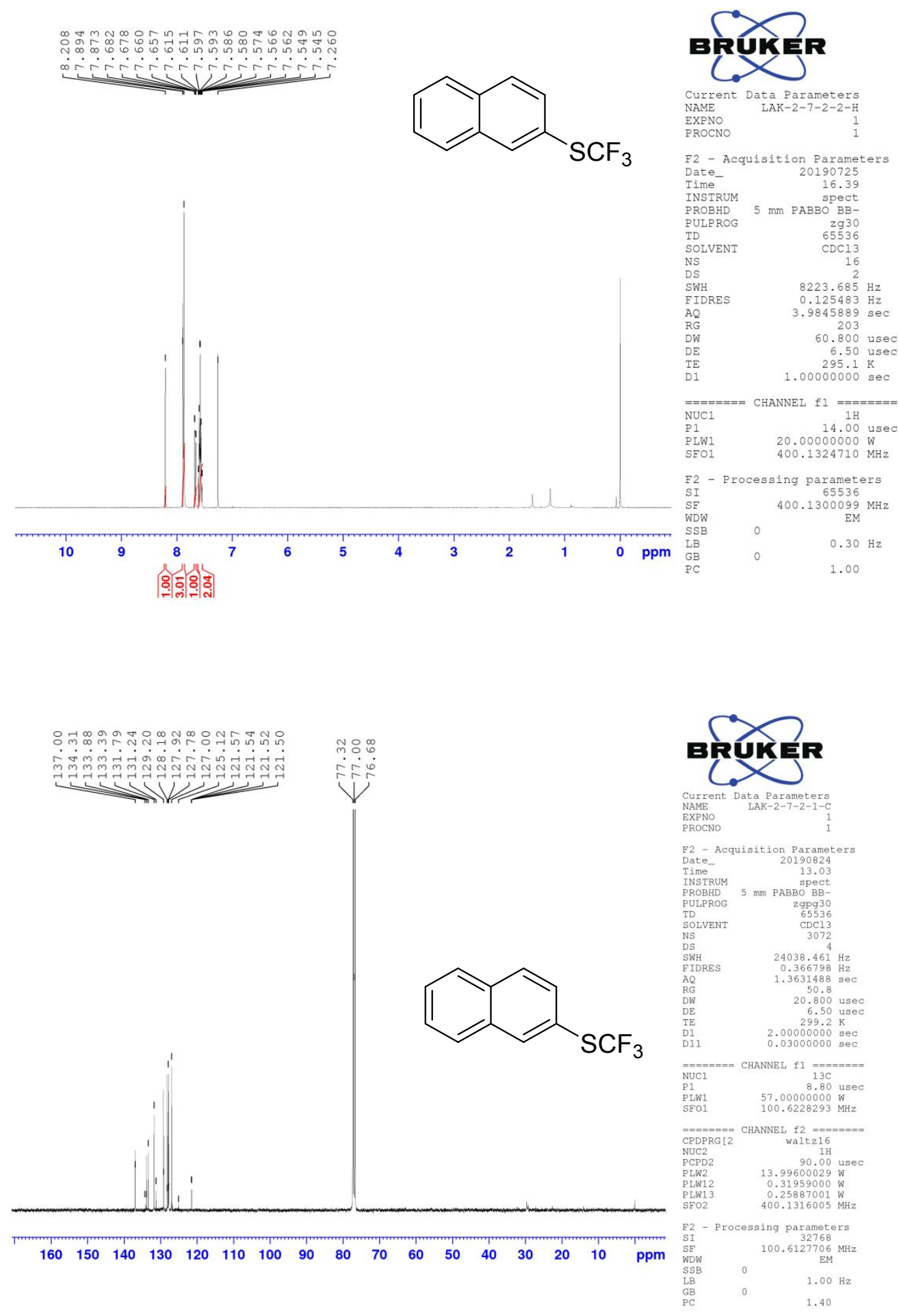


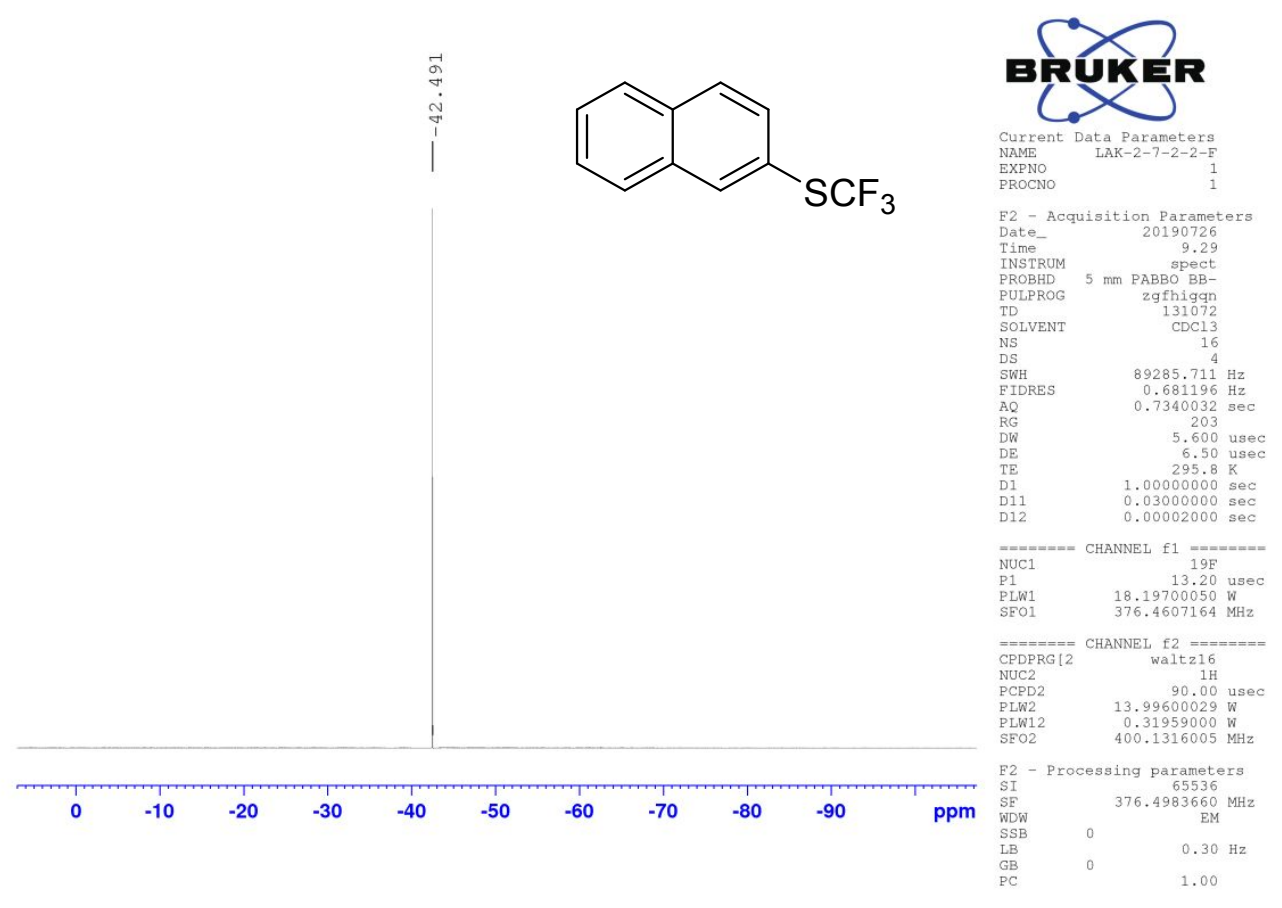

${ }^{1} \mathrm{H}, \quad{ }^{13} \mathrm{C}$ and ${ }^{19} \mathrm{~F} \quad \mathrm{NMR}$ spectra of ethyl 5-((trifluoromethyl)thio)-2,3dihydrobenzofuran-2-carboxylate (3r) in $\mathrm{CDCl}_{3}$

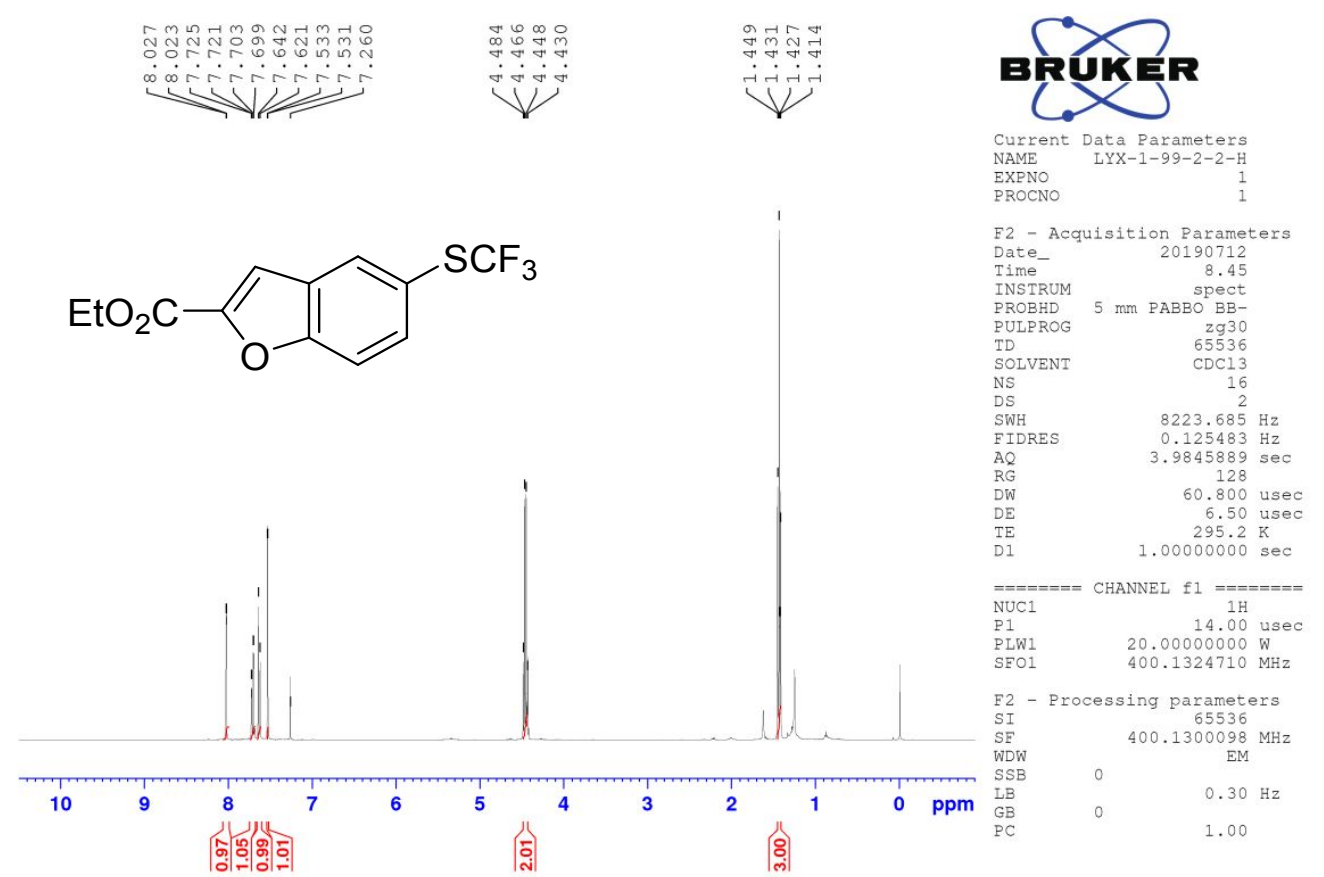



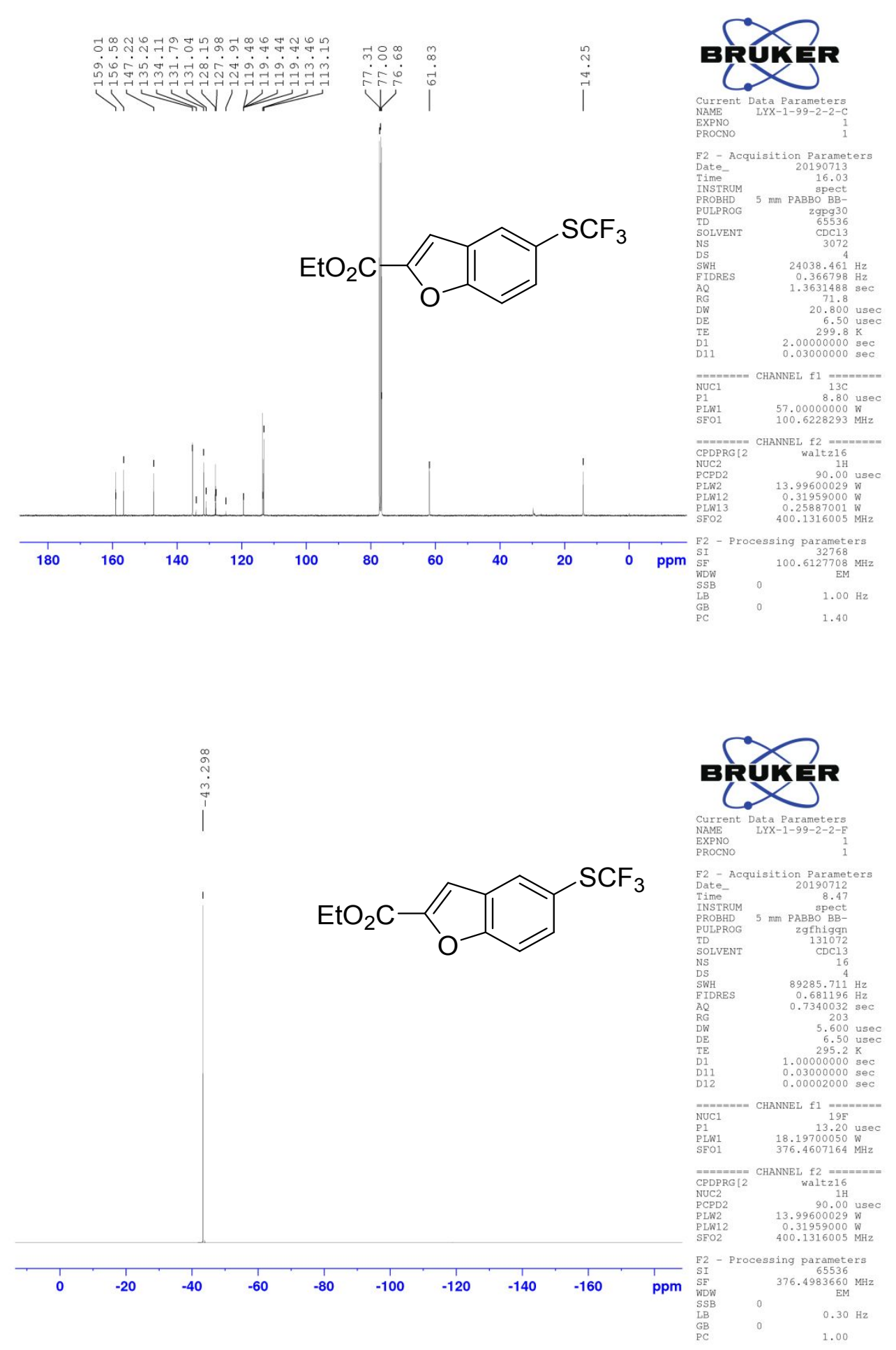
${ }^{1} \mathrm{H},{ }^{13} \mathrm{C}$ and ${ }^{19} \mathrm{~F}$ NMR spectra of 2-methyl-5-((trifluoromethyl)thio)benzo[d]thiazole (3s) in $\mathrm{CDCl}_{3}$
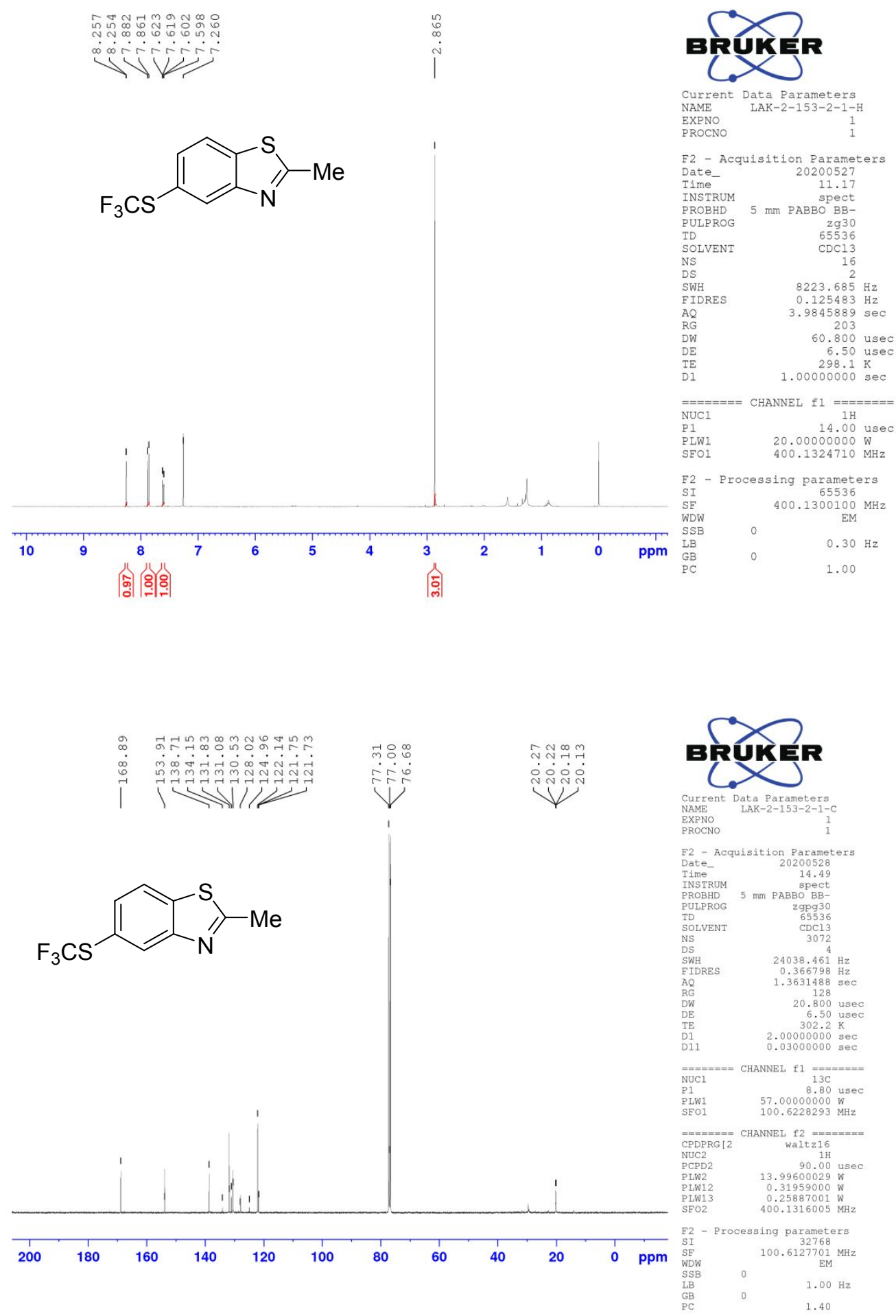


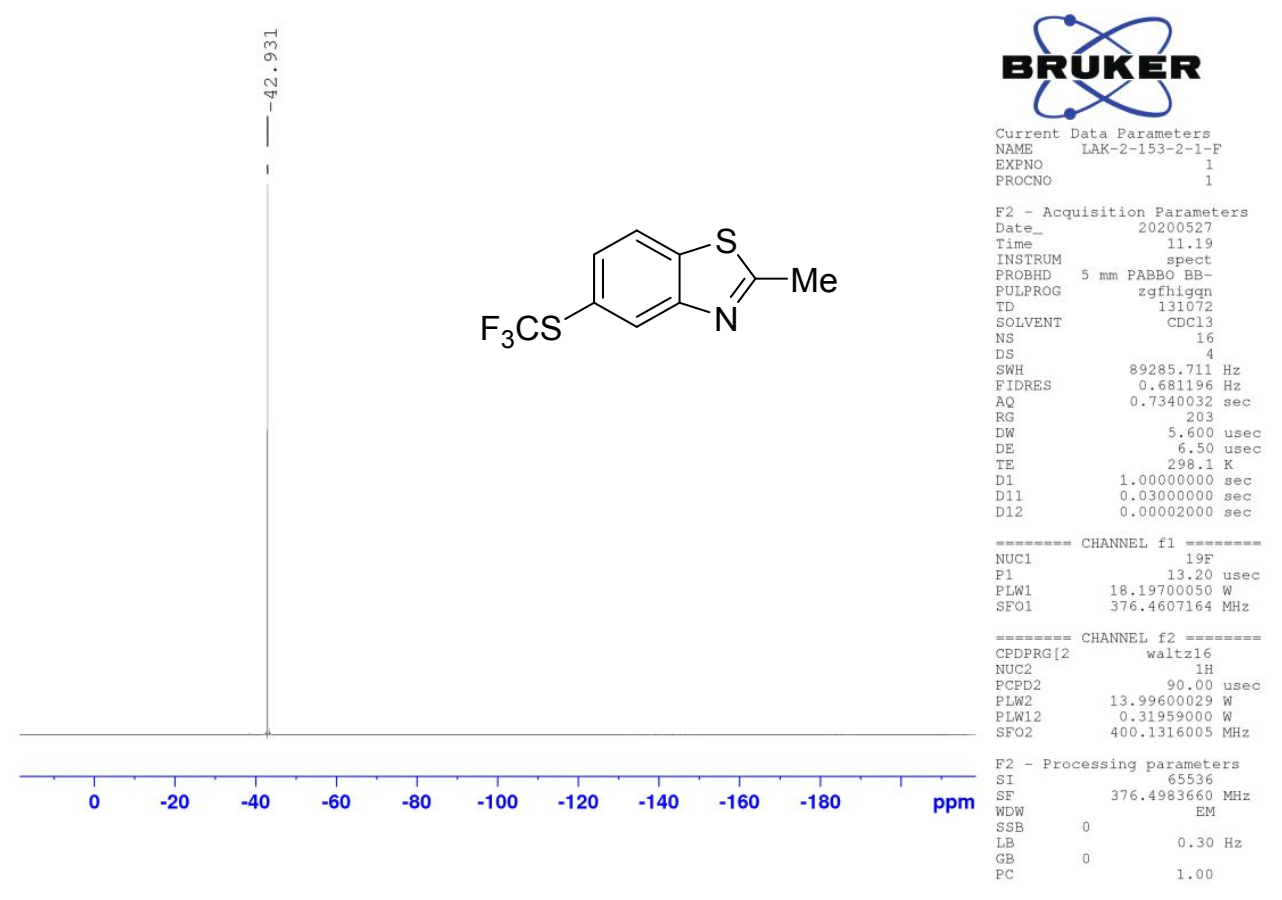

${ }^{1} \mathrm{H},{ }^{13} \mathrm{C}$ and ${ }^{19} \mathrm{~F}$ NMR spectra of methyl 5-((trifluoromethyl)thio)nicotinate (3t) in $\mathrm{CDCl}_{3}$

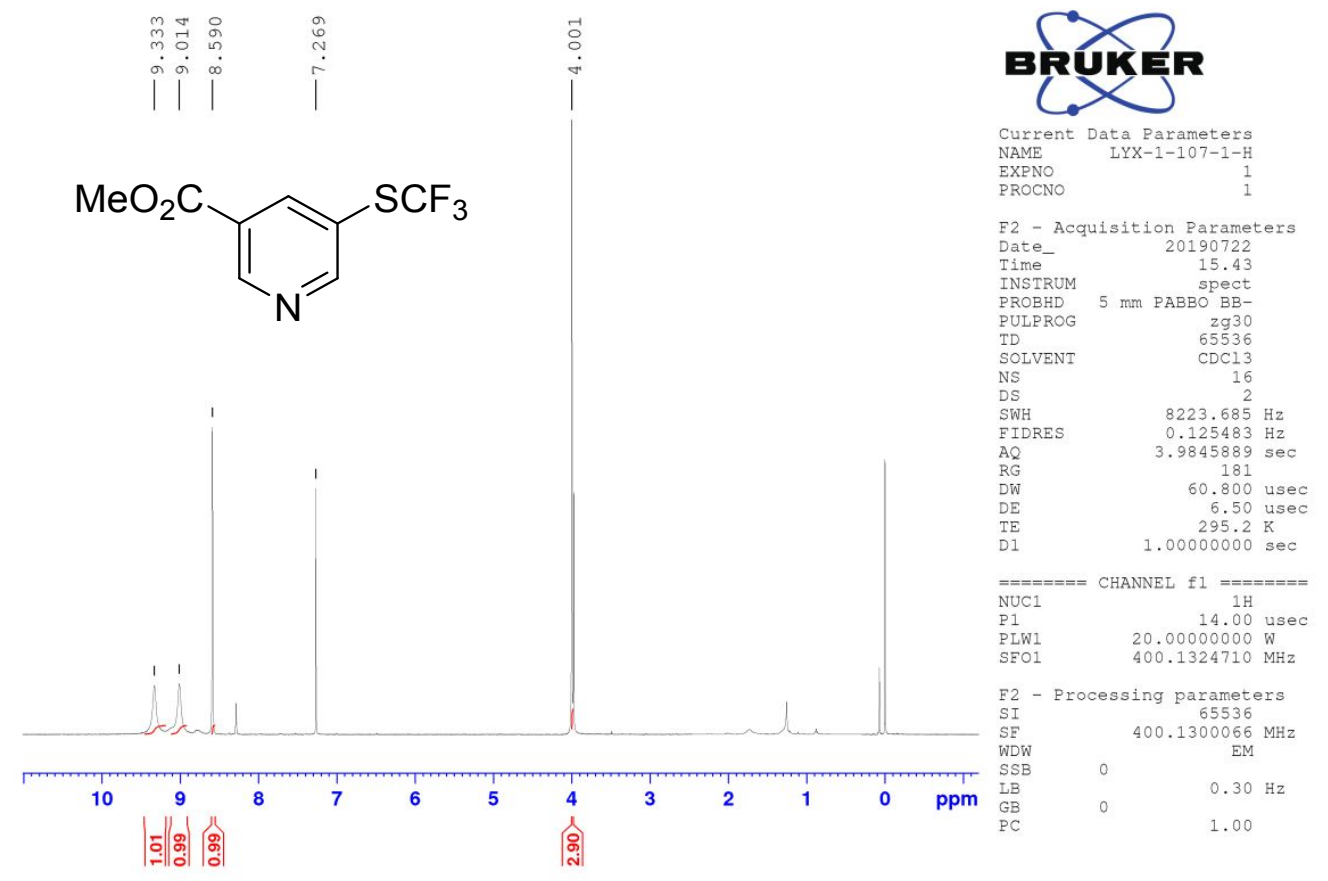



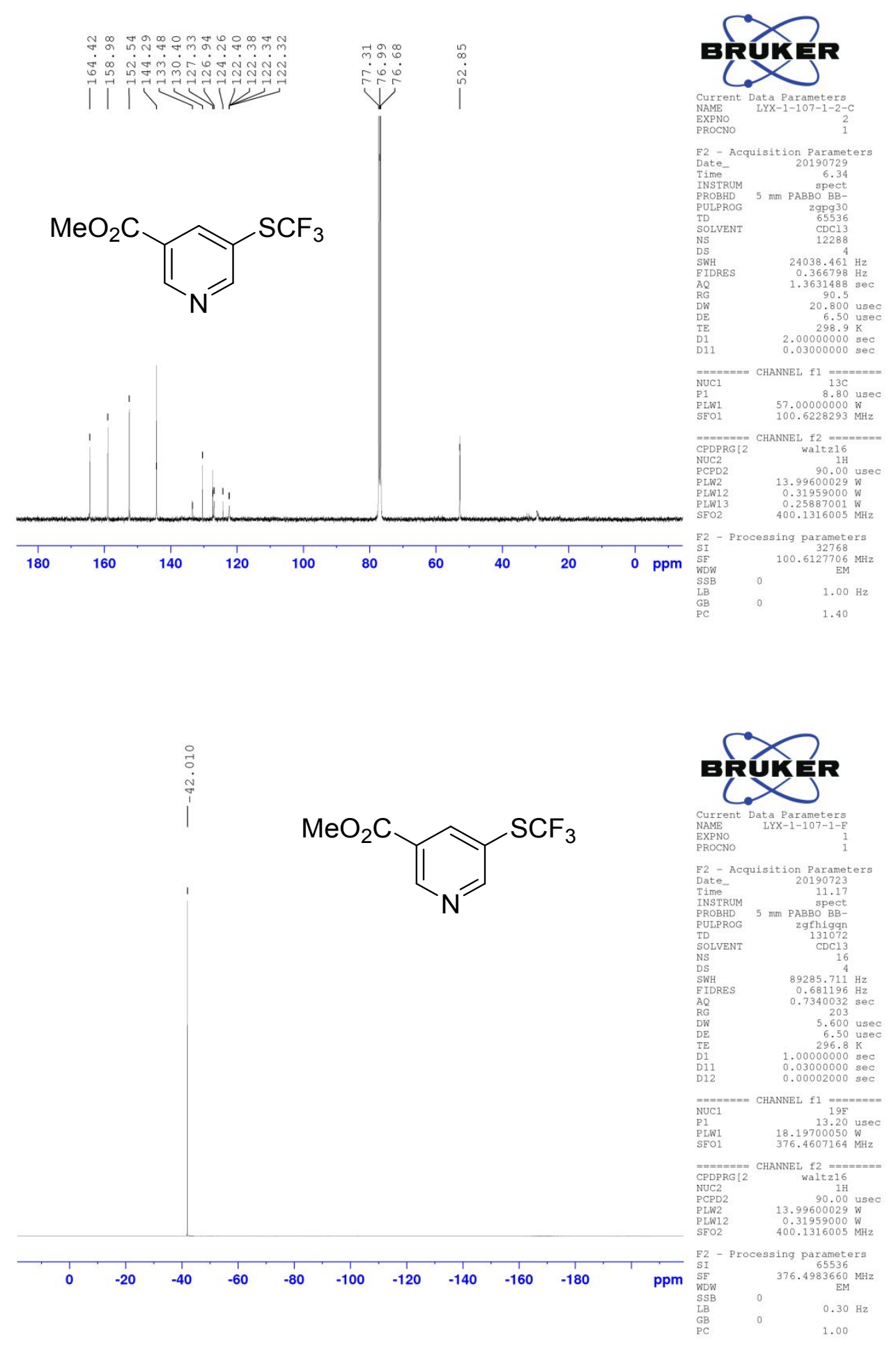
${ }^{1} \mathrm{H},{ }^{13} \mathrm{C}$ and ${ }^{19} \mathrm{~F}$ NMR spectra of 7-((trifluoromethyl)thio)quinoline (3u) in $\mathrm{CDCl}_{3}$
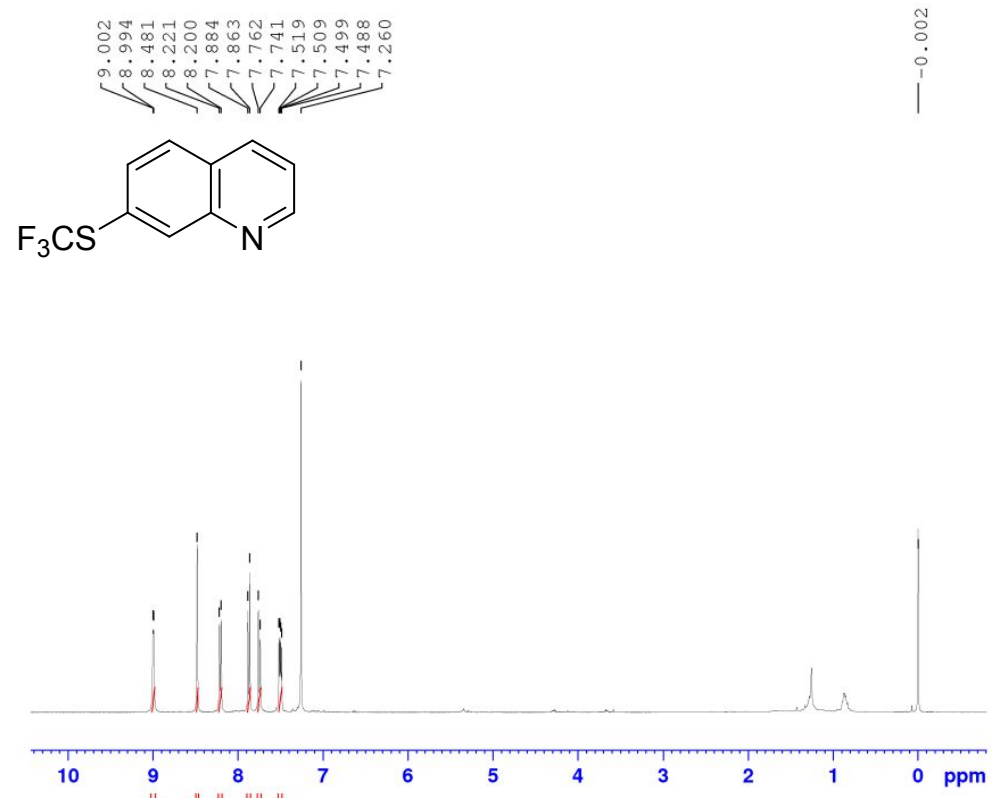

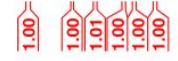
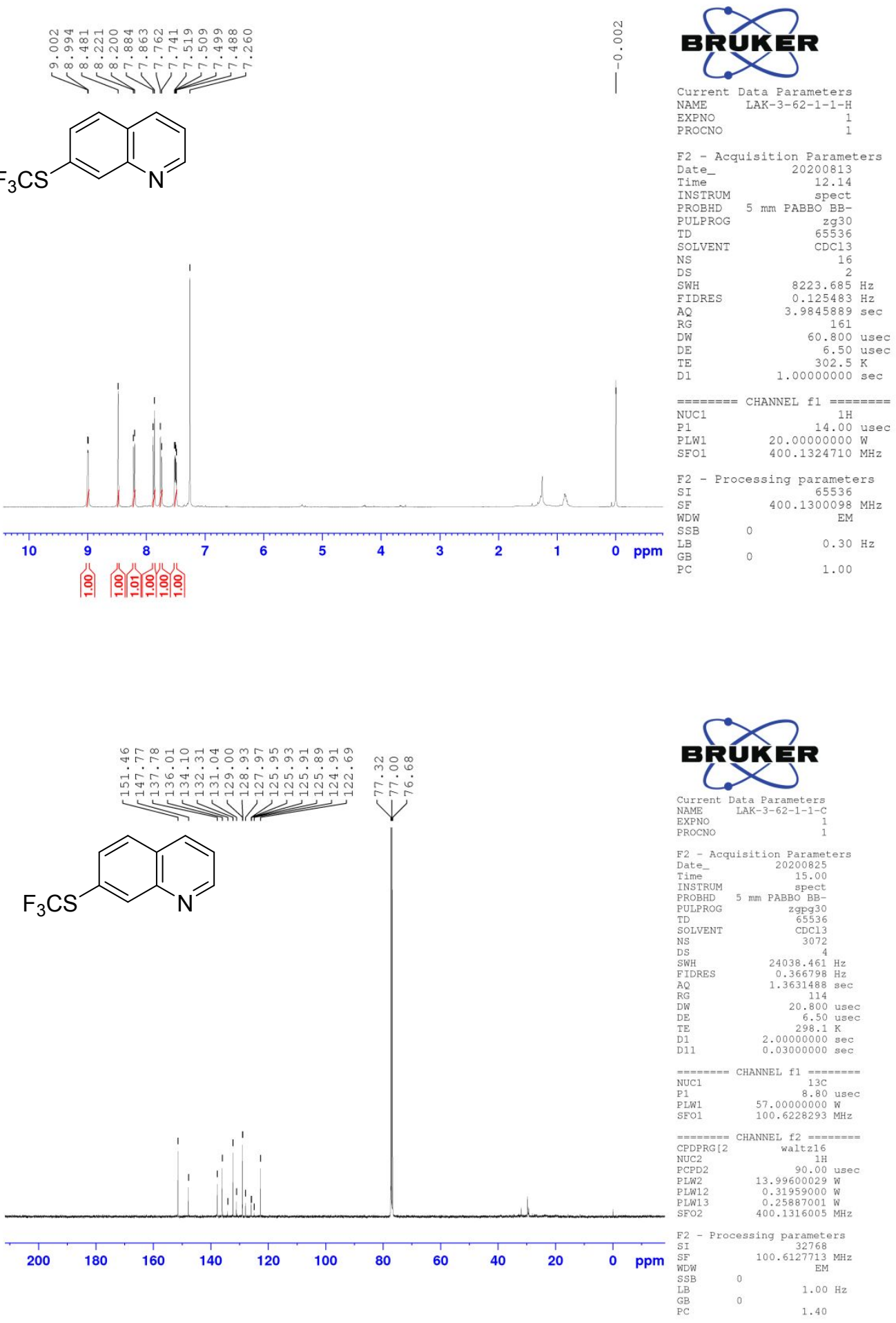


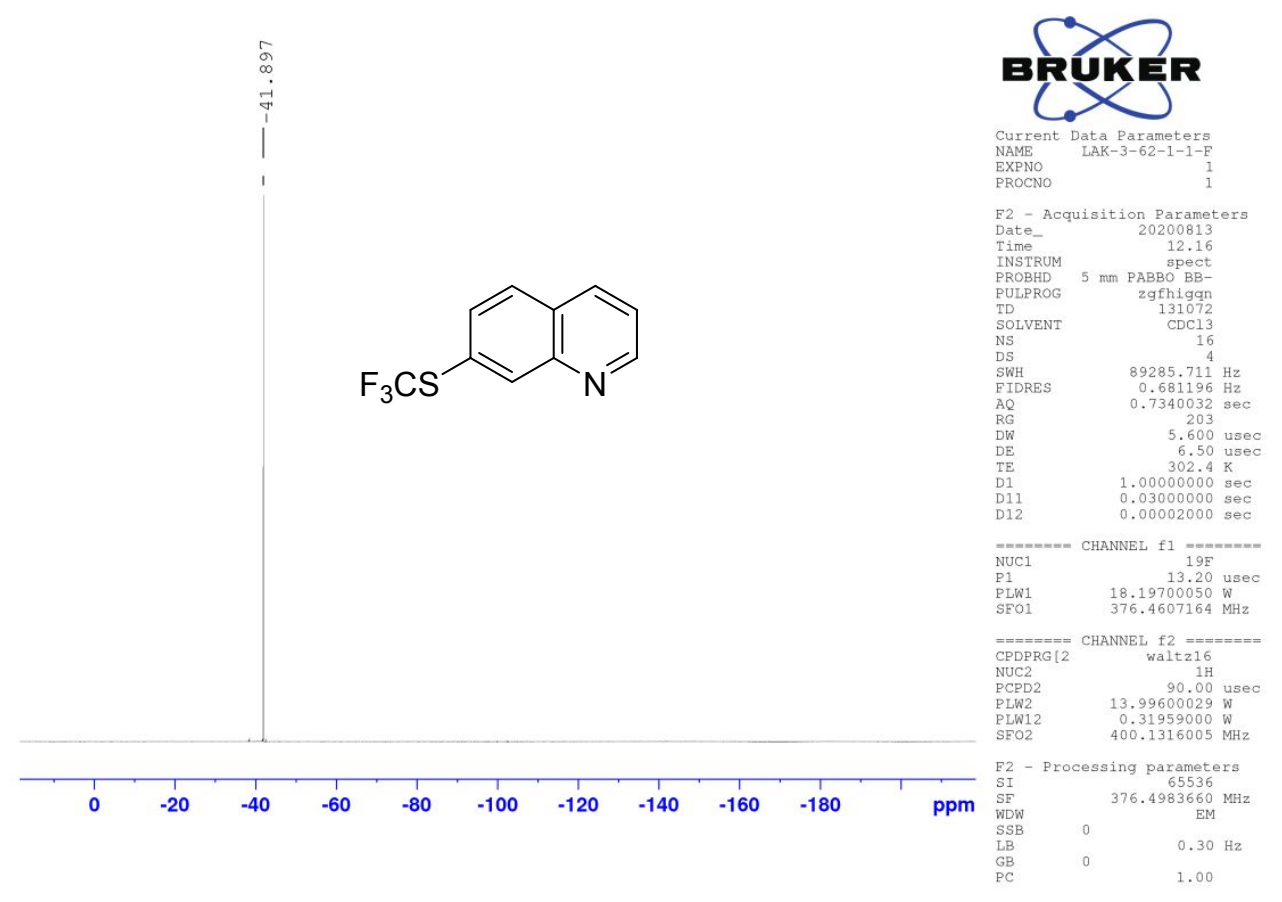

${ }^{1} \mathrm{H},{ }^{13} \mathrm{C}$ and ${ }^{19} \mathrm{~F}$ NMR spectra of 4-methyl-7-((trifluoromethyl)thio)-2H-chromen-2one (3v) in $\mathrm{CDCl}_{3}$

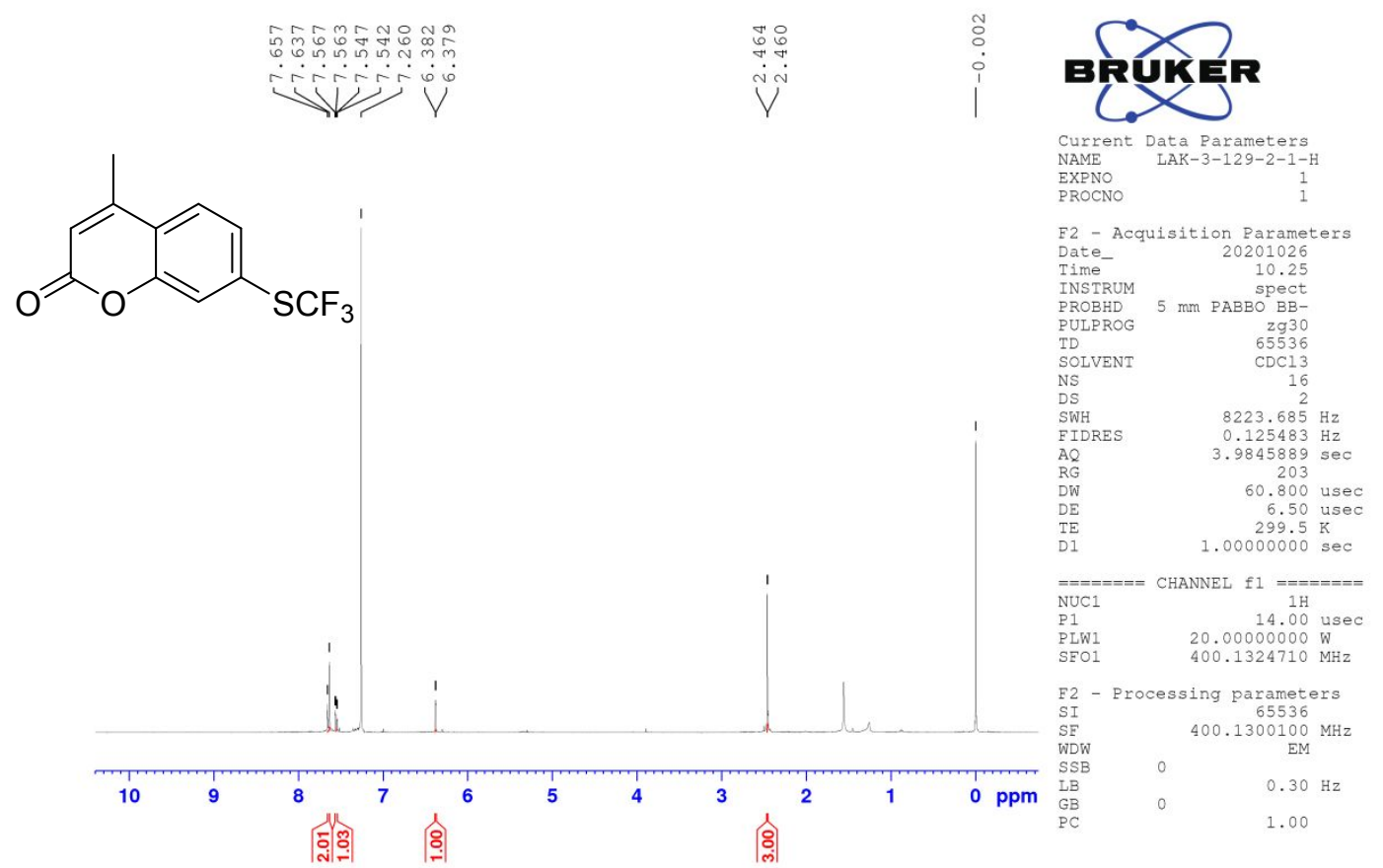



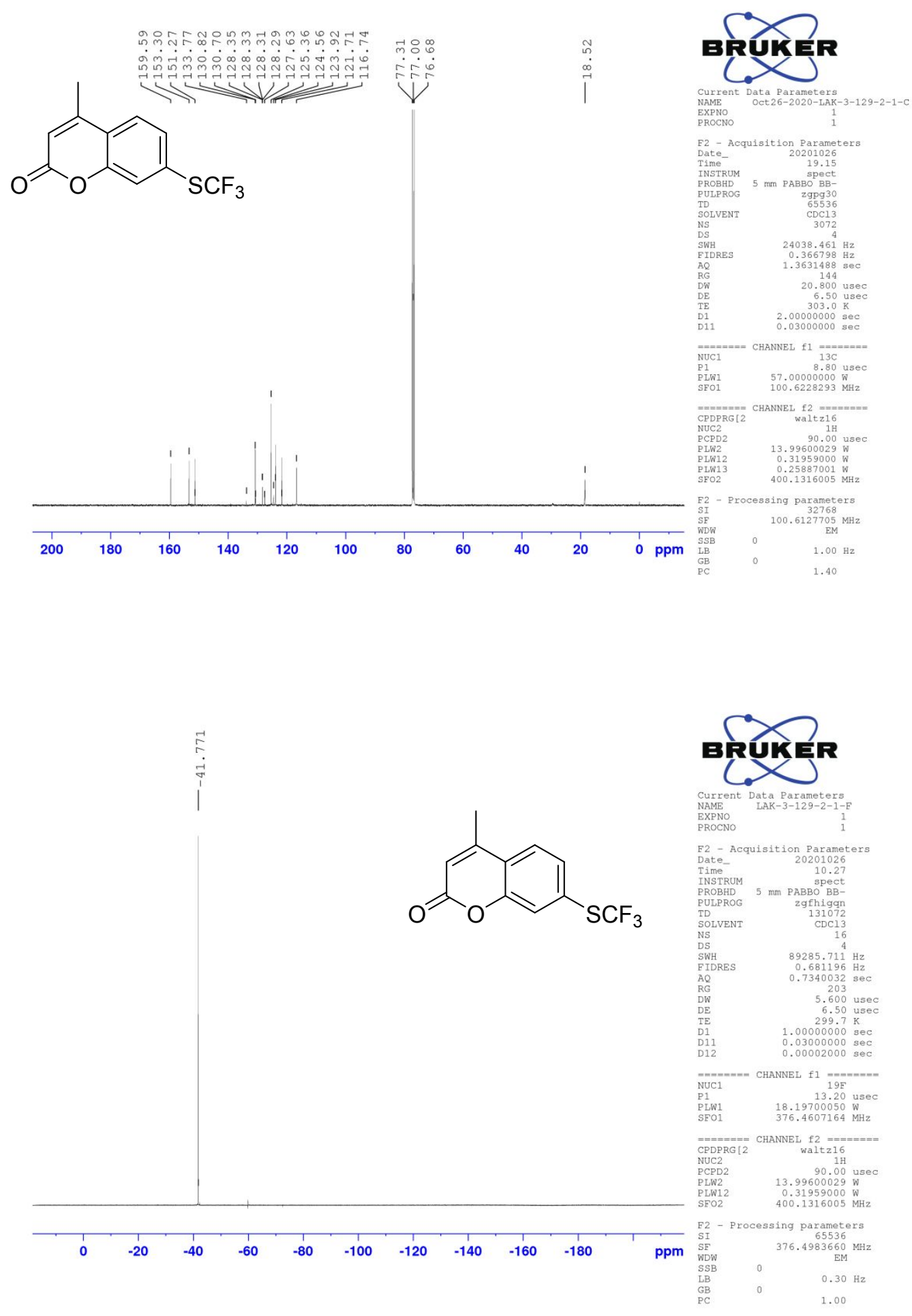
${ }^{1} \mathrm{H},{ }^{13} \mathrm{C}$ and ${ }^{19} \mathrm{~F}$ NMR spectra of ethyl-3-((trifluoromethyl)thio)-9H-carbazole (3w) in $\mathrm{CDCl}_{3}$
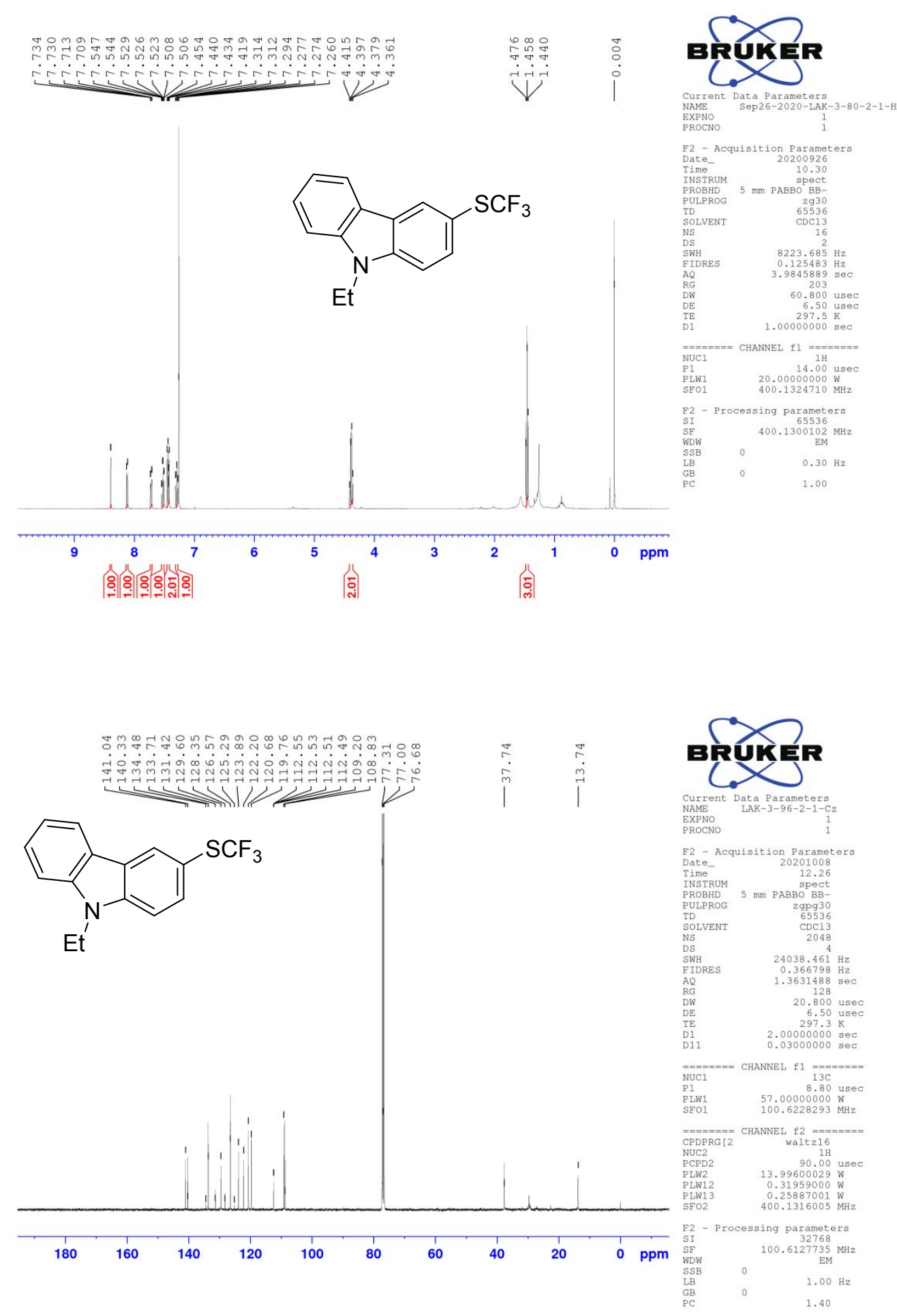

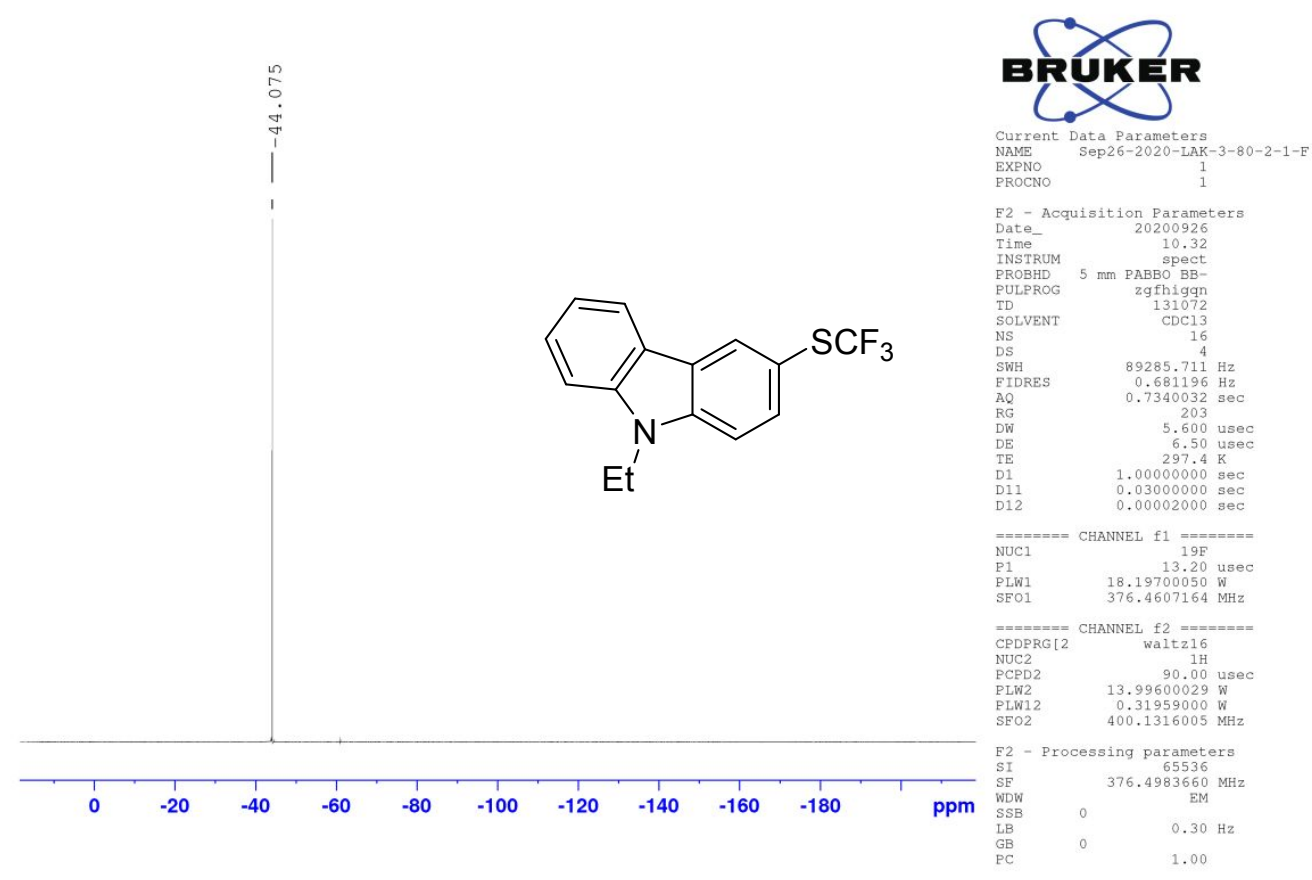

${ }^{1} \mathrm{H},{ }^{13} \mathrm{C}$ and ${ }^{19} \mathrm{~F}$ NMR spectra of 5-((trifluoromethyl)thio)benzo[d]thiazole (3x) in $\mathrm{CDCl}_{3}$

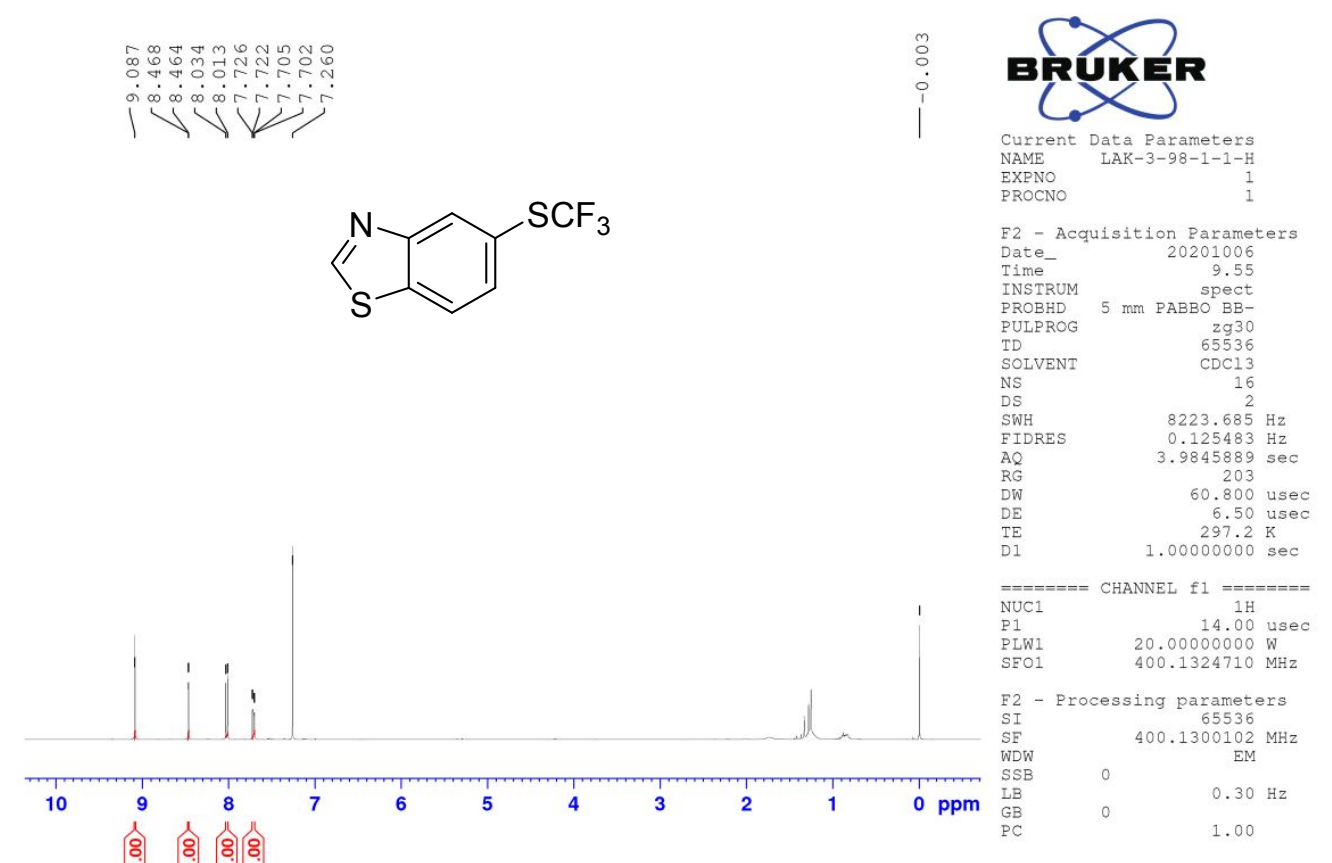



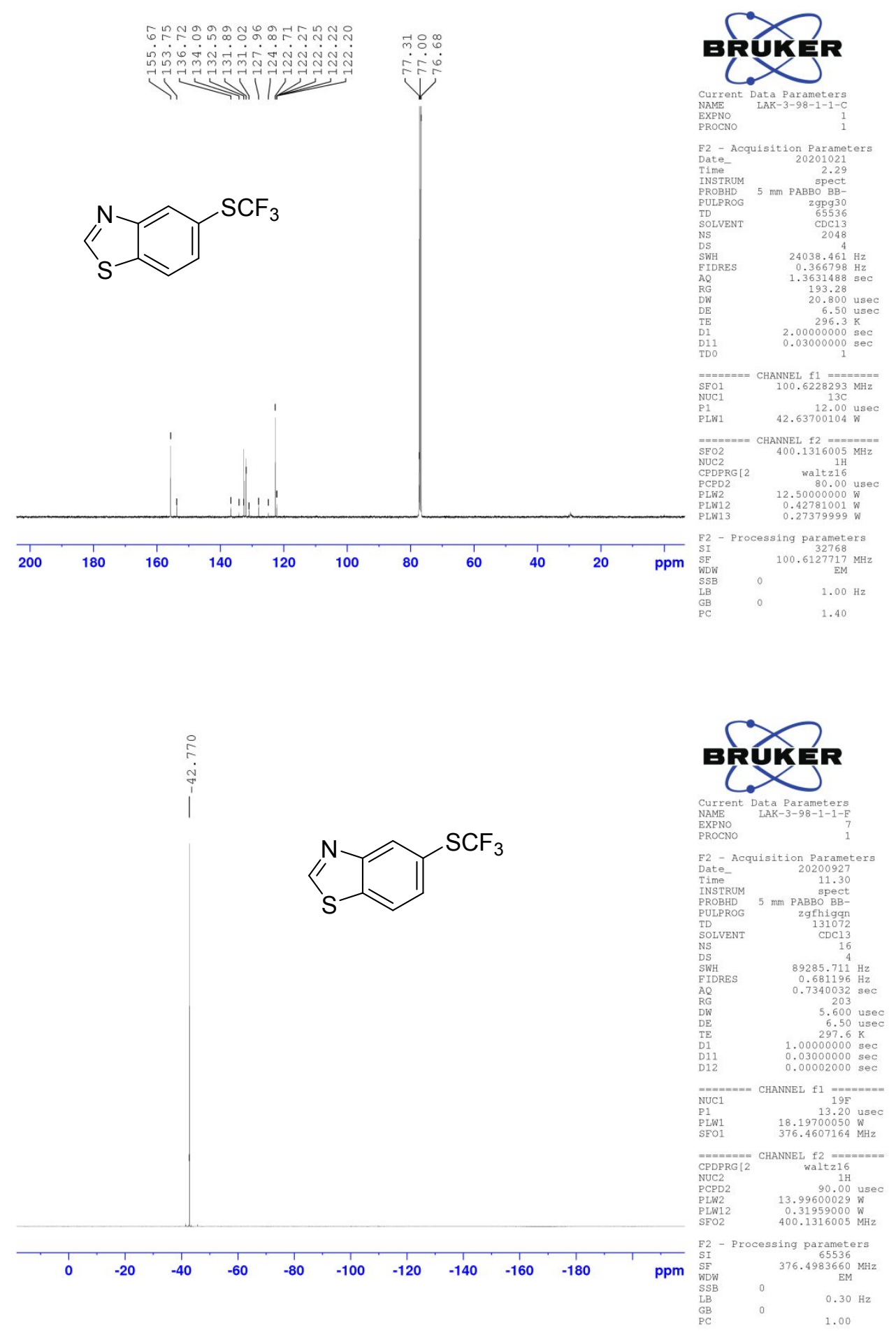